\title{
An Exploratory Case Study into the Cultural Effects on Knowledge Management Practices in the Solomon Islands
}

\author{
200380038003
}

by

Joseph Baeoro Sanga

$\operatorname{soc}$

\author{
A thesis \\ submitted to Victoria University of Wellington \\ in partial fulfilment of the requirements for the degree of \\ Master of Management Studies
}

Victoria University of Wellington

2009 


\section{Dedication}

\section{In memory of Wawari}

From whose residual substance I was crafted,

Who lent me his cushioned cradle to protect me,

And his sapling milk for food until I was

w e a n e d. 


\begin{abstract}
Knowledge management (KM) is an emerging discipline and in recent years it has received increased attention both from academics and practitioners. At the academic front, the major debate is over the conceptual plurality of KM. This is as a result of the subject having its roots from various disciplines. To practitioners the subject is attractive since it promises the management of knowledge, an abstract concept and the most elusive one to manage. Some think KM is just another fad but the realities experienced by multinational corporations trying to do business across cultures forces both academics and practitioners to constantly think about knowledge management and culture.
\end{abstract}

This thesis posits that there is such a thing as national cultures. In this work, Solomon Islands' national culture with its main features of multiplicity of subcultures, bigmanism, wantokism, pijin and the people's experiences through mission work, government and war are highlighted as providing encouragement and also barriers to knowledge management.

Using De Long and Fahey's four frameworks, a case study was conducted informed by the ethnographic tradition. The study drew on methodological triangulation which included semi-structured interviews, focus groups, document analysis and observations. The use of multiple data collection tools was employed to ensure convergence of data and the dependability of this work.

This study finds two important considerations. First, important knowledge is cognitive understanding and to a lesser extent technical. Structured knowledge is not central to $\mathrm{KM}$. There are two reasons given for this view. One, due to scarcity of resources, there is high competition for education which is regarded as cognitive knowledge, although in practice it is structured knowledge. Two, indigenous knowing is socially constructed and mainly exists in tacit form. Second, even when solicited, participation from subordinates is difficult to come by. This behaviour is embedded in kastom relating to big-manism.

This thesis contributes both to theory and practice. The main theoretical contribution is the argument that knowledge management theorist must take into consideration the 
effects of national cultures on knowledge recognition and the evaluation of knowledge management concepts. For practitioners, an understanding of the recipient culture is critical for implementing proposed changes. Particularly for Solomon Islands practitioners, a special awareness is necessary from leadership to understand the minds of workers, otherwise change interventions will always be a frustrating vocation. 


\section{Acknowledgement}

If I were a dog, you would see me wagging my tail.

\section{Enga Proverb}

In my native Gula'ala tongue, we do not have an equivalent for 'thank you'. This does not mean that we do not know how to acknowledge kind gestures or we do not have the capacity to appreciate. To us, gratitude is a deep emotional expression that emanates from the soul and is equated only to loyalty - loyalty for life. Despite saying this, I will now try to say 'thank you' to individuals and institutions that have contributed to making this project a success.

Before I do so, I must acknowledge God's grace and gift of life and good health. Without life and health, nothing else matters!

I thank Dr. Kala Retna my supervisor, for her direction, dedication and encouragement in this arduous journey. Her expertise, continuous support, feedback and team spirit is highly commendable and has resulted in the completion of this work. Special thank you to Penelope and Benny for proof-reading my drafts and comments from Dr. Deb Laurs and Ass. Prof. Kabini. I would like to register my appreciation to the Victoria Management School, the Victoria International and staff and to Student Health Services for the academic, administrative and health services during the whole program. NZAID was a major contributor to this work. Thank you for providing me the scholarship to study. This has been an experience of a life time and I appreciate the faith you had in me.

I would also like to acknowledge and thank the Management of the institution under study for giving me access into their establishment to gather data. A special thanks go to the participants for their time, and the impartation of their knowledge to me. To all my friends and former colleagues in this institution, thank you for sharing your coffee and lunch with me. I also acknowledge the kindness of Harry and Leah Zoleveke for billeting me during my data collection stay in Honiara. 
My deepest gratitude goes to the Lower Hutt Baptist Church for spiritual support during my stay here in New Zealand. I thank Richard Willis, the Vaughan clan and all my Christian brothers and sisters at LHBC for their kindness and hospitality. I thank the Solomon Islands community in Greater Wellington for sharing their life with me and making my stay here an enjoyable one. I must also register my appreciation to my fellow Solomon Islands students for their support and also for those soccer games that helped me keep active. Last but not least, I am eternally grateful to my own family. I thank Jan for giving up her own career for mine. Thank you to Jon Oge, Erik Rafa and LaRain Mangona for your support during our time here in Moera, Lower Hutt.

To all of you, blessings! 


\section{Important Disclaimer}

1. Victoria University of Wellington and its Council, its members, staff, employees, students and agents undertake no duty of care in contract, tort, or otherwise to users (whether direct or indirect) of this "An exploratory case study on the cultural barriers to knowledge management practices in the Solomon Islands", and makes no warranties or representation of any kind whatsoever in relation to any of its contents.

2. "An exploratory case study on the cultural barriers to knowledge management practices in the Solomon Islands" is only made available on the basis that all users of it, whether direct or indirect, take appropriate legal or other expert advice in relation to their own circumstances and must rely solely on their own judgment and such legal or other expert advice.

3. Under no circumstances will Victoria University of Wellington and its Council, its members, staff, employees, students and agents be liable in any way whatsoever, whether in contract, tort (including negligence), for breach of any statutory or regulatory duty (to the fullest extent permissible by law), or otherwise, to any user (whether direct or indirect) of this "An exploratory case study on the cultural barriers to knowledge management practices in the Solomon Islands" for any loss or damages whatsoever arising directly or indirectly as a result of the use in any way of this "An exploratory case study on the cultural barriers to knowledge management practices in the Solomon Islands".

4. Each exclusion in the clauses of the disclaimer and each protection given by it is to be construed as a separate exclusion applying and surviving even if for any reason any of the exclusions or protections are held inapplicable in any circumstance. 


\section{Table of Contents}

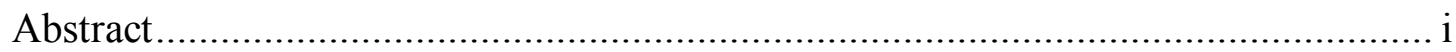

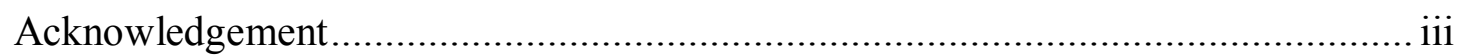

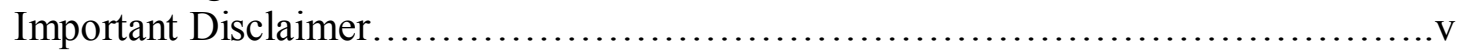

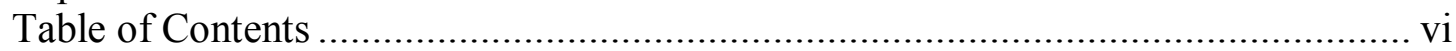

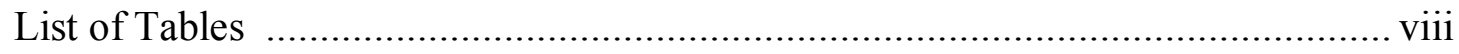

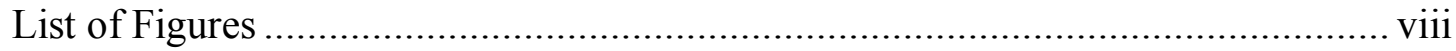

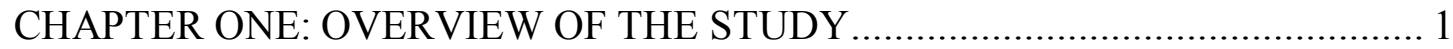

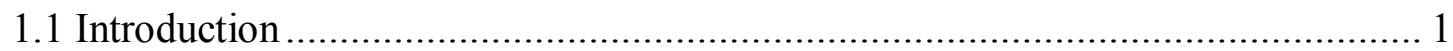

1.2 Research Question and Objectives .............................................................. 2

1.3 Theoretical Perspective: Interpretivist Paradigm ................................................ 3

1.4 Definition of Relevant Concepts ............................................................... 4

1.5 Qualitative Approach: Ethnography and Case Study ....................................... 5

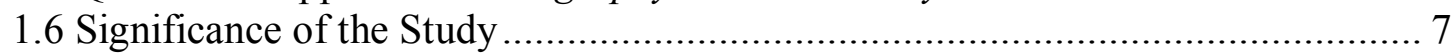

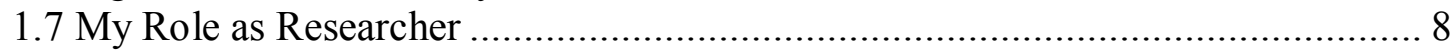

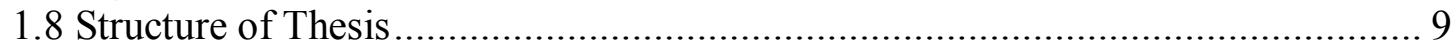

CHAPTER TWO: KNOWLEDGE MANAGEMENT LITERATURE.................... 11

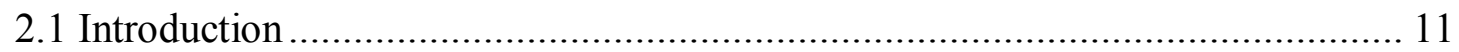

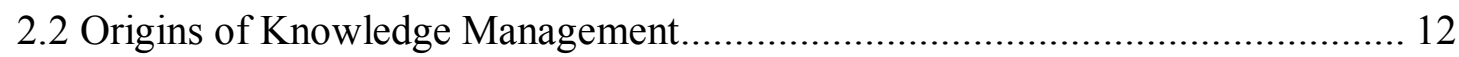

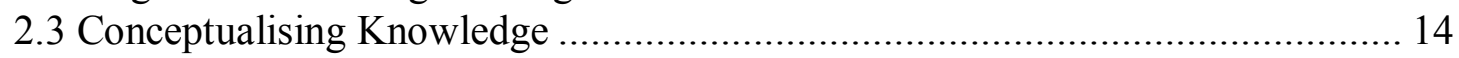

2.4 Knowledge and Knowledge Management ................................................ 16

2.5 Management in Knowledge Management ...................................................... 20

2.6 The Oxymoron Nature of Knowledge and Management.................................. 21

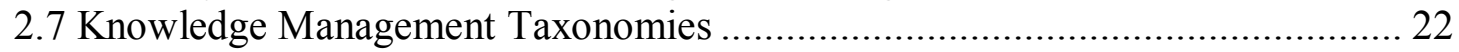

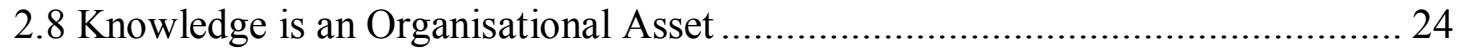

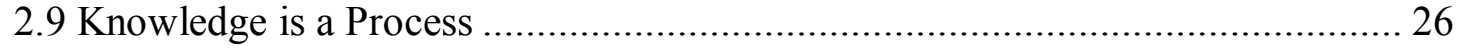

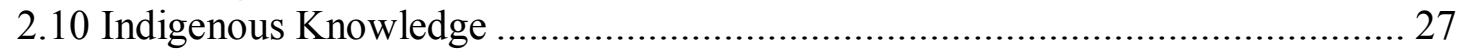

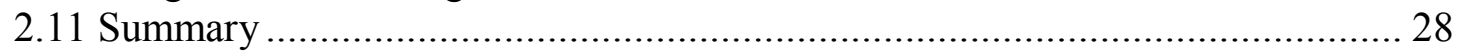

CHAPTER THREE: CULTURE AND KNOWLEDGE MANAGEMENT.............. 30

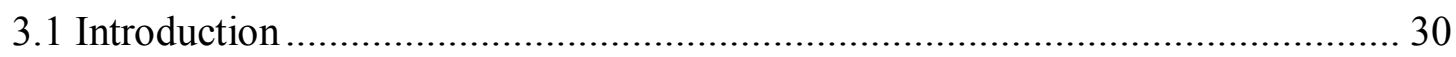

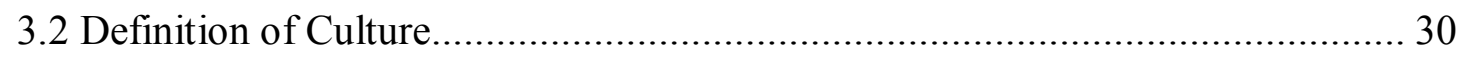

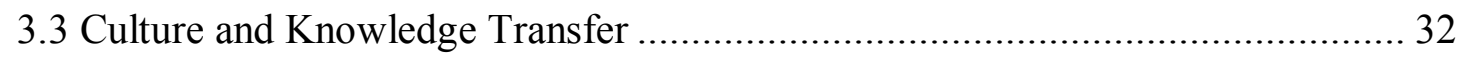

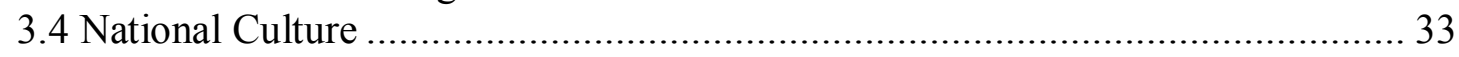

3.5 Conceptual Framework: De Long and Fahey ................................................ 39

3.6 Culture Shapes Assumptions about which Knowledge is Important .................. 41

3.7 Culture Mediates the Relationships between Levels of Knowledge ................... 42

3.8 Culture Creates a Context for Social Interaction.............................................. 43

3.9 Culture Shapes Creation and Adoption of New Knowledge ........................... 45

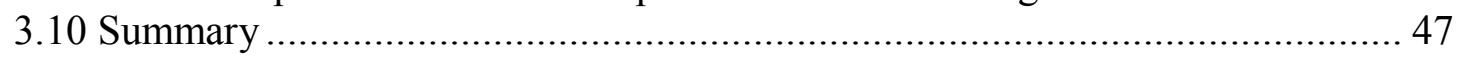

CHAPTER FOUR: THE RESEARCH METHODOLOGY ................................. 48

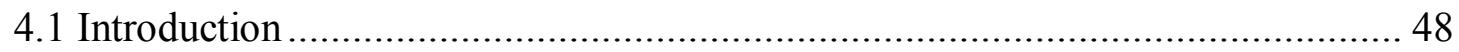

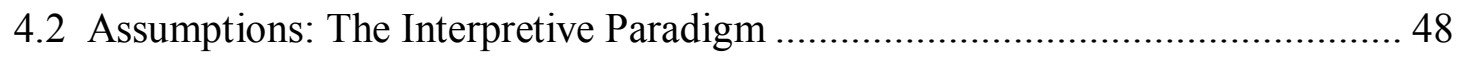

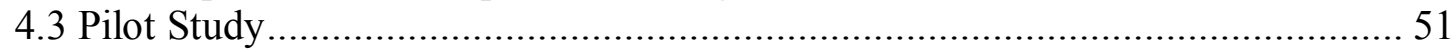

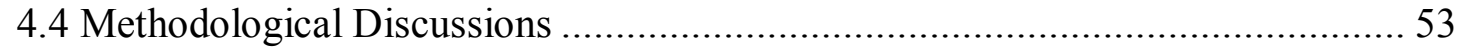

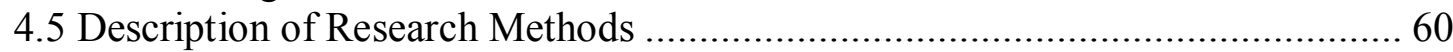




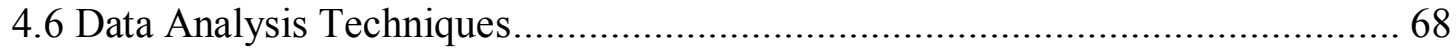

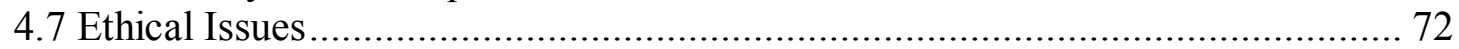

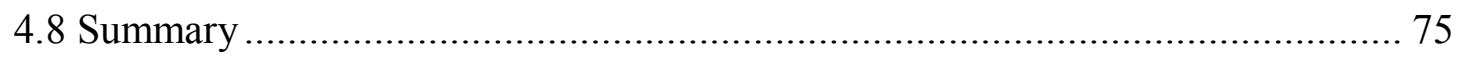

CHAPTER FIVE: BACKGROUND OF SOCIAL SECURITIES ENTERPRISES .. 76

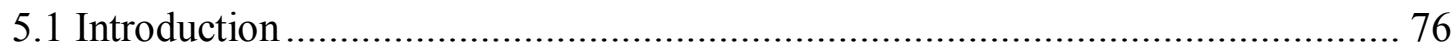

5.2 Background of Solomon Securities Enterprises........................................... 76

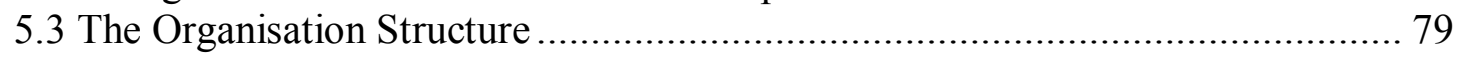

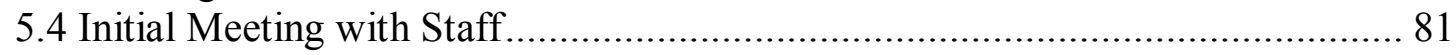

5.5 The Importance of Knowledge Management and Culture to SSE................82

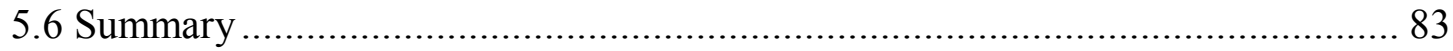

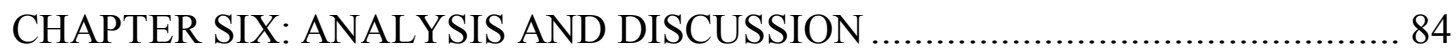

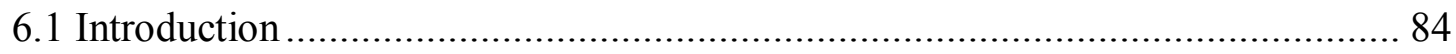

6.2 Culture's Influence on what Constitutes Important Knowledge ........................ 84

6.3 Levels of Knowledge: Individual and Organisational .................................... 91

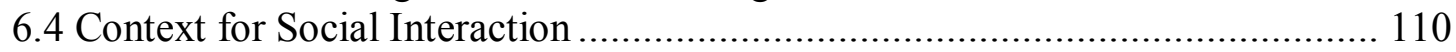

6.5 Culture Shapes Creation and Adoption of New Knowledge ......................... 120

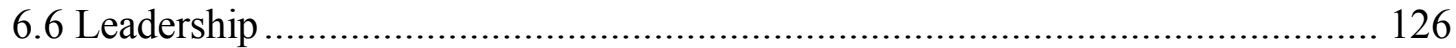

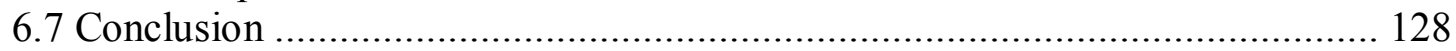

CHAPTER SEVEN: RESEARCH CONTRIBUTIONS AND IMPLICATIONS ... 129

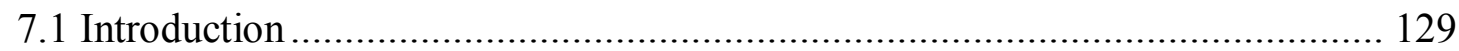

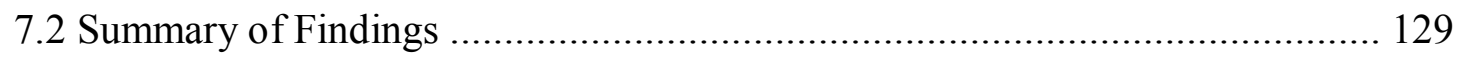

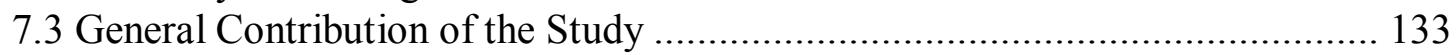

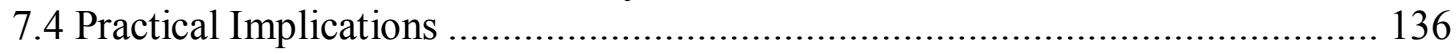

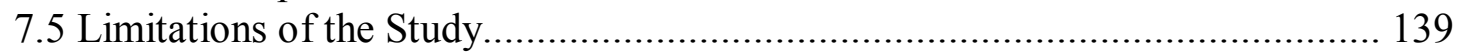

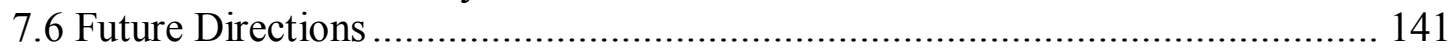

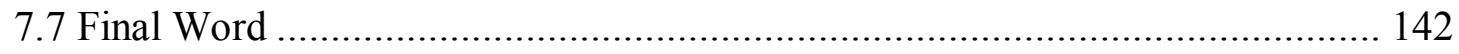

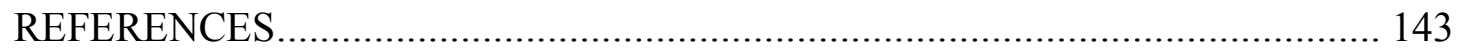

APPENDIX A: INFORMATION HANDOUT TO MANAGEMENT OF SSE...... 153

APPENDIX B: JOINT AGREEMENT BETWEEN SSE MANAGEMENT AND JOSEPH SANGA...................................................... 156

APPENDIX C: INFORMATION HANDOUT TO ALL INTERVIEW

PARTICIPANTS AND FOCUS GROUP MEMBERS …............. 157

APPENDIX D: INTERVIEW CONSENT FORM ........................................... 159

APPENDIX E: INTERVIEW SCHEDULE .................................................... 160

APPENDIX F: FOCUS GROUP CONSENT FORM...................................... 162

APPENDIX G: DISCUSSION SCHEDULE: FOCUS GROUPS ......................... 164

APPENDIX H: GENERAL OBSERVATION INFORMATION SHEET .............. 166

APPENDIX I: TRANSCRIBER AGREEMENT FORM .................................... 167

APPENDIX J: E-MAIL CONTACTS WITH CASE ORGANISATION

MANAGEMENT. 168 


\section{List of Tables}

Table 1: Definition of Terms Used .................................................................... 4

Table 2: Documentation Table for Categories Development ................................. 71

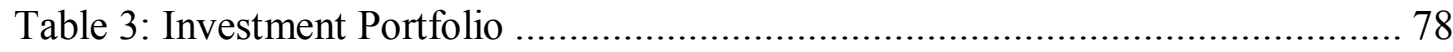

\section{List of Figures}

Figure 1: Culture Elements Influence Behaviours ............................................ 41

Figure 2: Culture Mediates the Relationships Between Organisational and Individual Knowledge....

Figure 3: Cultural Characteristics that Shapes Social Interaction.......................... 44

Figure 4: Creating and Adopting New Knowledge........................................... 45

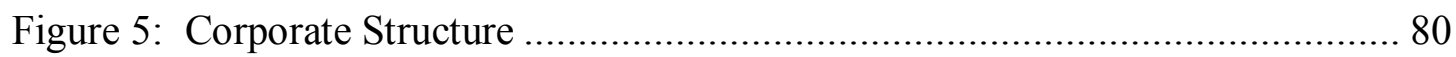




\section{CHAPTER ONE \\ OVERVIEW OF THE STUDY}

Genius is more often found in a cracked pot than in a whole one.

E. B. White

\subsection{Introduction}

Globalisation, information communication and technology (ICT) and a more liquid workforce have created a turbulent environment, forcing organisations to seek to capture, codify, store, retrieve and share knowledge internally to maintain competitiveness. It has proved futile for firms to maintain competitive advantage against their competitors that also have the same technology and resources they do. According to Alvesson and Kärreman (2001), the buzz was that proper knowledge management (KM) could do the trick.

However, as many multinational corporations (MNCs) have found out, a smooth transfer of knowledge to new cultures is easier said than done. In order to maintain competitiveness, MNCs must transfer distinctive knowledge to their foreign subsidiaries (Kogut \& Zander, 2003) and in order for interventions to increase their success rates, the need for an understanding of recipient cultures is critical.

This work recognises the centrality of national culture. This will be dealt with in greater detail in chapter three. Given this understanding, this research will explore what knowledge management is in the Solomon Islands' cultural context. In order to achieve this goal, this thesis considers how culture impacts the understanding, creation and distribution of knowledge at the organisational level. Case study research was conducted over five weeks in which the culture in Solomon Securities Enterprises (pseudonym) was studied to identify the cultural effects on KM practises in the Solomon Islands. 
The research question and objectives of the study are presented in this chapter to set the direction for this thesis. An overview of the paradigm assumed for this study is herein established to be an interpretivist work, employing the qualitative techniques of ethnography. Also in this chapter, brief definitions of important concepts are provided. The background of the researcher is also clarified for a better understanding of the viewpoints I hold. The remainder of this chapter highlights the significance of this study and a brief of what each chapter of this thesis contains.

\subsection{Research Question And Objectives}

My interest in this research is to look at how Solomon Islands' culture acts as a barrier to knowledge management. According to De Long and Fahey (2000), culture and knowledge are intrinsically related in organisations. These authors posit that any idea expressed that does not take into account culture, could be misleading. In this research the framework by De Long and Fahey was used to explore the phenomenon of interest. The central research question is:

\section{"How does culture affect knowledge management practices in the Solomon Islands?"}

De Long and Fahey's (2000) meta framework provides four sub-questions to ask. These authors established four frameworks linking culture and knowledge. They are:

1. How does culture shape assumptions about which knowledge is important?

2. How does culture mediate the relationships between levels of knowledge?

3. How does culture create a context for social interaction? and

4. How does culture shape the creation and adoption of new knowledge?

By using these frameworks I wanted to achieve three main objectives. Firstly, this study is a first in the field of knowledge management in Solomon Islands and so the nature of this work has to be exploratory. Cavana, Delahaye and Sekaran (2001, p. 108), defined an exploratory study as a study “...undertaken when little is known about the situation..." Since little is known about the phenomenon in this particular 
context, it is required that an extensive study be conducted to better understand the phenomenon. However, as a former employee of the case organisation, my many years of experience in the institution waive this requirement.

Secondly, it is inevitable when conducting this research to make comparisons with mainstream views, since the research tools used in this research work are borrowed from studies conducted in the western world. This objective does not feature prominently, but contrasting features that are unique to Solomon Islands were highlighted. Where findings are similar to the mainstream, they were not mentioned due to time and space constraints of this research.

Thirdly, due to my personal attachment to the case organisation and partly to show appreciation for the access given, this research was also aimed at providing suggestions to management for improvement and change to knowledge management practices in SSE.

Although these three objectives are major, my vast experience in the case organisation is also key to my taking a comparative and critical view in this exploratory work.

\subsection{Theoretical Perspective: Interpretivist Paradigm}

This work takes an interpretivist worldview. As such, I hold the assumption that people experience physical and social reality in various ways (Cavana, Delahaye, \& Sekaran, 2001). It is assumed that the world is so complex we can never know the entirety of knowledge because there are countless variables in the world and nothing is fixed, and so 'truth' can depend on our ability to define shifting phenomena. Therefore, it is assumed that there is a multiplicity of reality. What is the 'truth' for one person many not be so for another. 
Since this is an interpretivist paradigm, it is assumed that people's reality is socially constructed. It recognises the inter-subjective world which can be described by using concepts. While research is often aimed at providing reason to the senses, it can be intuitive. By saying this, the presence of hunches, metaphors and creativity as legitimate ways of learning and knowing the world, is recognised (O'Leary, 2004, p. 6) and used freely in this work. It is also assumed that qualitative research is holistic and there is a need to study the whole, as the whole is more than the sum of its parts "when the relevant theory underlying the case is itself holistic" (Yin, 2003, p. 45). It is therefore assumed that having a better understanding of the culture can help us better understand knowledge management practices in the case organisation.

\subsection{Definition Of Terms Used}

This section presents some of the important concepts used in this thesis. They provide succinct meanings but detailed definitions and explanations are also presented under their respective headings in various sections within the body of the thesis.

\section{Table 1: Definition of Terms Used}

\section{Terms Definition}

Big-man In Melanesian society the big-man is one who builds on long-term family and group involvement, to achieve wealth and surplus (social) production, allowing him to pass different social grades.

\footnotetext{
Cross-functional sub-cultures such as clerical staff,

sub-cultures $\quad$ supervisors and managers
}

The system of shared beliefs, values, customs, behaviours, and artefacts that the
members of a society use to cope with their world and with one another, and that
are transmitted from generation to generation through social interaction


Knowledge In simple terms, knowledge is defined as information plus beliefs, commitment, perspectives, intention and action. In this qualitative study the contextual, subjective and relational view of humans and the world they live in is recognised. Nevertheless, knowledge is viewed holistically and exists in both explicit and tacit form

\section{Knowledge}

Management the management of knowledge

Multiple numerous sub-cultures where there is no dominant culture

Subcultures

National the national behaviour and value systems

\section{Culture}

Pijin or

Pijin English a new language created by using English and local dialects

Subculture a smaller grouping within a bigger culture

Wantokism is a rallying philosophy that brings together, in common cause, people who are related, those who speak similar languages, those from the same area or island, and even the country as a whole

\subsection{Qualitative Approach: Ethnography And Case Study}

Qualitative researchers believe that humans are complex beings that can be unpredictable and put individual needs and idiosyncrasies over any notion of universal laws of human behaviour (Cavana, Delahaye, \& Sekaran, 2001, p. 34). 
Thus, a primary reason for choosing the qualitative methodology is because it allows for “more flexible meaning” than quantitative work (Silverman, 2005, p. 306).

In taking a qualitative approach, I chose ethnography because it is the relevant approach. This study is about understanding culture. Other methods, such as questionnaires or surveys of some population sample might not be able to capture contextual causal relationships because they are designed to observe and report a different set of data - quantitative data, which are distinct variables (Cavana, Delahaye, \& Sekaran, 2001, p. 35).

Secondly, ethnography is premised on the assumption that knowledge is socially constructed. Therefore its understanding will rely on how close a researcher is to the phenomenon (Goffman, 1961; Punch, 2005, p. 152). As a native of the culture, the researcher carries an "insider" perspective (Gegeo \& Watson-Gegeo, 2001, p. 57). Ethnography requires study to be conducted in its natural setting (Fielding, 1996; Punch, 2005, p. 152). My role dovetailed with this requirement.

In order to capture the underlying dynamics, methodological triangulation was used (Punch, 2005, p. 153). These various data-gathering techniques were used to supplement each other and ensure dependability of the research process, serving to ensure credibility of the work.

Finally, had there been easy access, a look at several cases would have been preferred. Nevertheless, this particular case was an instrumental case (De Long \& Fahey, 2000) since its peculiarity was not the phenomenon of interest; rather, Solomon Securities Enterprises was examined mainly to provide insight into cultural effects on knowledge management. The results were considered for their transferability. The specific case was of secondary interest. It played a supportive role, and it facilitated our understanding of something else - cultural barriers to knowledge management. 


\subsection{Significance Of The Study}

In the Solomon Islands, no study has previously been conducted in this field at the organisational level. Only as recently as February 2007 has a firm run a two-day workshop on the subject in an attempt to put in place a human resource strategy that incorporates knowledge management. Otherwise, knowledge management is little known in Solomon Islands. Therefore, this research is significant for three reasons.

Firstly, to academia, this work lays a foundation for future research on the subject in Solomon Islands. Continuous expansion of knowledge and testing the frontier is the voluntary vocation of humans. To shed more light on any subject matter is a good thing. Through this exploratory work, future researchers may be able to conduct further research and develop theory.

Secondly, to learn new knowledge merely for the sake of learning may not fall within the greatest needs of small island states. Therefore this research was designed to provided useful tips to SSE's management on the culture in operation there and areas that need improvement or changing. Whether change will actually take place, we might never know. However, as far as this research is concerned, decision-makers are now well-informed through research about their organisation.

To the wider community of practitioners, an understanding of the cultural context in Solomon Islands is useful knowledge. It is common knowledge that multi-national corporations (MNCs) are shifting their operations to countries such as India and China to exploit the cheap labour, infrastructure and technology (Inkpen \& Ramaswamy, 2007). In a small way we also see investors coming into Solomon Islands to tap the abundant natural resources. The question the CEOs of these MNCs often face is how to make their corporations work with these new cultures. This study is therefore significant not only to those thinking of establishing business in Solomon Islands, but also other Melanesian countries such as Papua New Guinea and Vanuatu since they share a lot in common culturally. 


\subsection{My Role As Researcher}

As qualitative work, it is assumed that my biases has certainly affected my data analysis and interpretation (Patton, 2002), and the way findings were received and presented. In order for the reader to fully understand my take, a paragraph on my background is provided.

As a mature student with 3 grown children, my curiosity and desire to study has always been there. This dream could not be realised until the opportunity presented itself through a chain of events. These included my domestic situation, work conditions and finally when the scholarship was available, I took the offer.

Knowledge management was introduced to me for the first time at the beginning of the master degree coursework. In one of the strategy courses, the course outline required completion of two major assignments. The first assignment had an optional component with a choice between mergers and knowledge management. Since 'mergers' was covered earlier in the trimester and since I wanted to start my assignment as early as possible, I opted to do my assignment on mergers.

However, the fascination with the material covered in the latter part of the course on knowledge management stayed with me. From then on, I considered ways to study this useful discipline further. I also imagined how this subject could one day become a part of the organisational language in Solomon Islands and possibly become the normal way of doing things.

About the same time, I was introduced to both quantitative and qualitative study methods. A full trimester course on qualitative research made me realise that scientific research can be both qualitative or quantitative (Cavana, Delahaye, \& Sekaran, 2001, p. 28). Given the cultural emphasis in this work, I chose to conduct research from the interpretive paradigm and the use of qualitative tools for this work. 
Since knowledge management (KM) work has not been studied previously in Solomon Islands, this work had to take an exploratory nature and extensive preliminary work could have been required. However, my 22 years of employment with Solomon Securities Enterprises provided the confidence to undertake this study without the need for an extensive preliminary study. In practice, Solomon Islands firms do not consciously engage in the management of knowledge, although in the larger organisations, information and communication technology (ICT), rules, regulations and practices have been adopted in their operations as part of their management strategies that also serve to manage knowledge.

All the above facts established for me, the motivation and boundaries within which to conduct this work.

\subsection{Structure Of Thesis}

There are seven chapters to this research. Chapter One: Overview of the Study, which is this chapter, provides an overview of the whole dissertation framework, content and layout. The remaining chapters are outlined below.

Chapter Two: Knowledge Management Literature: This is a review of the first part of the relevant literature. The chapter presents philosophical and theoretical discussion of knowledge management. It provides the definition of knowledge in greater depth, classifications and ends with indigenous understanding or knowledge. This is a necessary requirement as it sets the scene for 'culture', the phenomenon of interest, to be introduced.

Chapter Three: Culture and Knowledge Management is a continuation of the literature review but the focus moves from KM to culture. In this chapter, culture is defined, and then explained as various levels such as national and organisational cultures. The roles they play as barriers to knowledge management are introduced in the form of the framework used to study this phenomenon. 
Chapter Four: The Research Methodology chapter outlines the research methodologies, assumptions, rationale for the methodologies chosen are provided and a discussion of ethnography and case study as research strategies. A description of a pilot study that was conducted to test my instruments is also provided. Then a description of the methods used, namely documents analyses, semi-structured interviews, observations and the use of focus groups are given. An explanation of Constas' method of analysis is also provided. Finally, this chapter ends with a discussion of ethical issues, in which the questions of validity, reliability and generalisability are addressed.

Chapter Five: Background of Social Securities Enterprises is the background to the case study. This provides the reader with relevant information on the inception, nature, place and role of the organisation in the economy. A brief on the administrative structure of the organisation is also given. The chapter provides a description of the expectations of various staff before the research was conducted and ends with the importance of KM and culture to SSE.

Chapter Six: Analysis and Discussion: This chapter focuses on the analysis of data collected from SSE. It also includes discussions of the findings of this research. In this analysis, I discuss the data under four frameworks given by De Long and Fahey. Each major theme considers emergent sub-themes as expressed by the three functional subcultures of clerical staff, supervisory staff and management staff.

Chapter Seven: Research Contributions and Implications: This is the concluding chapter and plays the role of tying the whole thesis together. It provides a summary of the thesis findings, its general implications, specific recommendations, weaknesses and future directions. This chapter shows how the whole research comes together. 


\title{
CHAPTER TWO
}

KNOWLEDGE MANAGEMENT LITERATURE

\author{
Ignorance is the curse of God; \\ knowledge is the wing wherewith we fly to heaven.
}

William Shakespeare

\subsection{Introduction}

This chapter will survey the literature on knowledge management (KM), which often is used interchangeably in discussion with knowledge. Although it views the subject broadly, it is necessary since research is never done in isolation (O'Leary, 2004), and its primary objective is to inform this research on the concepts of knowledge and knowledge management and also to provide a summary of the developments in KM thought. While it is definitely a learning opportunity for the researcher, for other students who might contemplate doing research, this serves as a signpost along their own learning journeys as well. For knowledge management scholars, this work is far from being an exhaustive work, but since knowledge is a product of human reflection and experience (De Long \& Fahey, 2000) and is created in the minds of each and every individual, a word or a phrase used here might bring enlightenment to some aspects of the subject for any open minded person and the true willing learner. It will take effort and a lot of humility to learn from those who may be considered as nonestablished and less 'credible' than oneself but the nature of knowledge is such that it is never an esoteric discipline restricted to a select few (Alvesson \& Kärreman, 2001). In Grant's (1996, p. 110) words, knowledge basically is "that which is known". This sets all humans as equals on a level playing field called 'knowledge management discipline'.

In this chapter, I will sketch knowledge management by looking at the Origins of Knowledge Management as a discipline, then Conceptualising Knowledge through bringing the philosophical foundations, otology and epistemology of commentators, understanding Knowledge in Knowledge Management through various disciplines 
such as Engineering, Psychology, Economics and finally, Management. Then the thesis will briefly explore the concept of Management in Knowledge Management, consider the Oxymoron Nature of Knowledge and Management, look at the various Knowledge Management Taxonomies. That is tacit, explicit, knowledge internalisation and externalisation and also other classifications. The economic view of knowledge under the heading Knowledge is an Organisational Asset will be revisited by looking at the resource-based theory of the firm and the knowledge-based theory of the firm. A balancing view will be explored under the heading Knowledge is a Process and finally this chapter will briefly introduce Indigenous Knowledge. An understanding of indigenous knowledge is important as it informs the reader of the lens wherewith respondents use to interpret their reality.

\subsection{Origins Of Knowledge Management}

Knowledge Management is an emerging field of study which has its roots in various theoretical frameworks ranging from philosophy and computer science to economics (Alvesson \& Kärreman, 2001). By comparison to other disciplines, knowledge management has relatively few works published since 1975, when its importance to competitive advantage was becoming recognised as a critical organisational asset (Nonaka \& Peltokorpi, 2006).

In the modern age, firms find it difficult to maintain competitive advantage since competitors can easily and quickly copy their products or technologies. So, they register their inventions or knowledge as intellectual capital in copyrights, patents and trademarks to ensure that the competitive edge they possess lasts a little longer. Knowledge, especially tacit knowledge however, is difficult to copy since it is embedded in individuals. The argument is that if this tacit knowledge, plus explicit knowledge are managed and transferred across an organisation, the firm can create leverage and can attain a competitive edge. Knowledge management became a means to an end, the end being competitive advantage (Retna \& Bryson, 2007). The popularity of knowledge management has been ever increasing especially over the last two decades to practitioners and also in academia, which has helped to form 
knowledge management as a new expertise area (Hull, 2000), therefore creating a separate discipline (Grossman, 2007).

There have been debates whether knowledge management is not just another fad and soon will disappear. Donaldson (2001) and Gu (2004) think that the concept is attractive to academics since it deals with intellectual discourse and lies within their sphere of competence. It provides a new relevance to an old subject and promises a future of debates and discourses on familiar questions and terrain. Suddaby and Greenwood (2001) on the other hand, believe that the popularity of knowledge management is as a result of good advertising by consulting firms. They maintain that this skilful advertising has made KM attractive and appealing to practitioners because it promises the management of knowledge, an abstract concept and a most elusive one to try to manage. Literature however, shows that knowledge management has outlasted many fads and the prospects are that it will continue this trend for many more years to come.

The concepts of knowledge and management have been around for a very long time (Alvesson \& Kärreman, 2001; Hansen, 1999; Vine, 2004), since the early Greeks (knowledge) and Egyptians (management), but one wonders why knowledge management had not been discovered as a discipline sooner, say in the seventeenth century, the Age of Reason or even at the turn of the twentieth century. Empson (2001) sees the importance of knowledge management at this particular time period (the last three decades) as opposed to other time periods, for several reasons. At the practical level, capital and labour-intensive firms have dwindled and been replaced with more information-intensive firms. Secondly, the rise of technological development has created the need to exploit organisational knowledge sources. Thus, firms shifted their total reliance from the tangible to explore intangible assets, such as intellectual capital and knowledge from the use of computers and other new technological inventions.

At the theoretical front, Empson (2001) maintains that two concurrent developments have pushed knowledge in to management literature. While the resource-based view of organisations sees knowledge as the critical resource to creating competitive 
advantage, post-modernists really challenged the nature and meaning of knowledge in organisations and society. The debate on knowledge management is across disciplines, epistemology and paradigm boundaries. From these debates emerged two general taxonomies of knowledge focus. Some view knowledge as 'asset' and others see it as a 'process' (Amit \& Schoemaker, 1993; Kogut \& Zander, 1996; Spender, 1996). These two major classifications have inundated academic debate and discourse ever since. These views will be explored in more detail later in this chapter.

\subsection{Conceptualising Knowledge}

Since the ancient Greeks, like Socrates, Plato and Aristotle, the philosophy of knowledge has been debated without reaching a consensus of what it is and means (Grant, 1996). The word "epistemology" comes from the Greek word episteme which means knowledge or science (Parry, 2003). Epistemology is the branch of philosophy concerned with the nature of knowledge, beliefs, and knowing how we know. While Socrates and Plato viewed knowledge as objects, Aristotle made the distinction between certain knowledge which was based on probability. For example, if you said something nasty to someone, you do not know whether what you said would anger or not anger that person. This type of knowledge (probability) applies in politics, psychology and ethics. This is in comparison to object knowledge such as in maths which when you add one and one, it will always give you a definitive answer, two. It is however, in the recent last two decades that the resurgence of the interest in knowledge has come to the forefront in conjunction with the new discipline of knowledge management (Grossman, 2007). In the next three paragraphs I will further explore the knowledge concept and the philosophical worldviews on ontological and epistemological paradigms.

\subsubsection{Philosophical Foundation}

In the earlier years when knowledge management discipline emerged, its roots were predominantly economic and these scholars held a positivist paradigm. According to Nonaka and Peltokorpi (2006), scholars such as Burrell and Morgan (1979) and Mitroff and Mason (1982) are among some of those who looked at the ontological and epistemological nature of knowledge in some depth. The discipline of knowledge 
management has had two streams of philosophical understanding of knowledge on a subjective-objective continuum. Positivism has its foundations in the natural sciences and has had a long influence on the social sciences with its objective view of social reality. On the other side of the ledger, interpretivism such as phenomenology places emphasis on subjectivity.

\subsubsection{Ontology}

The positivist ontological view is that researchers assume objectivity in their approach and that science can measure and simply "mirror" truth, usually by a privileged few (Cavana, Delahaye, \& Sekaran, 2001). This "truth" is out there and only needs to be discovered. Researchers aim to discover these universal laws that can be used to predict human activity. From this worldview, the nature of knowledge is understood to be a functional resource, representing a 'truth' or a subject matter and/or a set of principles for dealing with social phenomena (Alvesson \& Kärreman, 2001; Spender, 1996). In Nonaka's (1994) terms, knowledge is 'justified true beliefs', thus underscoring truth and principled justification.

The interpretivist ontology on the other hand, sees this world as intersubjective and connected and that science can be used to represent concepts. This is often done through the social construction of reality (Nonaka \& Peltokorpi, 2006). The knower seeks to uncover the socially constructed meaning of reality as understood by an individual or group (Cavana, Delahaye, \& Sekaran, 2001). Blending the view that knowledge is a functional matter with the social constructionist view of knowledge can create confusion. This confusion stems from the influence of the Cartesian distinction ${ }^{1}$ between knowing subjects and the knowable objects, which raises the problem that in social reality the knowable object to a large extent is found in the knowing subjects (Shotter, 1993).

\footnotetext{
${ }^{1}$ René Descartes was a French philosopher, mathematics, scientist and writer. In philosophy he was known for the concept of dualism in which he made the distinction between a human body working as a machine and soul or mind which was a nonmaterial entity which lacks extension and does not follow the rules of physics. The mind controls the physical body but sometimes the irrational body influences the rational mind.
} 


\subsubsection{Epistemology}

Positivist epistemology argues that researchers stand aloof from the research subjects so that discussions can be made objectively. They deny any influence of the subject and claim a value free study (Cavana, Delahaye, \& Sekaran, 2001). In the KM discipline the earlier views such as Wicks and Freeman (1998) were from a positivist paradigm and therefore knowledge was viewed as explicit, codified and a material functional asset. These also included the resources-based view which basically regarded knowledge as a firm's resource (Barney, 1991; Penrose, 1959; Wernerfelt, 1984) that is valuable, rare, inimitable and organisational in terms of its sustainability.

In contrast, interpretivists and this work argue that knowledge and social entities cannot be understood as objective things. They present a contextual, subjective and relational view on humans and the world they live in (Nonaka \& Peltokorpi, 2006). Knowledge is tacit and scholars would not get a fuller appreciation of knowledge unless they dig deeper into the reasoning and understandings of the subject. The researcher must interact with the subject to achieve a full understanding of the subject's world (Cavana, Delahaye, \& Sekaran, 2001). Much of this tacit knowledge is embedded in the mind of the knower but he or she may not even be fully aware of that knowledge (Sveiby \& Simons, 2002). It therefore requires researchers to employ richer research techniques than standing aloof, to be able to capture tacit knowledge.

\subsection{Knowledge And Knowledge Management}

The term "knowledge management" has entered the lexicon of management studies since the 1990s (Grossman, 2007). However, its definition is not a simple matter. Peter F. Drucker (1993) the management guru explains the shift in the definition of knowledge from 'being' to 'doing'. In other words, the concept of knowledge shifted from abstract (why the world exists), to practical (how to do something). This is an example of what is predominantly the misnomer of concepts. Alvesson and Kärreman (2001) claim that much of the literature, when dealing with the subject knowledge management actually focuses on the knowledge aspect of the discipline only. This is 
further discussed in this chapter under the section "Oxymoron Nature of Knowledge and Management". Since this research is not aimed at these philosophical debates, the researcher will use these conventional terminologies so that knowledge and knowledge management are for most part used interchangeably unless clearly expressed otherwise.

There are so many views of knowledge today and there is no universally agreed upon definition (Grant, 1996). There are however, two major worldviews of knowledge; positivist and interpretivist (Spender, 1996) paradigms that have already been discussed under the sections "Philosophical Foundations", "Ontology" and "Epistemology". Much of the literature views knowledge from a positivist epistemology except for a few scholars such as Nelson and Winter (1982), Spender (1989), and Nonaka and Takeuchi (1995), who have an interpretivist take (Spender, 1996). Positivist theory of knowledge gives little consideration to the problematic nature of knowledge. To positivists, tenable knowledge is the result of scientific analysis. Some of the more common views will be briefly cited here to give us an insight into those definitions these disciplines have of knowledge.

\subsubsection{In Psychology}

There are a range of views of knowledge in psychology, depending on what branch it is observed from. In behavioural psychology, knowledge is considered as a mass of "stimuli-response" relationships. A classical example is Pavlov's well-known experiment with conditioned reflexes. ${ }^{2}$ In cognitive psychology, the human intellect is viewed as a processing system and it attempts to understand mental process by recognizing this system. Here, there is classification of memory into three categories: sensory, short-term, and long-term memory. Long-term memory is recognised as the storage of knowledge although by the 1970s this school of thought began to decline as this definition was too simplistic an explanation of the instrument of human cognition.

\footnotetext{
${ }^{2}$ Ivan Petrovich Pavlov (1849-1936) was a Russian physician who contributed to many areas of physiology, neurology and psychology. Most of his works involved research in temperament, conditioning and involuntary reflex action. While measuring dog's saliva he discovered the phenomenon of "conditioned responses".
} 
The Piagetian school in the theory of cognitive development defines knowledge as actively constructed ${ }^{3}$ and humans have cognitive structures and that knowledge is constructed through adaptation of cognitive structures to the environment. According to Ernst von Glaserfeld, ${ }^{4}$ Jean Piaget is "the great pioneer of the constructivist theory of knowing".

\subsubsection{In Information Technology (IT)}

Often in IT, codified knowledge is emphasised and knowledge is something that is "integrated into" such things as the manufacturing process itself, resulting in workable solutions and procedures to improve the production process (Abdelkader \& Noor, 2006, p. 17). This view is similar to the engineering view of knowledge. For example, 'knowledge engineering' is the term used for the systemisation of knowledge which originated with the Heuristic Programming Project (HPP) in Stanford University in 1965. This system was developed so that it could transplant expert knowledge onto computers. It could however, only deal with "rule" formula - if A, then B - which is a limited ability problem-solving system. The objective was to grasp knowledge systematically and utilise it effectively. To engineers and computer people, knowledge was "that which can be stored and sorted in a way that can be readily accessed when needed" 5 . This is the positivist view of knowledge.

\subsubsection{In Economics}

Knowledge is considered a valuable resource of the firm and so it can be stored, retrieved, managed and used to create competitive advantage over rivals (Retna \&

\footnotetext{
${ }^{3}$ Jean Piaget (1896-1980) was a Swiss philosopher and psychologist who developed the new fields of science called developmental psychology and genetic epistemology.

${ }^{4}$ Ernst von Glaserfeld is a philosopher and cybernetician and is a proponent of radical constructivism. $\mathrm{He}$ is Emeritus Professor of Psychology at the University of Georgia, Research Associate at the Scientific Reasoning Research Institute, and Adjunct Professor in the Department of Psychology at the University of Massachusetts, Amherst. He is a member of the Board of Trustees, American Society of Cybernetics, from which he received the McCulloch Memorial Award in 1991; and a Member of the Scientific Board, Instituto Piaget, Lisbon.

${ }^{5}$ The original quote is from Information Processing Society of Japan (Ed.), Knowledge Engineering, Ohmsha, 1987, p.4.
} 
Bryson, 2007; Sveiby \& Simons, 2002). More of this view is covered below under the section "Knowledge as an Asset".

\subsubsection{In Management}

Since this paper is a Management paper, I will elaborate on the management perspective of knowledge in greater depth than those other disciplines already briefly explained above. A popular starting point in a lot of literature is to distinguish the difference between data, information and knowledge.

\subsubsection{Data}

Mostly in IT literature, people want to start by differentiating data, information and knowledge. Often data is taken to mean the raw numbers, facts, images and sounds derived from observation or measurement (Alavi \& Leidner, 2001; Nonaka, 1994). These often are symbols that are meaningless and not arranged in any shape or form such as the list of clients in a firm.

\subsubsection{Information}

Information to Nonaka (1994) represents data that has been arranged in a meaningful way. The general interpretation of this is in the meaning of that which particular information represents. There is however, debate whether this 'meaningful way' is really in meaning or in some other way. Zack (1999, p. 46) thinks 'meaningful way' here refers to a meaningful context rather than meaning in itself, and often in the form of a message; whether it be oral, written or in some other form.

\subsubsection{Knowledge}

Knowledge is different from information. Vine (2004) defines it simply as information plus action. Nonaka's definition is much more than just information plus action. It is about beliefs, commitment, perspectives, intention and action (Nonaka, 1994). This brings in a whole broader perspective to cover cultural context, belief systems and tacit dimensions. Dependent on context, knowledge is a resource that is 
always located in an individual or a collective, or embedded in a routine or process, in language, stories, concepts, rules, and tools. Knowledge results in an increased capacity for decision making and action to achieve some purpose (De Long \& Fahey, 2000). Taking this broader definition of knowledge, this research will bring out an indigenous epistemology; combining the expressions of knowledge of the subjects and captured by an indigenous researcher; the product should be purposeful meaning and would be available to those that want to operate within Solomon Islands.

\subsection{Management In Knowledge Management}

Management has been around since the early Egyptians where various works was codified and distributed to build their pyramids, sphinxes and in fact their whole civilisation. The keen interest in Knowledge Management has only become a discipline in around the 1990s (Alvesson \& Kärreman, 2001; Grossman, 2007). In the study of KM , people typically are more interested in focussing their literature on knowledge but not management (Alvesson \& Kärreman, 2001). While there are taxonomies in knowledge, there is hardly any classification of Management in KM literature. It is obvious that there is a tendency and a conscious effort to explore the concept of knowledge but there seems to be no interest in giving balance to the idea of management. Gore and Gore (1999) and (Hansen, Nohria, \& Tierney, 1999) seem to believe that management to researchers is a self-evident concept and unproblematic or irrelevant (Cook \& Brown, 1999; Lam, 2000; Nahapiet \& Ghoshal, 1998) and therefore needs no explanation.

Nonaka (1994) however, highlights the problematic nature of managing knowledge and its creation. Since knowledge is inherently embedded in individuals, who themselves have no way of explaining or describing that knowledge, it must follow that decision makers who are charged with the responsibility to manage this most important organisational resource must find it difficult, if not impossible. He considered the link between management practices and knowledge creation in an attempt to manage knowledge and its creation. However, he did not attempt to theorise on what management is (Alvesson \& Kärreman, 2001) in knowledge management. This is a problem faced by many scholars and has been so far avoided. 


\subsection{The Oxymoron Nature Of Knowledge And Management}

The terms Knowledge and Management are contradictory in their nature and this creates difficulty for researchers, often leading them to concentrate on Knowledge but not Management. Alvesson \& Kärreman (2001, p. 1000) quote Gore and Gore (1999), Hansen et al. (1999), Cook and Brown (1999), Lam (2000), and Nahapiet and Goshal (1998) that much of the academic debate and discourse on KM has highlighted the knowledge side of the discipline but has neglected or considers the management side to be well-covered by other management literature and definitions, or that management is seen as unproblematic, or self-evident, and does not warrant their time. This view assumes that all readers have the requisite knowledge of what management is and is all about. This is far from the reality. According to Alvesson \& Kärreman (2001), knowledge management should be about communication. The more knowledge is restricted, the less it will be understood. Conversely, enlightenment, understanding or knowing increases with increased communication. Where restrictions are put into place, it creates a negative $b a^{6}$ or place/space and context (Anthes, 1998), for an esoteric readership, thus defeating the purpose of knowledge creation, sharing and appropriate action; or in other words, management.

Some scholars view the study of KM as a 'mixed-bag' without a coherent theoretical base (Donaldson, 2001; Nonaka \& Peltokorpi, 2006; Nonaka, Toyama, \& Konno, 2000). The ontological and epistemological debate over the years has kept academics apart. This has been the result of KM having its roots in various disciplines so that there has been no consensus on its definition. Fewer researchers such as (Alvesson \& Kärreman, 2001; Donaldson, 2001) take a pragmatic approach, leaning toward interpretivism in the hope of providing some balance. For example, Polanyi (1967), Kogut and Zander (1996), and Wicks and Freeman (1998), argue that since meaning emerges from subjective experiences, tacit knowledge should take precedence for study.

\footnotetext{
${ }^{6} \mathrm{Ba}$ is a concept originally proposed by the Japanese philosopher Kitaro Nishida and further developed by Shimizu. $B a$ in Japanese roughly translates into the English words "place" and "space".
} 
However, knowledge is not all tacit or all explicit. Nonaka and Toyama (2005) drew a balance between explicit knowledge, which is studied objectively, and tacit knowledge, which must be viewed from an interpretivist paradigm. Taxonomists make classifications in order to reduce complex concepts into small enough categories where they can be comfortable to work with and also in, toward an attempt of sensemaking. The tacit and explicit dimensions of knowledge are not mutually exclusive but rather complementary (Nonaka \& Toyama, 2005) and scholars should learn to think outside their own little box in order to begin to appreciate the enormity of the subject. In this thesis, I will take a pragmatic approach from an indigenous epistemology which views knowledge holistically (Gegeo \& Watson-Gegeo, 2001, p. 59).

\subsection{Knowledge Management Taxonomies}

Knowledge Management is often categorised in two key dimensions: focus and source (Nonaka \& Peltokorpi, 2006). The focus dimension is further divided into two categories; tacit or explicit form. On the other hand source refers to where the knowledge originates from; internal, organisational sources or external resources and individuals. These various classifications are further explored in the following paragraphs.

\subsubsection{Explicit Knowledge}

In the early stages of knowledge management coming into a discipline, the view was mostly positivist and when knowledge was referred to, it was actually explicit knowledge (Alvesson \& Kärreman, 2001; Nonaka \& Peltokorpi, 2006). Explicit knowledge is codified knowledge (Kogut \& Zander, 1996) or knowledge embedded in artefacts such as rules, regulations, IT hardware and software etc, and is easy to articulate (Hedlund, 1994) and can be shared formally and systematically. According to Nonaka and Konno (1998) "Explicit knowledge can be expressed in words and numbers and shared in the form of data, scientific formulae, specifications, manuals, and the like". This is quite a contrast to tacit knowledge. 


\subsubsection{Tacit Knowledge}

Tacit knowledge is knowledge embedded in individuals' minds and being abstract, cannot be fully explained nor understood by the individual (Polanyi, 1967). According to Nonaka and Konno (1998, p. 42) tacit knowledge is highly personal, not visible and difficult to express. It is "deeply rooted in an individual's actions and experience as well as in the ideals, values, or emotions he or she embraces". They further propose that tacit knowledge can be classified in two dimensions: the technical and cognitive dimensions. The technical dimension refers to "know-how" or informal personal skills or crafts. The cognitive dimension on the other hand "...consists of beliefs, ideals, values, or emotions..." Although it is difficult to express this cognitive dimension of knowledge, it is the part that "...shapes the way we perceive the world." (Nonaka \& Konno, 1998, p. 42). According to Sveiby and Simons (2002, p. 420), knowledge "...is not a discrete object..." and that the most valuable knowledge is embedded in people and so difficult to transfer outside the immediate context that it becomes a major competitive advantage. In Davenport, De Long and Beers' (1998, p. 43) view, knowledge is " ...information combined with experience, context, interpretation, and reflection. It is a high-value form of information that is ready to apply to decisions and action."

In summary, it must be mentioned here that these authors also expressed difficulty in distinguishing between the two at times. In its simplest definition and for the purposes of this research, tacit knowledge can be said to be abstract information that is given a context, applied with experience for a specific purpose and is embedded in an individual, sometimes without that person knowing how to explain it.

\subsubsection{Knowledge Internalisation}

Internalisation of knowledge refers to the conversion from explicit to tacit knowledge by the organisation, which is closely related to the traditional notion of learning (Nonaka, 1994; Nonaka \& Takeuchi, 1995). In an organisation context, one has to identify the knowledge relevant for oneself and to 'learn-by-doing' (Nonaka \& Konno, 1998). This learning-by-doing helps the individual to tap into the organisational knowledge realm. 
In practice, internalisation relies on two dimensions. First, explicit knowledge has to be embodied in action. So, the process of internalising actualises concepts about strategy, motivation and tactics of the organisation. Second, through the act of experimenting or simulation, knowledge is triggered in the knower. So, it is only through 'doing' that learning actually takes place.

\subsubsection{Knowledge Externalisation}

Externalisation requires tacit knowledge to be expressed in easily understood forms in order to be comprehended by others. In order for that to happen, the individual must commit to the group; become one of them, then convert the embedded tacit knowledge into explicit knowledge (Nonaka, 1994; Nonaka \& Konno, 1998; Nonaka \& Takeuchi, 1995). In practice, dialogue is an effective way of transmitting tacit knowledge. During the processes, ambiguities and contradictions between individuals and the structure, or between individuals, are ironed out through synthesis (Nonaka \& Toyama, 2003).

\subsubsection{Other Classifications of Knowledge}

Besides the existence of knowledge in tacit or explicit forms, in practice, at the organisational context, knowledge exists at individual, group and organisational levels (De Long \& Fahey, 2000). This will be discussed further in the next chapter.

\subsection{Knowledge Is An Organisational Asset}

To understand the concept of viewing knowledge as an organisational asset, we must go back to its roots in economics. Traditional microeconomics is viewed as two branches, the theory of the consumer (ToC) and the theory of the firm (ToF). The ToC studies consumption by utility-maximizing agents and the ToF studies the supply of goods by profit-maximizing agents. The counterpart to the supply and demand for goods is the supply and demand for labour by consumers and firms. The underlying objective of the theory is that firms combine quantities of production factors in order to produce outputs and those outputs are priced and sold for profit (Pass, Lowes, \& 
Davies, 2005). The most important construct of the theory of the firm is the resourcebased view.

\subsubsection{Resource-Based Theory Of The Firm}

The resource-based view (RBV) argues that firms possess resources, a subset of which enables them to achieve competitive advantage, and a subset of those that lead to superior long-term performance. While conventional microeconomic's theory of the firm assumes that all firms are equally endowed with resources, the Penrose (1959) RBV postulates that all firms differ to a greater or lesser degree. Resources that are valuable and rare can lead to the creation of competitive advantage (Barney, 1991). Barney also believes that advantage can be sustained over longer time periods to the extent that the firm is able to protect against resource imitation, transfer, or substitution. In general, empirical studies using the theory have strongly supported the resource-based view.

\subsubsection{Knowledge-Based Theory Of The Firm}

According to Cooper, Argyris and Starbuck (2005) the knowledge-based theory or knowledge-based view (KBV) of the firm regards knowledge as the most strategically significant resource of the firm. Its proponents argue that because knowledge-based resources are usually difficult to imitate and socially complex, heterogeneous knowledge bases and capabilities among firms are the major determinants of sustained competitive advantage and superior corporate performance. This knowledge is embedded and carried through multiple entities including organisational culture and identity, policies, routines, documents, systems, and employees. Originating from the strategic management literature, this perspective builds upon and extends the resource-based view of the firm (RBV) initially promoted by Penrose (1959) and later expanded by others such as Wernerfelt (1984), Barney (1991) and Conner (1991).

Although the resource-based view of the firm recognizes the important role of knowledge in firms that achieve a competitive advantage, proponents of the knowledge-based view argue that the resource-based perspective does not go far enough. Specifically, the RBV treats knowledge as a generic resource, rather than 
having special characteristics. It therefore does not distinguish between different types of knowledge-based capabilities (Spender, 1996). Information technologies (IT) can play an important role in the knowledge-based view of the firm in that information systems (IS) can be used to synthesize, enhance, and expedite large-scale intra- and inter-firm knowledge management (Alavi \& Leidner, 2001). Special attention and focus on these technological advancements therefore must be used to capture that competitive edge. Interpretivists however, do not see knowledge as an asset that can be acquired, stored, retrieved and used, but rather as a process.

\subsection{Knowledge Is A Process}

Researchers who hold a collective-level perspective emphasize the socially constructed nature of knowledge (Brown \& Duguid, 2001; Nahapiet \& Ghoshal, 1998; Nonaka, 1994; Tsoukas, 1996). Proponents of this view argue that knowledge is held collectively and that it is a result of continuous social interactions. People do not just "learn about", they also "learn to be" (Bruner, 1996). This learning does not just involve acquiring "knowledge about", but it involves knowing "how" to respond in a socially acceptable way.

In this social environment, the knower must be accepted by the group in order to respond in an acceptable and appropriate manner. For example, a person does not become a lawyer by speaking like one (Ibarra, 1999); he or she must be accepted by the group and proven to have the skills and ability. The group then confer the title of a lawyer on that individual. Learning involves how the learner sees the world and also how the world sees the learner (Brown \& Duguid, 2001). Even learning the most simple tasks takes place in the individual's head (Simon, 1986) and is an intrinsically social and collective phenomenon. While the learning itself may be simple, the social dimension is complex (Brown \& Duguid, 2001). Thus, a social context in organisational learning involves the firm as a whole, immediate colleagues, relevant disciplines as well as external social forces.

According to Nonaka and Konno (1998) there needs to be a $b a$ or space. There has to be shared space for relationships whether it is physical, virtual, and mental, or a 
combination. They go on to say that knowledge is embedded in ba. In socialisation ${ }^{7}$ and through what these scholars refer to as combination, ${ }^{8}$ knowledge is captured. These processes have a spiralling effect, propagating more of knowledge creation.

Knowledge, specifically tacit knowledge, is embedded in the mind and body of an individual and, when required, is put into action. However, it is not individual knowledge that determines competitive advantage. Rather, it is group or organisational learning in Learning Organisations (LO), through socialisation and combination that create shared knowledge, which results in leverage, and in turn competitive advantage.

\subsection{Indigenous Knowledge}

When a knowledgeable old person dies, a whole library disappears.

\section{An old African proverb}

Having looked at knowledge and knowledge management at some length I will now consider knowledge through the indigenous lens. In order for us to better understand what is meant by indigenous knowledge, I must now define the word "indigenous." According to Berkes, Colding and Folke (2000, p. 1251), from the beginning the word "Indigenous", sometimes used interchangeably with "Traditional”, has ideological connotations of people who do not conquer or non-Europeans, people who were colonised, savage and static, who had no power and were devoid of strength. Power defines knowledge, and not to have it was to be ignorant. These ignorant peoples include those from Africa, North and South America and Oceania (Maurial, 1999). Colonisers simply assumed that these people lacked knowledge. But far from the truth, indigenous peoples have their own systems of knowing (Harris \& Wasilewski, 2004) that has served them for thousands, if not millions of years, to live successfully in their own environments.

Indigenous knowledge according to Maurial (1999), is people's cognitive and wise legacy as a result of their interaction with nature in a common territory. Indigenous

\footnotetext{
${ }^{7}$ Socialisation refers to the joint activity between people resulting in knowledge creation.

${ }^{8}$ Combination involves the conversion of explicit knowledge to more complex sets of explicit knowledge through communication and diffusion process and the systemisation of knowledge.
} 
knowledge is local, holistic and agrapha ${ }^{9}$. It is local because it involves relationship in families and communities. The people are actors of the knowledge, unlike western knowledge that is stored in archives and laboratories. Indigenous knowledge is totally immersed in a culture and is embodied in folklore, oral traditions, language, flora and fauna, ways of doing things and the general environment.

Indigenous knowledge is holistic because it is not broken down into disciplines such as religion, economics, politics, law and so on and so forth. Knowledge is one and is produced and reproduced in relationship between humans and the nature around. Fully appreciating indigenous knowledge takes place in a cultural "wholeness". Finally, indigenous knowledge always takes place in oral or agrapha form. It refers to societies that do not have written cultures or did not invent written text. In reality, these cultures have their own written stories which are recorded through paintings, engravings and carvings.

Solomon Islands is one such society. According to Gegeo and Watson-Gegeo (2001, p. 62) "all knowledge is subjective knowledge" and there is no detachment of the knower from the known as in mainstream Anglo-Western objectivism. Furthermore, Gegeo and Watson-Gegeo (2002, p. 381) define indigenous epistemology as "a cultural group's way of thinking and creating, (re)formulating, and theorising about knowledge via traditional discourses and media of communication, anchoring the truth of discourse in culture." It goes to say that indigenous knowledge cannot be divorced from culture. How indigenous knowledge plays out in culture will be further explored in Chapter Three.

\subsection{Summary}

Although the concepts of knowledge and management have been around since the early Greeks and the Egyptians, it was not until the 1990s that the two words were put together to form the discipline now known as Knowledge Management. Many of the early studies such as Penrose (1959), Wernerfelt (1984), Barney (1991), and Wicks and Freeman (1998) in knowledge management held a positivist worldview and were

\footnotetext{
${ }^{9}$ From Greek word meaning unwritten form according to Merriam-Webster Online Dictionary. http://www.merriam-webster.com/dictionary/agrapha
} 
predominantly from economics backgrounds where knowledge was regarded as an asset that could be stored, retrieved, and utilised to create competitive advantage. The proponents of this view used technological advancement during that time to facilitate the management of knowledge. After a while however, it was realised that IT alone could not create that competitive edge because there is also a tacit dimension to knowledge.

The second wave of scholars concentrated on this tacit dimension (Brown \& Duguid, 2001; Nahapiet \& Ghoshal, 1998; Nonaka, 1994; Tsoukas, 1996), which is knowingby-doing. Tacit knowledge to them is a process and is often difficult to express because it is embedded in the minds and bodies of individuals and is simply expressed at specific moments in context. It covers a very broad spectrum to include belief systems, commitment, values and emotions. The proponents of this view posit that since tacit knowledge is embedded in humans, it must follow that this type of knowledge is socially constructed. It is through these social interactions that new knowledge is created and transferred to the receiver who, in turn, applies some action to create leverage and therefore competitive advantage.

Finally, this chapter has explored indigenous knowledge. In indigenous knowledge, there is no distinction between codified and tacit knowledge, rather knowledge is viewed holistically. In indigenous understanding, knowledge is a result of social construction within a local context and mostly is created through verbal interaction. Indigenous understanding is a direct result of the culture. The next chapter will explore culture and how it affects knowledge management in the Solomon Islands context. 


\title{
CHAPTER THREE \\ CULTURE AND KNOWLEDGE MANAGEMENT
}

\author{
A people without the knowledge of their past history, origin and culture is like a tree \\ without roots. \\ Marcus Garvey
}

\subsection{Introduction}

The previous chapter provided the foundational literature on knowledge management (KM). This chapter will explore literature on culture and how it affects KM praxis in general and also in the Solomon Islands context. It is argued that culture provides the context for knowledge creation, sharing and use. It can become a stumbling block to any good knowledge management strategy.

In order to understand culture, in this chapter a Definition of Culture is provided and then a brief on how Culture affects Knowledge Transfer. A short description of how culture affects international business is also provided and then the idea of National Culture is explored and how it affects knowledge management practices. The next section discusses the framework used in this study and how organisational culture shapes the assumptions about which knowledge is important, the relationships between levels of knowledge, the context for social interaction and how it shapes the creation and adoption of new knowledge. In the discussions the Gap for this research is established.

\subsection{Definition Of Culture}

Culture is one of those concepts that seem to have an inexhaustible number of definitions. According to Kroeber \& Kluckhohn (1952) as reported by Pauleen and others (2007), there were already over 160 definitions more than 50 years ago. This seems to reflect the complex nature of culture. In a sense culture is defined as identity, 
and so Westrup and others (2003) think that everyone seems to think that they know what culture is. Some of the more common definitions are cited below.

Bates and Plog (1990, p. 7) define culture as: "the system of shared beliefs, values, customs, behaviours, and artefacts that the members of a society use to cope with their world and with one another, and that are transmitted from generation to generation through learning." Many of the definitions are similar. For example, Shiraev and Levy define culture as "a set of attitudes, behaviours, and symbols shared by a large group of people and usually communicated from one generation to the next." Both talk about shared attitudes, values and communication from one generation to another. Attitudes include beliefs (political, ideological, religious, moral etc), values, general knowledge (empirical and theoretical), opinions, superstition, and stereotypes. Behaviours include a wide variety of norms, roles, customs, traditions, habits, practices, and fashion. Symbols may be in the form of material object, a colour, a sound, a slogan or a building etc.(Shiraev \& Levy, 2004). Besides these definitions, there are classifications of culture.

According to Pauleen et al.(2007), there are three ways of categorising culture: content, construction and sustainability. Culture as content refers to an underlying set of norms, and values of behaviour, shared by a group of people tied together through affiliations or bonds (Clark, 1990; Hofstede, 1980). Construction of culture refers to a group's response to the problems encountered in their environment and creating solutions to those problems (Schein, 1985). Sustainability in culture means the embodiment of culture in symbols, stories, artefacts, rituals and so on that are transmitted from one generation to another to keep the culture alive. The sustainability view of culture is being challenged as irrelevant since modern context is not static but dynamic (Walsham, 2002), and Holden (2001, p. 126) calls for a shift in paradigm to coincide with the current "infinitively overlapping and perpetually redistributable habitats of common knowledge and shared meanings".

Nisbett (2003) outlines a model in which what an individual learns is shaped by the environment in which they grew up. In this model learning is socially constructed, so what one learns is affected by his family and family relationships, and is an 
antecedent to the attention process, and epistemology. So that, for an individual to acquire knowledge in a new context, when an individual is placed in a new environment, there is no easy learning transition. They have to put aside their learning style and learn to learn using a new epistemology: that of the new culture. It is not simple factual knowledge, but a different cognitive structure. The difference is in how an individual learns and makes sense of their world. Failing to recognise these differences could prove fatal, for the unsuspecting or naïve entrepreneur.

Kozulin (1998) believes cross-cultural differences are mostly related to learning practice; characteristics of cultures and sub-cultures. Two major determinants of cognitive prerequisites are conceptual literacy and facility with other psychological tools, and a mediated learning experience, responsible for integration of those tools with a learner's cognitive system. While abstract concepts can be learned, there are also neurological bases for these differences in epistemology, according to Kuhl (2002). This view recognises the explicit and tacit dimensions of knowledge (Nonaka \& Peltokorpi, 2006). In KM, culture is the emotional side of learning (Retna \& Bryson, 2007).

From the discussion, it seems evident that there are a lot of similarities in the definitions of culture. For the purposes of this research, culture is recognised as the system of shared beliefs, values, customs, behaviours and artefacts; that culture is socially constructed and its purpose is an attempt by members of a society to understand their environment. It is also further recognised that there are differences across cultures or subcultures and this has to do with learning characteristics.

\subsection{Culture And Knowledge Transfer}

There is no simple way of transferring knowledge. In order for knowledge to be transferred, there have to be numerous preconditions (Fink \& Holden, 2007). The transferor of the knowledge has to determine the perceived value of the knowledge. It also depends on what motivates the knowledge provider and the esteem they enjoy. There has to be a decision made on the knowledge itself; whether it is important, relevant and possibly attractive to the recipient. Then, there are other preconditions 
that are dependent on the potential recipient, such as their capability to absorb that new knowledge.

The knowledge itself may not be absorbed by the recipient culture because it simply cuts into existing structures, values, beliefs and social norms. Since this challenges the identity of the affected group, knowledge managers may have to redefine values, social norms and beliefs to expose what has been hitherto regarded as reserved for private space (Fink \& Holden, 2007) to become public. However, any shift of position will depend on the recipient culture's willingness to relinquish control of its own turf. This willingness may need pressure from within and without. This may be easier said than done.

The scope of this research is not wide enough to cover the pre-conditions set by both the knowledge transferor and the receiver. However in a broad way, in terms of culture and knowledge transfer, this research will look at the culture related to valuing of important knowledge at the organisational level. It will also look at how culture determines the relationship between organisational and individual knowledge. This study will also consider the social context for interaction and knowledge sharing. And finally, this work will provide an explanation of how culture encourages the creation of new knowledge and it's adoption. More of this literature discussion is covered from section 3.5 to section 3.9 below.

\subsection{National Culture}

In a very real sense, it will not be one man going to the moon, it will be an entire nation. For all of us must work to put him there.

\section{John F. Kennedy}

There are various ways of classifying national cultures such as Hall's (1976) high and low context, Lewis' (2000 ) monochronic/polychronic perceptions, and Hofstede's (1980) cultural dimensions based on dichotomies. Hofstede's work was an exercise to classify 50 national and 3 regional cultures and study their national behaviour and value systems. There has been much debate in the legitimacy of the concept of national culture (Pauleen, Wu, \& Dexter, 2007). Holden (2001) suggested that globalisation has brought people from different cultural backgrounds to work in the 
same office creating multicultural societies. Therefore, classifications based on nation-states no longer reflect ethnic and regional differences. However, in the case of Solomon Islands where little change has taken place in terms of business, the vast majority of the workforce is Solomon Islanders. Therefore, this study recognises Solomon Islands as a nation-state with a distinct national culture.

In the next section an outline of what is perceived as Solomon Islands' national culture is provided. These include multiplicity of cultures, big-manism $^{10}$, the work of church, government, wantokism ${ }^{11}$, pijin $^{12}$ language, and the effect of World War 2.

\subsubsection{Solomon Islands National Culture}

According to Fugui (2007), national culture developed from a convergence of four main factors. One is the work of churches, two is the sharing of the lingua franca, pijin, three is the concept of wantokism and fourthly, the experience of Solomon Islanders during World War 2. But it is clear this is a nation with multiple subcultures operating the big-man system of governance. Although this is no longer practised in any great way, the understandings, and ways of thinking arising from this system are still very much embraced. The work of government too, cannot be ignored. Its role in changing Solomon Islands culture from what it was to what it is today is enormous and so it would be naive to ignore it.

\subsubsection{Multiple Subcultures}

Solomon Islands is a country made up of six main islands and about 900 smaller ones. The majority of the population are Melanesians (94.5\%) with 3\% Polynesians and $1.2 \%$ Micronesians $^{13}$. There are 120 indigenous languages spoken, making a national culture seem an impossible feat. However, recognising the multiplicity of cultures is the first step to understanding Solomon Islands' national culture. It is one that is created from the intertwining of all these subcultures. In this mesh of subcultures is the system of traditional governing: the Big-man System.

\footnotetext{
${ }^{10}$ Big-Man is the system of governance in traditional Melanesia.

${ }^{11}$ Wantokism is a rallying philosophy in Melanesia that brings people who speak the same language or share a culture to work together.

${ }^{12} \mathrm{Pijin}$ is a form of Creole.

${ }^{13}$ http://www.infoplease.com/ipa/A0107975.html (20th Aug 2007)
} 


\subsubsection{Big-Manism}

The Melanesian "Big-Man" is a term coined by Marshall Sahlins (1963). According to Sand (2002), Sahlins defined the Melanesian Big-Man society as "one in which the leaders build on long-term family and group involvement, to achieve wealth and surplus (social) production, allowing the leader to pass different social grades." Despite family support, Godelier (1982, p. 163), thinks the big man is "a man who has acquired his power through his own merit". This power can be neither inherited nor inheritable. His merit lies in his proven superiority in various fields, for example, his skill and efforts as a gardener, his bravado in battle, his oratorical gifts, or his magical powers. But none of these abilities would make him complete as a big-man without the ability to amass and re-distribute wealth (Sahlins, 1963). These talents, this wealth, and the skills in excelling in giving and counter-gifts, slowly make the others become his obligees and so he becomes a big-man, a renowned leader in his tribe and then to neighbouring tribes.

A Solomon Islander, Sam Alasia (1989, p. 138), defined the Big-man system to mean " individuals become leaders as a result of their ability to influence people in the society, and to command the support of many people for a considerable period of time and over a specific area." Sam Alasia made further distinctions between three important big-men in a community. The fata $a b u^{14}$, the ramo $^{15}$ and the aofia ${ }^{16}$.

The fata $a b u$ is chosen by the spirits and so he is divinely appointed to be the priest of the tribe. He is the link between men and the gods. The ramo is the chief warrior. From an early age he begins to show signs of ramo nga'a. These would include fearlessness, courage and notoriety. Not until he kills someone from another tribe would he be recognised as a ramo. Finally, the aofia is the feast-giver, the organiser, orator, the political head of his society. Again, he assumes leadership through his own merit.

\footnotetext{
${ }^{14}$ Fata' abu is priest in Northern Malaita.

${ }^{15}$ Ramo is chief warrior in Malaita.

${ }^{16}$ The feast-giver, the organiser, the orator, the political head or big-man.
} 
The big-man system was the recognised system of government until outsiders entered the lives of Solomon Islanders, first as explorers, then traders, missionaries and later government. From these interactions, Solomon Islanders began to create a unified culture through language, religion, governance and indeed experience.

\subsubsection{Pijin English}

Pijin English, according to Mühlhäusler and Mühlhäusler (2005, p. 4), was a language originally developed on plantations in Australia where thousands of Melanesians (referred to as Kanakas) worked on the sugar plantations between 1860 and 1906 during the black-birding ${ }^{17}$ era. It was a form of simple English. Often it was regarded as "Broken English". The Queensland Kanaka Mission's ${ }^{18}$ (QKM) aim was to convert but not educate and civilise the Melanesians and so pijin was thought to be sufficient. However, it was not "simple". It had its own complex grammatical and lexical conventions (Mühlhäusler \& Mühlhäusler, 2005, p. 7) which early Europeans found relatively difficult to learn. When the QKM work was transferred to Solomon Islands, they changed the mission to South Seas Evangelical Mission (SSEM) which later became South Seas Evangelical Church (SSEC) after gaining autonomy from the expatriate missionaries.

The lingua franca (Keesing, 1988), pijin English, is a gel where there are so many languages spoken. It becomes social glue that binds ordinary folk when they communicate with each other on the streets and when they travel inter-island. It is not a compulsory subject in school but children pick it up when they interact with those who speak it. Even children living in villages and surrounded by speakers of their own native languages learn to speak pijin from others of their community, and so, spreading the language to all villages in Solomon Islands.

\footnotetext{
${ }^{17}$ Black-birding is the name given to the enslaving of South Sea Islanders mostly from Solomon Islands and Vanuatu to work in the plantations in Australia, Fiji and Samoa. This illegal activity was stopped when Britain made Solomon Islands its protectorate in 1893.

${ }^{18}$ Queensland Kanaka Mission (QKM) was the name given to Florence Young's Sunday school classes to the black South Seas Islander slaves brought to work on Australia's CSR sugar cane plantations. This was later changed to South Seas Evangelical Mission, when Australia's policy was changed and in 1904 the islanders had to be repatriated to their homelands and Greeks, Italians and other people from the Mediterranean region were employed instead.
} 


\subsubsection{Christian Mission}

According to Fox (1967, p. 31), Christian missions came to Solomon Islands 50 years before the British Government. The various missions engaged in education. The first primary and later secondary schools were run by the various missions. Five of the seven biggest high schools are still mission owned. They are Su'u, on Malaita and owned by SSEC; Goldie College, owned and run by the Methodists/United Church in the Western Province; and Selwyn College (Anglican), Tenaru (Catholic) and Betikama (SDA) which are outside the capital Honiara. The other two high schools which are run by the government are King George VI in Honiara and Waimapuru on San Cristobal Island. All these schools have seen an inter-island migration of students over the last forty or fifty years. Amongst the churches, there is an enviable level of tolerance and reciprocity developed in the last century. Churches have also built clinics, hospitals, church buildings and goodwill. The churches have inherently facilitated the different cultures to assimilate in the social gospel of sharing and caring.

\subsubsection{Government}

Government came in late, in 1893, in relation to black-birding according to J.W. Sanga (2001, p. 7). They too, along with the churches, had major influences on the culture. Sanga (2001, p. 8) said “... the British contribution to development has been quite significant. Through the British assistance, urban centres were developed in Gizo, Buala, Tulagi, Auki, Kira Kira in the 1920s and 30s and later at Lata." From its headquarters in Tulagi first, and later Honiara, after World War 2, the colonial government ruled through its sub-stations in the main islands and helped to bring the people together through governance and providing a sphere for internal migration and interaction.

\subsubsection{World War 2}

The development of a national culture was also influenced by the battles Solomon Islanders experienced during World War II. Although the "war was not our war," the fact that many Solomon Islanders had common experiences, including putting their 
lives at risk to save their country from the enemy (the Japanese), helped unite them into one people. Jan Sanga (1989, p. 30), for example wrote:

\footnotetext{
"Although with the passing of time people's memories of the war... will grow $\operatorname{dim} .$. numerous reminders of the past survive. Besides archaeological remains and written records there is an abundance of place names and marks upon the landscape and, indeed, of forms of behaviour, to remind Solomon Islanders of the present day that the country and the way of life that they have inherited is not entirely of their own making. ... Today is a product of yesterday, just as tomorrow will be a product of today".
}

Solomon Islanders had no choice. The war had forever shaped their lives. It created a people with a common experience from those who were diverse and once had little connection or contact with each other. The war, in a bizarre way had gelled a nation together.

\subsubsection{Wantokism}

Concomitant with the above is the concept of wantokism. Wantokism is a rallying philosophy that brings together, in common cause, people who are related, those who speak similar languages, those from the same area or island, and even the country as a whole. Its social pliability means that it can be applied in more than one situation especially when one is new to a place or unfamiliar to a group of people. It is a concept in which mutual hospitality is shared among and between different individuals and groups. The concept also traverses national boundaries. It is shared particularly among the three main Melanesian nations, the Solomon Islands, Vanuatu, and Papua New Guinea.

\subsubsection{Summary}

The Solomon Islands national culture is a product of the big-men system and multiplicity of subcultures. From this background, the process of interaction with missionaries, government and the experiences of war created a new national language and a sense of camaraderie. 
It is in this national cultural environment that the Social Securities Enterprises as detailed in Chapter Five exists. The next section will now focus on the framework used to study culture's effects on knowledge management practices. By virtue of the organisation dynamics, this framework assumes organisational cultural elements from within, affecting KM practices together with the external environment.

\subsection{Conceptual Framework: De Long And Fahey}

For this research, I used the conceptual framework by De Long and Fahey (2000) on cultural barriers to knowledge management. This framework recognises the existence of knowledge in three forms; human, social and structured knowledge. More explanation is provided in the whole of section 3.5.1 to section 3.5.3 below. But the main thrust of their paper was on culture's effects as a barrier to leveraging intellectual assets. It is this effect that this research is all about, based on the Solomon Islands' context. Further discussion of this framework is provided in sections 3.6 to 3.9 of this chapter.

In De Long \& Fahey's view, knowledge exists as three types or "forms": Human, Social and Structured knowledge. These are briefly defined below.

\subsubsection{Human Knowledge}

Human knowledge involves 'what' individuals know and 'know how' to do (De Long \& Fahey, 2000, p. 114). Knowing what and knowing how is what makes individuals perform what they do. This knowledge is manifested in skills to do something and also expertise or a deep understanding of why things happen as they do. Human knowledge exists in both tacit and explicit forms. Sometimes it is sentient or located in the body such as knowing how to ride a bicycle, or it can be cognitive. That is knowing conceptual and abstract ideas.

\subsubsection{Social Knowledge}

De Long and Fahey (2000), referred to social knowledge as the existence of knowledge only in relationships between individuals or within groups. This 
knowledge creates synergy, is largely tacit, is shared by group members only and develops through working together. Only members of the group have this form of knowledge which is created through social interaction of group members.

\subsubsection{Structured Knowledge}

Structured knowledge is knowledge embedded in an organisation's systems, tools, processes and routines. According to De Long and Fahey (2000), structured knowledge is explicit and rule-based. The distinction between structured knowledge and the previous two is that structured knowledge exists outside of humans and therefore is an organisational resource.

In De Long and Fahey's (2000) framework, the authors state that culture and knowledge are inextricably linked in organisations. Any view expressed that does not take into account culture could be misleading. They also further found that behaviours that are culturally generated and condoned at both individual and group level can be unfavourable to developing and leveraging knowledge. Managers must first understand how culture influences knowledge-related behaviours before they can evaluate how an organisation's current culture influences the creation, sharing and use of knowledge.

De Long and Fahey (2000) established four frameworks linking culture and knowledge. These are:
a. Culture shapes assumptions about which knowledge is important;
b. Culture mediates the relationships between levels of knowledge;
c. Culture creates a context for social interaction; and
d. Culture shapes creation and adoption of new knowledge.

The next sections discuss these four frameworks. 


\subsection{Culture Shapes Assumptions About Which Knowledge Is Important}

According to De Long and Fahey (2000), culture shapes assumptions about which knowledge is important. As they put it, "this belief about which knowledge is important does not occur in organisational vacuum. They are shaped by values and norms." This is illustrated diagrammatically below.

\section{Figure 1: Culture Elements Influence Behaviours}

Elements of Culture:

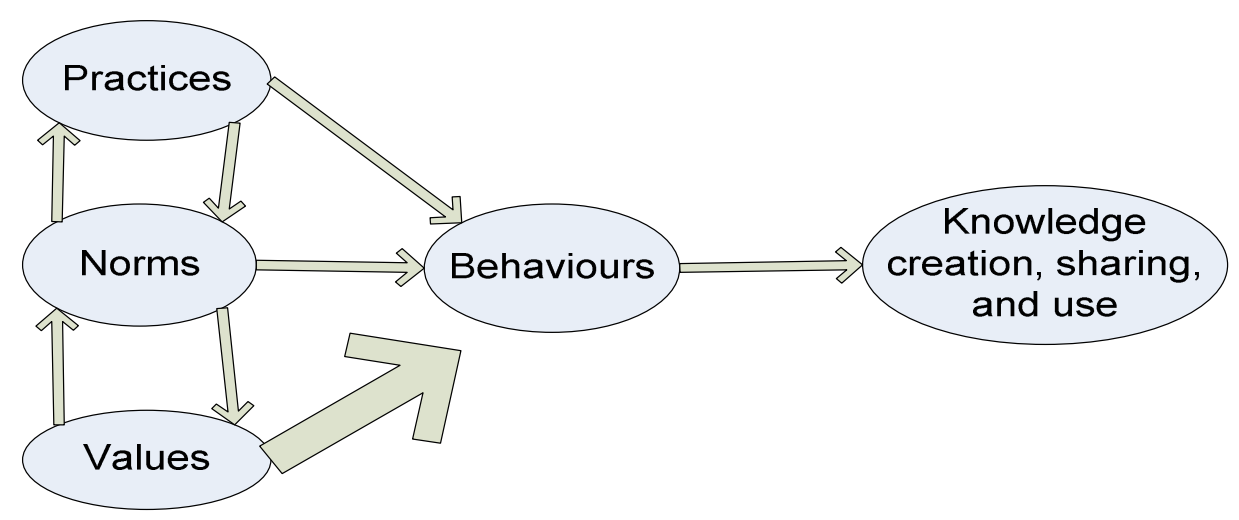

Note: The thicker arrow denotes the predominant impact of values on behaviours. Adopted from De Long and Fahey (2000).

Practices are the easiest to observe as they involve repetitive behaviour such as filling in the attendance book, how the phone is answered or how the weekly meetings are conducted. These repetitive behaviours are the easiest to change and they are the easiest way of leveraging knowledge creation, sharing and use.

Norms are less identifiable and they include such attitudes as information sharing in an organisation. Is information shared freely, or is it considered a risk to one's security? These norms are derived from values.

Values are difficult to identify and they are embedded, tacit preferences about what an organisation should strive to attain and how it should do so. For example, if an organisation truly values their customers, it should show that staff treat their 
customers with utmost respect and cordiality. A mutual understanding should occur and values that inspire staff to regard their customers as partners are more likely to create behaviours that create useful knowledge about customers.

The distinct Solomon Islands' culture provides a unique research setting. In relation to this first framework, this research will look at how the culture in SSE and generally in Solomon Islands affect what people value and consider as important knowledge.

\subsection{Culture Mediates the Relationships Between Levels Of Knowledge}

The culture of an organisation embodies all the unspoken rules about how knowledge should be shared between the organisation and its individuals as shown in Figure 2. below.

\section{Figure 2: Culture Mediates the Relationships Between} Organisational and Individual Knowledge

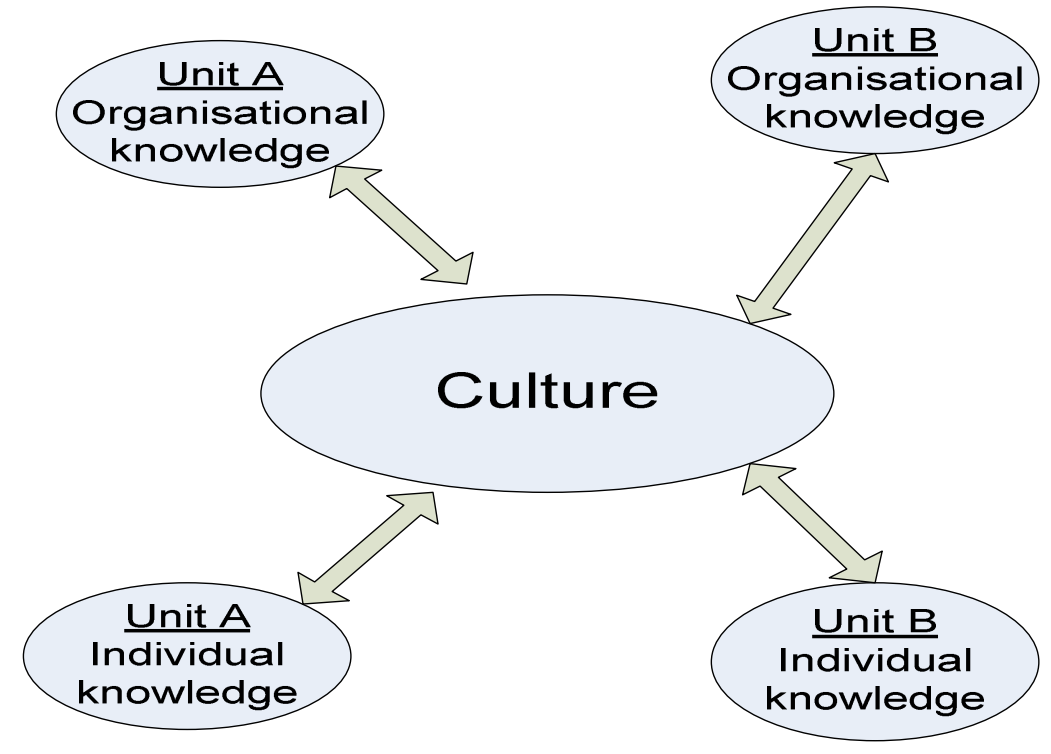

Adopted from De Long and Fahey (2000).

Culture dictates who should share knowledge and who should hoard it. When looking through the culture lens, three important themes emerge. That is, who controls what knowledge and where it is located. 
In Solomon Islands culture, who is always an important consideration. Even people who are of low status gain importance through a relationship with someone who is of a high status. It is not uncommon for Solomon Islanders to introduce themselves as an important person's relative. It would be noteworthy to observe this culture in an organisational context.

In connection to the above, in Solomon Islands organisations the CEO is seen as someone with great power and control. Often knowledge contained at the executive level is viewed as very important. Important knowledge also includes technical knowledge held by individuals with specialist skills. Individual knowledge is treated as private property. It is not always easy to get individuals to part with their knowledge and to convert it to structured, organisational knowledge.

This study then is designed to uncover the relationship between organisational knowledge and individual knowledge. Particular interest is in how the SSE and Solomon Islands cultures mediate this relationship and determine their importance and where they are located.

\subsection{Culture Creates A Context For Social Interaction}

Social interaction and skill make humans different from all other creatures (Tomasello, 2008). Everything that humans have created, including technology, language, government, numbers and so on, are products of collective cognition. How we actually socialise is realised in the context of culture. An important result of human socialisation is the creation of social institutions.

Figure 3 below illustrates cultural characteristics that shape social interaction at the organisational level. 


\section{Figure 3: Cultural Characteristics that Shapes Social Interaction}

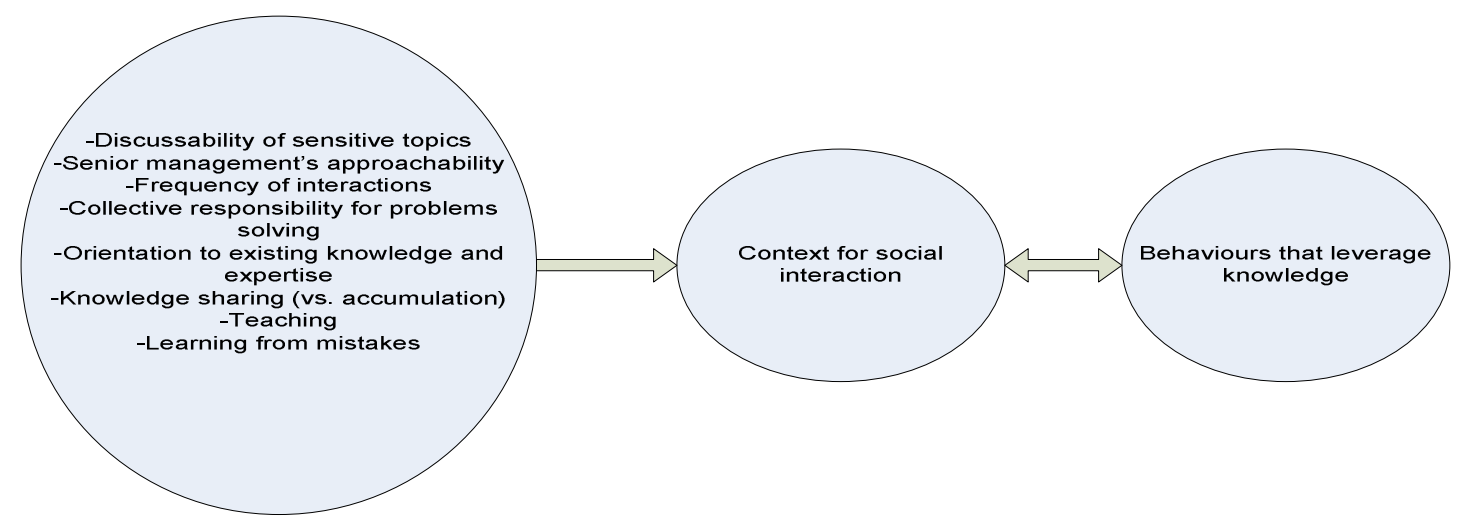

Adopted from De Long and Fahey (2000)

Culture shapes perceptions and behaviour. One of the ways it does this is through providing the context for social interaction (De Long \& Fahey, 2000, p. 120). By defining the context for social interaction, culture provides the unspoken norms, rules, expectations and penalties that govern social interaction and the use of certain knowledge at certain times. This shapes people's perception of their range of options acceptable to the organisation.

In line with De Long and Fahey's (2000) view, this research will assess three dimensions where culture impacts on as the context for interaction. These are vertical interaction, horizontal interaction and special behaviours that promote knowledge sharing and use.

Firstly, I wanted to find out how easy it was to discuss sensitive issues and how approachable were managers or the CEO? The responses to these questions would highlight the effectiveness or otherwise of knowledge sharing.

Secondly, this studied looked at horizontal interaction in order to observe the patterns and qualities of interaction among people of the same level. My interest was in the volume of interaction, level of collaboration and collective responsibility, and the tendency to seek out existing knowledge. The volume of interaction is important as it demonstrates the flexibility of that organisation to communicate. Similarly, the level of collaboration is important as it shows to what extent people are willing to assist others. Also horizontally, I was interested to see how the culture encourages staff to 
seek out existing knowledge and build on that knowledge. It would be time consuming and a waste of resources to re-invent the wheel.

Thirdly, there are numerous desirable behaviours that help shape the context for social interaction. However, De Long and Fahey (2000, pp. 121-122) looked at two that seemed the most important. These are sharing and teaching, and dealing with mistakes. Cultures that favour knowledge sharing over knowledge acquisition will provide a context for sharing and leveraging knowledge. Mistakes too, though undesirable, provide opportunities for learning. How mistakes are treated evidences the norm of an organisation. Where an organisation culture views mistakes as punishable offences, people would not readily admit their faults. Whatever approach is taken will influence how people interact and how knowledge is shared and leveraged.

\subsection{Culture Shapes Creation And Adoption Of New Knowledge}

According to De Long and Fahey (2000, p. 123), knowledge becomes valuable when it is used for decision making and translated into action. Sometimes new knowledge is adopted wholesale and other times external information is converted internally to become valuable knowledge. How new knowledge about the external environment is created, made legitimate or rejected, and distributed in an organisation is heavily influenced by an organisation's culture and sub-cultures. Figure four below illustrates these relationships.

\section{Figure 4: Creating and Adopting New Knowledge}

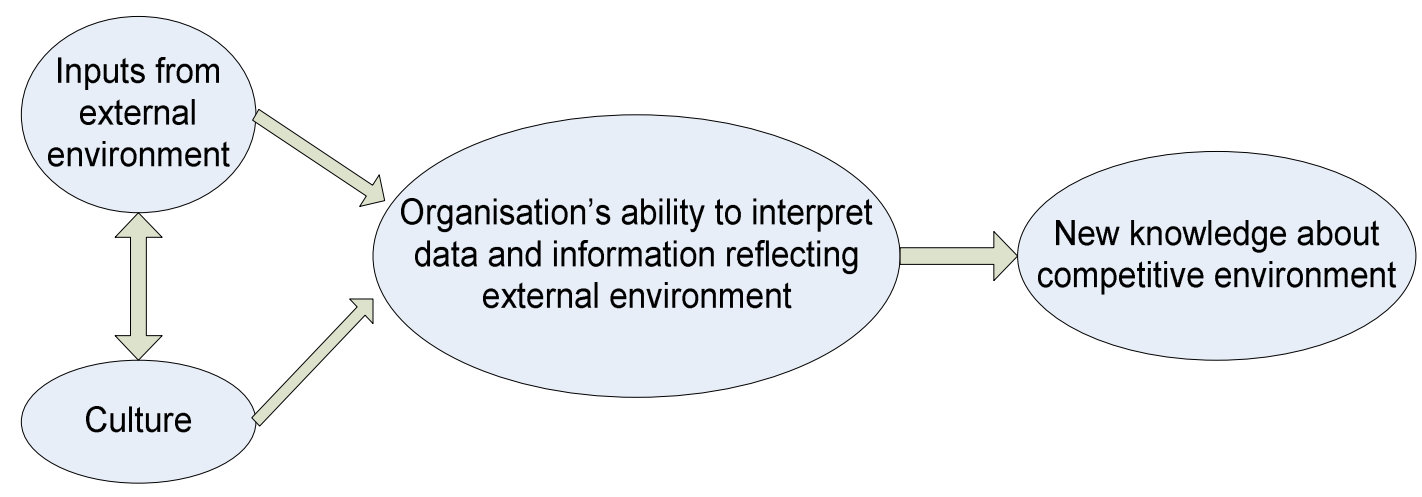

Adopted from De Long and Fahey (2000) 
In this framework, four characteristics of culture that help a firm to acquire and distribute new knowledge were observed. As an exploratory study, the rate of adoption and distribution would be too wide for this work.

I was more interested firstly, on the understanding of innovation in SSE. Knowledge from external sources should be seen as the starting point and not the end. Innovation should be based on improving external structured knowledge instead of trying to rediscover existing knowledge or wholesale adoptions. To remain competitive, an organisation must allow continuous trial and error.

Secondly, cultures that encourage intense debate on key strategic issues develop adaptability in volatile situations. While management may not always accept their subordinates' views, the encouragement of discussion amongst staff creates a healthy environment for learning and knowledge sharing. In the case of SSE the low level of debate reflects a stable environment.

Thirdly, not only should staff be encouraged to debate and discuss important strategic issues; they should also be encouraged to seek out external knowledge and participate in it's synthesis to important business issues. By encouraging staff to participate in knowledge gathering and distribution, companies create a culture that is effective in creating and integrating new knowledge.

Finally, firms should encourage their workers to challenge assumptions and beliefs that shaped their earlier successes. Thinking outside the square can often generate new ideas and ways of doing things. Nevertheless, it is always a challenge for decision makers to change from existing successful assumptions because of the emotional attachments they have to the past and also due to costs involved in implementing change. However, it is a key step to creating new knowledge for the organisation. 


\subsection{Summary}

Culture plays a vital role in cross-cultural management. As the result of globalisation, there is no longer a single country that truly has a monoculture because of the fluidity of human resources. These are the difficulties MNCs face all the time. In the above literature I endeavoured to explain national culture and its role in providing the context for knowledge creation and leverage in any organisation. In particular, a national culture for Solomon Islands was provided. Within the context of Solomon Islands' national culture, I introduced De Long and Fahey's framework. The framework provided the four main questions explored in this research. In general this framework looked at the various ways that culture creates barriers to better knowledge management. The spin of the research is its setting in Solomon Islands context. 


\title{
CHAPTER FOUR
}

\section{THE RESEARCH METHODOLOGY}

\begin{abstract}
An investigator starts research in a new field with faith, a foggy idea, and a few wild experiments. Eventually the interplay of negative and positive results guides the work. By the time the research is completed, he or she knows how it should have been started and conducted.
\end{abstract}

\section{Donald James Cram}

\subsection{Introduction}

Having surveyed the literature on Knowledge Management in Chapter Two and Culture in Chapter Three, and having located a gap, this chapter will now outline the research methodologies which were used to explore the research question. It starts by stating the assumptions of this study, then a rationale of the methodologies chosen are provided and a discussion of ethnography and case study as research strategies. A description of the methods used, namely semi-structured interviews, document analysis, observations and the use of focus groups will be given. In the next section, the procedures followed in data collection and analysis are presented. Finally, this chapter ends with a discussion of ethical issues, in which the questions on validity, reliability and generalisability are addressed.

\subsection{Assumptions: The Interpretive Paradigm}

This study is informed by the interpretive paradigm. There are many terminologies used for interpretivism. O'Leary (2004, pp. 7-8) listed some as "post-postivists, antipositivists, and many other post-modern 'ists"'. Often post-positivism refers to new scientific philosophy that arises in reaction to positivism. In a general grouping, these would include phenomenology, Marxism, critical theory, post-structuralism and postmodernism, although Guba and Lincoln (2005, pp. 193-196) provided distinctions to these. Lincoln (2005, p. 165), makes other classifications in terms of "paradigms, theoretical perspectives, ...epistemological stances, ... and interpretive lenses.” To 
complicate definitions, another view of post-positivism is that it represents reformed positivism; this is in response to the critics of positivism. For example, Guba and Lincoln (2005, p. 193) suggest that the ontological perspective of post-postivism is "critical realism - "real" reality but only imperfectly and probabilistically apprehendible." Similarly, anti-positivism refers to these same philosophical perspectives. It would be beyond the scope of this study to provide definitions and explanations of these various terminologies. For the purposes of this study, I focus on the interpretivist worldview which will be considered in some detail.

According to Cavana, Delahaye and Sekaran (2001, p. 9), interpretivism, as opposed to positivism, does not believe that "people share the same meaning systems." Instead, interpretivist researchers believe that it is "more likely that people experience physical and social reality in different ways" and reality is a result of social construction. These concepts are further explored in the interpretivist assumptions I hold, which are spelled out below. These encompass the worldview held, the nature of this research, my role as a researcher, methodological assumptions and finally what the findings of this study represent.

\subsubsection{Assumptions Of The World View}

Taking an interpretive approach, it is assumed in accordance with O'Leary (2004, p. 6), that the world is chaotic and ambiguous, and therefore this study takes a qualitative world view. This view holds that science and quantitative analysis have helped us to understand some things, but not all. Some of the things we thought we knew were later proved wrong. It is assumed that the world is so complex we can never know the entirety of knowledge because there are countless variables in the world and nothing is fixed, and so 'truth' can depend on our ability to define shifting phenomena. Therefore, it is assumed that there is a multiplicity of reality. What is the 'truth' for one person may not be so for another.

\subsubsection{Assumptions Of The Nature Of This Research}

The second set of assumptions is that while research is often based on the senses, it can also be intuitive. By saying this, the presence of hunches, metaphors and 
creativity as legitimate ways of learning and knowing the world (O'Leary, 2004, p. 6) is recognised. It is also assumed that by nature, research is holistic and there is need to study the whole, as the whole is more than the sum of its parts - "when the relevant theory underlying the case is itself holistic"(Yin, 2003, p. 45). It is therefore assumed that having a better understanding of cultural effects on knowledge management in the case organisation can be achieved by understanding the whole.

\subsubsection{Assumptions Of The Researcher's Role}

As a researcher taking an interpretive approach, it is assumed that my work will be as a participant who will collaborate with subjects. It is recognised that this work will be both for and with participants. Therefore, subjectivity in my work (O'Leary, 2004, pp. $6,7)$ and its value-bound nature is acknowledged. It follows that I will be very much involved in choosing the tools to work with, and as a native of the culture, and former employee of Solomon Securities Enterprises, my views will not be considered as biases, instead they will bring enrichment to the study.

\subsubsection{Methodological Assumptions}

The methodologies that are employed have the potential of rejecting or expanding upon the rules of scientific method (O'Leary, 2004, p. 7). As an interpretive work, by nature, inductive reasoning is open-ended at the beginning. It is the plan that this study will observe phenomena and record emerging patterns. It must be made clear here that this work is not hypothesis-driven, but rather, an exploratory work. In this instance, the study is exploring the role of Solomon Islands culture on knowledge management policies and practices. With interpretive qualitative study, it is difficult to claim reliability of methods used. Therefore, this work will rely on qualitative methodological triangulation to provide balance and dependability. And finally, by employing ethnography, it is assumed that the reproducibility of this work will be difficult. However, the aim of this study is to produce a verifiable work, through transparency and clear explanations of methods employed. 


\subsubsection{Assumptions About The Findings}

Finally, as an interpretive work, the findings are assumed to be qualitative (O'Leary, 2004, pp. 7-8). Again, the extensive use of imagery and words in this work is accepted as normal. Mostly the findings will be idiographic or unique to the case and so intrinsic, and difficult to generalise. However, the findings, or lessons learned, are transferable to other contexts because, it is assumed that the findings will be valuable, and that they will contribute to the production of social knowledge, and in turn, to some changes for the better.

\section{Pilot Study}

In order to be well equipped before going into the field, there was a need to run a pilot study. Bloor and Wood (2006, p. 99) define a pilot study as:

\footnotetext{
“...the conduct of preliminary research, prior to the main study. It provides a structured opportunity for informed reflection on, and modification of, the research design, the research instruments, costings, timing, researcher security and indeed a whole gamut of issues concerning the everyday conduct of the research."
}

The primary purposes of the pilot study were the informed reflection and modification of the research design, the research instruments and timing. It was also an opportunity to try out the use of someone to transcribe and translate the interviews.

It was not possible to conduct the pilot study in my case organisation due to geographic and logistics difficulties. Nevertheless, using my network connections I was able to interview two Solomon Islanders who were on in-service training at VUW. The convenient choice of these two was appropriate for testing the instruments. Their experience in a particular organisation was irrelevant. I was more interested in how they answered my questions. Their responses helped me to adjust my questioning techniques. As a former employee of the case organisation, my understanding of the structure and the organisation meant the focus of the design was appropriate to the context of the case organisation. 
The research was designed from the general question "How does culture affect knowledge management practices in the Solomon Islands?" as a transferable concept. Using De Long and Fahey's (2000) framework, these four sub-questions were asked:

a. How does culture shape assumptions of what knowledge is important?

b. How does culture mediate the relationship between levels of knowledge?

c. How does culture create a context for social interaction?

d. How does culture shape creation and adoption of new knowledge?

To answer these questions, further questions were asked, some of which included their understanding of what knowledge is, who owns it, where it is located, knowledge reception flexibility and adaptability, informal interactions and power relations. For more detail see Appendix E.

In conducting the pilot study, VUW formal requirements were followed. I gave a full description of my study and my purpose for conducting the pilot study. Having fully understood the purpose of the study and their role in it, they gave signed consent for the interview, and willingly accepted to be tape recorded. The data was content analysed to form thematic categories. This was done for practice.

The pilot study also served to test the instruments and to note the sort of responses that were derived from them. Though question guides were formulated in English, they were asked in pijin. This pilot has provided practice in reading English in the mind, and translating to pijin when the questions are asked.

The pilot study also provided data to help in practise transcribing skills to verbatim pijin, then translating the text into English. From the pilot study, I was made aware of my weaknesses in speaking for a tape recorder. Since the transcriber was not involved in the actual interview, there was a need for me as well as the participants to speak loud enough and clearly to avoid mistranslation and therefore misinterpretation of conversations which would skew the findings of the study. 
It was also important that I got my timing right. The pilot study gave me the realistic time needed to conduct each interview. As has been shown in the pilot study, one interview lasted an hour while the other took forty-five minutes. This meant that I had to be realistic about the number of interviews that could be conducted together with four focus groups. From this experience, valuable lessons were learned in intelligent questioning techniques.

Finally, but not the least important, is the testing of the logistics. From the pilot study, a valuable lesson was learned. There is no substitute for advance preparation of logistics such as venue, resources and even ensuring participants are available and on time. Preparation of logistical support is costly and can be time-consuming, and if not carefully planned can be very frustrating. These have been valuable lessons that were taken to heart when I reviewed my research design.

\subsection{Methodological Discussions}

The ontological and epistemological assumptions of this study are informed by the interpretive paradigm and my role as the researcher here is to actively construct meaning as well as to actively interpret reality. It is therefore assumed here, that knowledge creation and management is a social construction. In context, through interaction, members of staff of Solomon Securities Enterprises (pseudonym) try to make sense of their knowledge world. This study sought to find out more about the dynamics that shape knowledge management at the organisational level by using a cultural lens to observe and probe barriers to knowledge management in Solomon Securities Enterprises (SSE). The choices of ethnography and case study as research strategies and tools were influenced by several factors.

\subsubsection{The Rationale For Qualitative Research}

The over-arching reason for the choice of ethnography and case study as strategic tools is the research approach, namely, Qualitative Research. Given that humans are creative by nature, there is also a variety of research methods that have been suggested, but they can be roughly grouped into two clusters- quantitative and qualitative (Cavana, Delahaye, \& Sekaran, 2001). While Quantitative research is 
broadly based on the works of Auguste Compte (1798-1857) ${ }^{19}$, "Qualitative researchers believe that humans are complex, somewhat unpredictable beings and that individual differences and idiosyncratic needs override any notion of universal laws of human behaviour" (Cavana, Delahaye, \& Sekaran, 2001, p. 34). Thus, a primary reason for choosing qualitative methodology is because of its "more flexible meaning" than quantitative work (Silverman, 2005, p. 306). This flexibility means this chapter could be written in more lively and interesting ways than if it was quantitative work.

\subsubsection{Ethnography: The Strategic Approach}

According to Bloor and Wood (2006, p. 69), and Denscombe (2007, p. 61), ethnography is the description of culture or social groups. The word literally means the description (graphy) of cultures (ethno). In this case, my study is a "graphy" or description of Solomon Islands culture and how it affects knowledge management at the organisational level. Davies (2007, p. 168) explained that ethnography traditionally was used by anthropologists who studied foreign or exotic cultures that were considered endangered. Since the second half of the twentieth century, however, a new body of literature has emerged which uses ethnography to study contemporary settings in the developed world, such as hospitals, commercial undertakings, and local government departments.

Ethnographic research is not straightforward, since its primary concern is the understanding of normative patterns (O'Leary, 2004, p. 119). Ethnography is premised on the assumption that knowledge is socially constructed. Therefore its understanding will rely on how close a researcher is to the phenomenon (Goffman, 1961; Punch, 2005, p. 152). While this requirement is generally true, it applies to "outsider scholars". As a native of the culture, the researcher carries an "insider" perspective (Gegeo \& Watson-Gegeo, 2001, p. 57).

\footnotetext{
${ }^{19}$ Auguste Compte was a French thinker who coined the term sociology. In the English speaking world he is famous for his views of the universal "law of three phases". The world has gone through three phases: theological, metaphysical and scientific phase. The scientific phase, he also called "Positivism" because of the polysemous connotations of that word.
} 
Secondly, ethnography has to be studied in its natural setting (Fielding, 1996; Punch, 2005, p. 152). In so doing, a better understanding of the group, culturally significant act, event or process will be garnered. Conversely, it is not possible for ethnographic work to be conducted in isolation from the natural setting of the phenomenon of interest. Instead, as Punch (1996, p. 157) puts it, ethnography is an "evolving sort of study." It is difficult to pre-plan how it will unfold. Though the ethnographer may have some general conception of the questions to ask, the issues will unfold in situ or in the place, as the research progresses. Again, this underpins the flexible nature of this research strategy.

Thirdly, in ethnography the researcher has to be sensitive to the meanings that behaviour actions, events and contexts have, in the eyes of the people under study (O'Leary, 2004; Punch, 2005, p. 152; Spindler \& Spindler, 1992). Instead of passing judgement using Western worldviews, the researcher's aim is to understand through empathising with the subjects, constructing and interpreting meaning and providing thick descriptions ${ }^{20}$ (Geertz, 1993). And so, the researcher recognises the multiplicity of realities and interpretations of the subjects.

To capture these underlying dynamics, methodological triangulations are used. According to Shaughnessy et al., (2005, p. 153) as reported by Davies (2000, p. 100):

\footnotetext{
"Ethnographers frequently combine data obtained through various observational methods, such as naturalistic observation and participant observation, as well as that obtained through the examination of documents and interviews, in order to describe the context and meanings of everyday social situations."
}

These various data gathering techniques are used to supplement each other and ensure dependability of the research process, serving to ensure credibility of the work.

Hence, the ethnographer must enter the field prepared and with an open mind. The first hurdle is to get participants to trust enough to willingly admit their true, honest preferences or thoughts. As a native of this culture, I know that people do not easily

\footnotetext{
${ }^{20}$ Thick description was a term coined by Geertz to explain his own method of doing ethnography. Thick descriptions of human behaviour also include the context so that the explanation become meaningful to the outsider.
} 
state their true preferences in public (Frank, 1996; Kuran, 1995) or to people they do not know well (O'Leary, 2004, p. 60).

\subsubsection{Rationale For The Use Of Ethnography}

In summary there are three reasons for the choice of ethnography as the strategic approach to this study:

First and foremost, ethnography is the logical choice. This study is about understanding culture. Other methods, such as questionnaires or surveys of some population sample might not be able to capture contextual causal relationships because they are designed to observe and report a different set of data- quantitative data, which are distinct variables (Cavana, Delahaye, \& Sekaran, 2001, p. 35).

Secondly, ethnography is used because of its strength to provide a rich and in-depth exploration of values, beliefs and practices of cultural groups through thick descriptions of real people in their natural settings (Gerring, 2007, p. 62). To explore means to understand, discover, describe, and interpret. The world is so complex it is only possible to understand a little. Hopefully with the little understanding we have, we may be able to generalise a theory to all contexts.

Finally, it is only through lengthy immersion (Denscombe, 2007) in the field that one can claim to begin to understand a culture or the perspectives the researched hold. O'Leary (2004, p. 119) and Grbich (2007, p. 40) explain ethnography to be a tool designed to explore a way of life from the point of view of its participants. If research is conducted from a distance, it would be quite an onerous task to understand participants' standpoints.

\subsubsection{Case Study: The Strategic Tool}

Firstly, case study is not all qualitative or quantitative. It can be either, and or. According to Yin (2003, p. 12), case study is a research strategy in its own right, although others, mostly in the social sciences, don't see it that way. There are numerous definitions given to the case study. Yin (2003, p. 12), believes that these 
definitions arise from the definers' focus on such topics as decisions, individuals, organisations, processes, programs, neighbourhoods, institutions and even events. Still others confuse case study with ethnography. Yin (2003, pp. 13-14) claims, and this study holds similar views, that case study begins with a "logic of design" and can be stated in two ways.

\section{A case study is an empirical inquiry that}

- investigates a contemporary phenomenon within its real-life context, especially when

- the boundaries between phenomenon and context are not clearly evident.

Secondly, because of the grey area between phenomenon and context, the second part of the definition addresses the methods of inquiry, such as data collection and data analysis strategies.

\section{The case study inquiry}

- copes with the distinctive situation where there will be more variables of interest than the data points, and as one result

- relies on a multiplicity of sources of evidence, with data needing to converge in a triangulating fashion, and as another result

- benefits from the prior development of theoretical propositions to guide data collection and analysis.

Yin's (2003) definition recognises that case study is in investigative study of a contemporary phenomenon. Bloor and Wood (2007, p. 19), Gerring (2007, p. 20) and O'Leary's (2004, p. 119), also recognise case study as a study of phenomenon of some sort occurring in a bounded context and being contemporary. Yin was not concerned about defining case study as 'bounded' since by nature a case is bounded. He emphasised more that a case study must be conducted in its natural setting or in context. Otherwise, it would be difficult to observe the phenomenon, such as, in the case of experiments, where the researcher simply controls the research procedures in a laboratory environment.

Yin's (2003, p. 13) first part of the definition also highlighted the haziness between phenomenon and context. Similarly, Gerring (2007) notes the difficulty in demarcating the boundaries between phenomenon and context. He asserts that case 
connotes space and boundary of a phenomenon- spatial and temporal- studied at a point in time or over a period of time. Gerring (2007, p. 19) notes that "the spatial boundaries... are often more apparent than the temporal boundaries." For example, in the case of a country, the spatial boundary is the physical geography, 'where' a country begins and ends. The temporal boundary, on the other hand, is difficult to determine; 'when' a country begins and ends. This difficulty seeps from the phenomenon to the context, because the context gives meaning to the phenomenon, and vice versa.

Because of the ambiguity between phenomenon and context, Yin's (2003, p. 13) second part of the definition of case study recognises that there would be "many more variables than the data points." This necessitates inclusiveness to cover all those possible variables. It is not possible to study all the aspects of a case, but Yin believes that the wide potential variables of a case need to be captured and brought together in some meaningful way. Bloor and Wood (2006, p. 27) called this concept "wholeness (holistic) or integrity" of the case, which must be preserved.

In order to achieve this holistic approach, Yin (2003) suggested triangulation or multiple sources of evidence as the way of converging data. Bloor and Wood (2006, p. 27) agree that an import characteristic of case study is data triangulation methods that are useful for validating data and must typically be used in the phenomenon's natural settings.

Finally, Yin's (2003, p. 14) definition recognises the benefits a study would derive from depending on prior developed theoretical propositions that would guide data collection and analysis. Without understanding this critical inter-dependence, inexperienced and undiscerning researchers will waste precious time trying to figure out methodological questions and research tools to use.

In summary, Yin's (2003, pp. 12-13) view of case study is that it is a methodological strategy, separate from other research strategies. It covers logic of design, data collection techniques, and specific approaches to data analysis. This definition 
recognises that a case could either be studied through qualitative or quantitative methods. But for the purposes of this study, a qualitative approach is taken.

Stake (2000) presents quite useful taxonomies of case study. He proposes three classifications of case studies, namely, intrinsic case study, instrumental case study, and multiple case study. These three types of case studies are defined as follows:

\section{Intrinsic case study:}

“...is undertaken because, first and last, one wants better understanding of this particular case. It is not undertaken primarily because the case represents other cases or because it illustrates a particular trait or problem, but instead because, in all its peculiarity and ordinariness, this case itself is of interest." (pp.445)

Instrumental case study:

“...if a particular case is examined mainly to provide insight into an issue or to redraw a generalization. The case is of secondary interest, it plays a supportive role, and it facilitates our understanding of something else.”(pp.445)

Multiple case study:

“...is instrumental study extended to several cases.” (pp.445-446)

This research is an instrumental case study focussing on a single case organisation and it is neither an intrinsic case nor is it a multiple case study. The justification for this is the case provided the opportunity to study a phenomenon that could be easily studied in any organisation. Culture operates in all organisations and not in particular cases only. SSE was chosen as a vehicle to facilitate research and the particular uniqueness of SSE was of no significance.

\subsubsection{Rationale For The Use Of A Single Case Study}

A single case study is chosen for several reasons. Yin (2007, p. 40) states a justification for a single case study to be when "the case represents an extreme or unique case". In this technical definition, all cases are chosen because they are particularly unique. However, this case organisation was not chosen because of its particular uniqueness, rather its ability to provide "insight into an issue" Sanga (1997, p. 67). The issue or phenomenon of interest was cultural effects to knowledge management. 
Secondly, this case is selected due to practical considerations. This point was highlighted by Denscombe (2005, p. 145), in which he states that "In the practical world of research, with its limits to time and resources, the selection of cases is quite likely to include a consideration of convenience." Due to my connections with management, entry was relatively easy and other institutions that were approached were not so forthcoming. This alone, could have determined my choice of a single case study.

Finally, as a former employee, a good rapport exists between the researcher and staff of the case organisation. This meant it was much easier to conduct research in a relaxed environment for both the researcher as well as the participants (O'Leary, 2004, p. 167). Unknown persons and strange environments can create nervous parties and so, artificial settings. This could skew the findings of this or any study. Therefore, I was comfortable to settle with a single case.

\subsection{Description Of Research Methods}

This section describes the research methods employed and the justification for their choice and procedures followed to collect data which results in the analysis outlined in chapter six. The methods used included semi-structured interviews, participant observations, document analysis and the use of focus groups. The use of methodological triangulation draws on the unique abilities of each tool to ensure the convergence of data (Yin, 2003, p. 14) and support the requirement for dependable work. Hence, this report will provide honest and full representations of the actual path in which this research was carried out.

\subsubsection{Semi-structured Interviews}

Semi-structured interview was my main tool for data collection. O’Leary (2004, p. 178) defines interviews as "A method of data collection that involves researchers asking respondents basically open-ended questions." When interviews are structured they become survey questions. Semi-structured interviews then, are interviews that are neither fully fixed nor fully free. 
The most important aspect of this technique for me is that there are some structures which can assist in creating some comparative work amongst the subjects. It is also flexible enough to allow participants to lead the conversation. This is important as I wanted to capture the phenomenon in its natural setting.

This technique was my major data collection tool. The plan was to interview twenty participants in total of which four were to be managers; six were to be supervisors or middle managers, and ten were to be from the shop floor. All were to be interviewed individually and confidentially in the training room. With this technique, it is impossible for participants to remain anonymous. The strength of anonymity is that respondents can express their views honestly. However, since members of staff know me well, a high level of confidence and trust developed between us. Now that I am no longer a staff in the case organisation, the level of trust is such that participants were frank and expressed their views freely without fear of retribution. Also, as a former manager of SSE, managers saw me as an equal and did not prejudice against me. This might have been different if I was a former junior staff or a total stranger. Their responses to the interview questions might not be forthcoming and honest. These factors reduced the 'gulf' between the participants and myself (2004, p. 162) and so it influenced the interview process in a positive way.

I was also aware that certain knowledge are regarded as confidential which managers are not prepared to divulge with outsiders. These are knowledge relating to serious corporate strategies and other Board businesses relating to finance. However, my cordial relationship with management gave me access even to knowledge considered confidential. Nevertheless, I restricted myself to information relevant to my research only.

The field work was aimed to capture as much data as possible. This was achieved through methodological triangulation. Methodological triangulation was necessary to ensure convergence of data and so the trustworthiness of this study. 


\subsubsection{Interview Procedures}

The Manager Administration submitted a list of twenty participants via email on $14^{\text {th }}$ November 2007 to the researcher. Ten of these were clerical staff, of whom five were females. Of the six supervisors or middle managers, three were females and of the four senior management staff, two were females. These choices were also made to represent the various departments. There were three from Information Technology (IT), three from Administration (AD), two from Internal Audit (IA), five from Operations (OD), four from Investment (ID) and three from the Finance (FD).

Since many of the staff chosen to participate were on leave, I had to ask around from those available to participate. I simply approached staff and asked if they were willing to be interviewed and depending on their work load, they were given the option to decide on the timing of the interview.

It was originally planned that a set of information sheets and questions (Appendices D \& E) would be given to the participants to take home overnight and study. This was to get them thinking about the topic and to formulate their responses. This view was seen as important since knowledge management was a new concept for all of the respondents. It was also seen as helping to reduce the interview time. However, after some thought this was decided against and staff were given these documents before the interviews were conducted. This was to avoid respondents from giving me the 'correct' answers of what they thought I was after. I was more interested in their honest opinions.

As a semi-structured interview, prepared guides were used to ask open-ended questions (Appendix E). Where responses were not clear, probing questions were asked. All the interviews were done in pijin and the questions were asked to address four cultural effects on knowledge management which included:

a) How does culture shape assumptions about which knowledge is important;

b) How culture mediates the relationship between levels of knowledge;

c) How culture creates a context for social interaction; and

d) How culture shapes creation and adoption of new knowledge? 
After each interview reflections were made on how the questions were answered to help me improve my interview techniques. As part of this process, I started with junior staff since there were more of them and so it was felt that I could better afford to make mistakes in my questioning technique with one or two of them rather than lose valuable data from the few supervisors and managers.

Staff were given the information sheet (Appendix C) and time to read and sign an agreement form (Appendix D) while I set up the recorder and MP3. The voice recorded interviews from the MP3 were uploaded to a website through Rapidshare. When uploading a voice record, my name was entered as the source of message my email address and the e-mail address of the transcriber were also submitted. An automated message was sent to the e-mail addresses of the transcriber and me, from Rapidshare which provided the link from which we could access the voice recordings. The recorded tapes were stored in a cabinet and locked away.

After all the interviews were completed, they were transcribed and translated from pijin to English. Since pijin is very similar to English, little difficulty was found in the transcribing and translation processes. Given the distance, communication difficulties and timeframe to complete the thesis, it was not possible to provide copies of the interview transcripts to the participants since I had returned to New Zealand. However, I exchanged transcriptions with the transcriber to confirm accuracy and interpretations of what the particpants were saying.

\subsubsection{Participant Observations}

Denscombe (2007, p. 217) cited Becker and Geer as giving the crucial definition of participant observation.

\footnotetext{
"By participant observation we mean the method in which the observer participates in the daily life of the people under study, either openly in the role of researcher or covertly in some disguised role, observing things that happen, listening to what is said, and questioning people, over some length of time." (Becker \& Geer, 1957).
} 
The key to this method is its potential to keep the setting natural. This was achieved by informing management of the general plan to carry out observation in the case organisation but not when and where and with whom. In this way, the setting was kept as normal as possible. This tool was used sparingly because it was simply to provide support to my main data collection method, which was the semi-structured interview. I relied on my past experiences as former employee, to aid me interpret the culture. All the while, I was consciously aware of the need to be careful and not to allow myself to interpret meaning for participants. Where clarifications needed to be made, participants were probed by further questioning.

\subsubsection{Observations Procedures}

Management was notified of this data gathering technique, to avoid any criticisms for unethical behaviour. Afterwards, copies of the information sheet (Appendix H) were pinned up on notice boards on all floors and departments of the building and a suboffice across the road, for the information of all staff. No one came forward to register their desire not to be observed.

Over the period of five weeks I actively participated in unofficial settings, with the general staff, in order to record the dynamics at work in its natural context. I was a non participant in official meetings except to those from the Administration department who were close to me and invited me to some of their group tasks. All employees were well-aware of my role as a researcher, since it was made explicit to management and staff, and since as a former employee, my role was well known to them.

I consciously made observations and took notes in both official and after hour settings. During official hours I joined a group excursion, observed discussions in various groups and observed staff interaction at their work place. Notes were taken of what was observed and the dynamics at work. In after-hour settings, I sat with informal groups and made notes of the dynamics and what was said. I also attended SSE's official Christmas party and made notes on the proceedings and also the dynamics at work. 
However, this technique was used as a supporting means to gather more data to corroborate the interview data I had collected. Since I was given an office space to work from it was easy for me to quickly move in and out, making notes and recording my findings.

\subsubsection{Document Analysis}

In social research, document analysis refers to the "collection, review interrogation, and analysis of various forms of text as primary source of research data" (Silverman, 2005). The word 'document' can be a misnomer, since it also means pictures, photographs, artwork and television. So, for the purposes of this work, document here refers to texts. The texts studied were those that covered authoritative sources, historical documents and personal communication.

O'Leary (2004, p. 177) describes authoritative source documents as those where authors try to be objective and free from bias. Next, O'Leary (2004, p. 178) describes historical documents as an organisation's records, minutes, and policy documents. By studying this second lot of documents, the policy issues relating to knowledge management in the case organisation were observed.

Thirdly, O'Leary (2004, p. 178) describes personal communication documents as "letters, e-mails, memoirs, sketches, drawings, photographs, diaries, memos, journals, etc., that are by their very nature personal and subjective." This added colour and provided details to the dynamics that played out in the study.

\subsubsection{Document Analysis Procedures}

Important documents such as the laws regulating the operations of the case organisation and annual reports were readily available to the researcher. These provided background information that helped to provide the background against which the research was conducted (Marshall \& Rossman, 2006). Based on these documents and my experiences, the background of the case organisation is provided in chapter five. 
The next set of documents analysed were the historical documents. As an exploratory work, my document analysis was of a general nature and the documents were used to corroborate respondents' stories. Since SSE policies are well-documented, it was easy to contrast views expressed by respondents to relevant policies.

To a lesser extent, personal communication documents were viewed. Mostly these documents related to disciplinary actions taken in SSE, and those related to performance appraisals and rewarding. Again, this set of documents was studied in a similar fashion to historical documents, mainly to establish the credibility of respondents' views.

Since I had no involvement as a researcher in collecting this documentary data, this important data-gathering technique enhances the trustworthiness and credibility of my own study.

\subsubsection{Focus Groups}

Bloor and Wood (2004, p. 165) view focus groups as a form of group interviews, but quite distinct from group interviews and Delphi group. They define focus groups as:

\footnotetext{
A series of audio-recorded group discussions held with differently composed groups of individuals and facilitated by a researcher, where the aim is to provide data (via the capture of intra-group beliefs and group norms in respect of a particular topic or set of issues. (Bloor \& Wood, 2004)
}

There are three distinct differences that make focus groups distinguishable, according to Bloor and Wood (2006, p. 88). Firstly, focus groups discuss one topic in depth whereas group interviews may cover a variety of topics. Secondly, group interviews are organised to collect data from more people at the same time in order to save time and money. Thirdly, focus groups are concerned with the dynamics of the whole interview process. It was mostly for reasons one and three that focus groups was being employed in this study. I wanted to get deeper views of issues and I was also very much interested in the power relations that could be observed in the various groups. My role was mainly a facilitating role and group members were expected to debate among themselves. 
Focus is also different from Delphi group, in that the latter is a panel of experts brought together in consultation to provide consensus authoritative statements on group belief or policy. In this case, the only criterion for selection of participants was that they were staff of SSE and nothing more.

\subsubsection{Focus Groups Interview Procedures}

After all individual interviews of the eighteen staff were completed, they were regrouped into focus groups. The first group was made up entirely of junior staff. The second group was made up entirely of management staff. The third was made up of managers, senior staff and clerical officers. However, their common characteristic was that they were people who had cordial relationships and interaction with each other. The fourth group was similar to the third, as it comprised managers, supervisors and junior officers. The difference is that this fourth group was made up of people who did not have a close connection officially or informally with each other. Rather, they were people who would interact with each other on a professional level only, and had little or no noticeable social connection.

Based on my experiences as a former staff, I consciously divided the participants into their groups. Various issues that were raised during interviews were raised with the groups. They were given an exclusive issue each to discuss. Then, they were given another one or two other issues to discuss which were also given to other groups.

I was interested both in what their views were on those issues and in the power dynamics of the groups and how they responded to each other and to the questions raised. These were recorded and formed an important part of this analysis. The next section will now discuss the data analysis procedures. 


\subsection{Data Analysis Techniques}

This section outlines the methods used to analyse data collected for this study. It elaborates on actual procedures of the research design. The use of the tools and techniques described in this chapter provide the data analysed in chapter six.

For qualitative work, Silverman (2005, p. 150) recommends researchers to "go to" their data, even before one has a research problem and a method of analysis. Otherwise, the researcher will do catch-up work for the remainder of thesis work. In trying to be true to Silverman's views, analyses of data were made during my writeup of the literature review and methodology chapters. As a former employee of the organisation under study, I consciously reviewed the literature in my head and weighing it up against my experiences in the organisation. At this point certain cultural themes began to emerge.

During the interviews notes were taken of other organisational themes that emerged. Data was actively analysed as it was being collected and collated. I asked myself questions that challenged the usual way of thinking. The relationships between my four sub-questions stated earlier in this chapter, and how I should ask my questions in order to answer my research question was considered. From this, issues emerged clearly which were later raised with the focus groups.

\subsubsection{Content Analysis}

Having collected my data, the next step was to proceed with content analysis of the interviews in an attempt to draw up important themes that emerged. According to Denscombe (2007), content analysis is a "method to help the researcher to analyse the content of documents". The process included selecting a text, determining the unit of analysis, developing relevant categories, coding the categories, tallying the frequencies of themes and analysis of the frequencies of themes and their relationship with other units that occurred in the text. My interview text provided the main data for analysis. It was decided that each sentence would be my unit of analysis. In order to 
help me understand and organise the data meaningfully, the transcripts were read and re-read until themes began to emerge.

For my first level of analysis, the interviewees were grouped according to their status in the office since I was also interested in what people of various levels in the organisation had to say. Therefore, all the clerical staff's responses were grouped together, likewise the responses of senior staff and managers. Their responses to each question were noted and compared to each other and to the other groups. By reading through what their responses were, themes began to emerge in my mind. Using Constas' (1992) framework, the categories for analysis were developed.

From this grouping of responses I could then highlight the various views on a subject. For example, when asked which knowledge was the most important in the organisation, respondents stated "management". From this theme, it was further possible to see the various aspects of management that were considered to be important. Those in the Accounts, Finance and Investment department saw good financial management as the most important knowledge while others from Administration functions saw management of human resources as the key knowledge.

To get a better understanding of the issues raised during the interviews, I also analysed the transcripts from the discussion of four focus groups. These groups were made up of the same participants, but were ordered into clerical staff, managers, and two mixed groups. One group was made up of those who were known to have close working relationships and the other was made up of people with little known relationships. This helped me to better interpret the thoughts of the participants on specific issues and to observe power relations.

Finally, a critical evaluation of how the categories would meet my research objective and so answer my research question was made. 


\subsubsection{Category Development}

In developing categories and to assist me organise my analysis into meaningful and logical themes, I used the framework developed by Mark Constas (1992). The categories were developed rather than just merely emerging, the summary of which is contained in the table below. The Component of Categorisation shows where the authority for creating themes reside, the justification of those categories and the source for naming them. For example, let us consider theme number one: Important Knowledge. The origin of the theme was found in literature and also the questioning programme. The justification for its use was because it seemed logical and it could be found in existing research findings. Finally the source for naming the theme was from the programme and literature.

The Temporal Design shows when the categories were developed, that is a priori, $a$ posteriori or iterative. Since knowledge in indigenous cultures is a social construction, it is also clear from the table that much of the categories were developed during the whole process of research and not at one particular point in time. In our example above, this was not the case. Since the theme was a major concept in existing literature, it was easy to identify the theme $a$ priori.

At the bottom of the table is the key for the data sources, for example, focus group, from which the theme is derived. Numbers were assigned for each theme developed. In total I had 15 themes that were constructed from the whole research work. 
Table 2: Key Categories and Categories Development

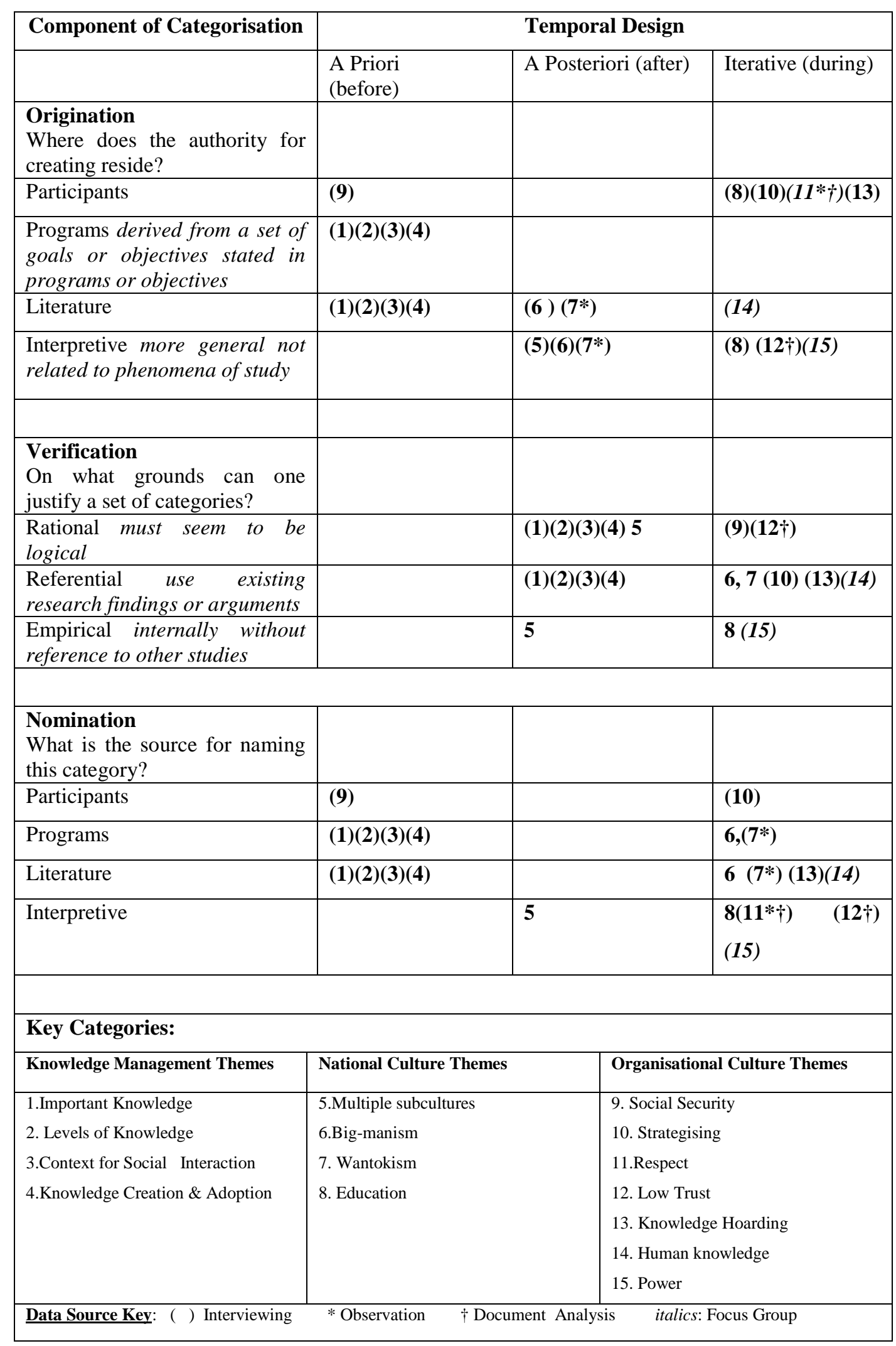

Adopted from Constas (1992), with only the elements relevant to this study included. 
Within the four KM themes, National Culture themes and Organisational themes are discussed in chapter six. This helped to show what level of culture was at play in the various knowledge management considerations. Since organisations are complex institutions, the analyses took into consideration various cross-functional views. The views of clerical staff, supervisor and managers were compared and contrasted to each other. This helped for a better understanding of the dynamics of the case under study.

\section{Ethical Issues}

In this section I will deal with ethical issues, both generally and also pertaining to this study. In summary I will deal with the necessary measures taken to maintain the level of ethical standards required of me. I will also discuss the frameworks that ensured credibility of this work.

\subsubsection{Ethics}

Cavana, Delahaye and Sekaran (2006, pp. 130-131) simply define ethics as " code of conduct or expected societal norms of behaviour." In conducting this research there were expected societal norms of behaviour in my interaction with the various parties that contributed to make this research complete.

Before other people's responsibilities could be discussed, I will first of all mention my own. During the whole research process, I was fully aware that at all times the information given by participants were to be protected. This was necessary to guard against possible repercussions for expressing deviant views.

Secondly, highly personal information was not solicited and avoided. At all times I was aware of my responsibilities not to be intrude in people's private lives. My work was strictly related to knowledge management and the study of the effects of culture. Similarly, care was taken not to violate the self-esteem and self-respect of subjects. I was aware that some of the concepts of this research might have been beyond the understanding of some of the subjects. Where this was so, care was taken not to drive 
my questions, as this would be demeaning. Along the same vein, I avoided driving questions in such a way that might cause mental harm.

This research was totally voluntary. Most of the selection was done internally and the list of the participants was simply given to me by the Manager-Administration of SSE. Where staff were on leave, replacements were made in consultation with the Administration Department. Participants were not coerced in any way to take part in the study.

My responsibility to report the findings accurately and not to misrepresent or distort data collected during this study was clear. Having served in SSE for 22 years, I still feel strong attachments to the establishment. This strong feeling helped me protect the good image of the firm and not defame it in any way.

Finally, it was made clear to the participants that they too had a responsibility to me. After they exercised their choice to participate in the study, I let them know that they were expected to co-operate fully. None of them retracted from their commitment. In all cases I thought they were being truthful and honest in their responses and no misinformation was given.

\subsubsection{Validity Versus Authenticity}

All scientific works are expected to raise the question of the validity of their research. Cavana, Delahaye, and Sekaran (2001, pp. 212-215) have an elaborate definition and clarification of various types of validity in mostly quantitative research. A simplified version is given by Bloor and Wood (2006, p. 147) in which validity is the "extent to which the research produces an accurate version of the world". O'Leary (2004, p. 58) on the other hand refers to validity as being "concerned with truth value; i.e. whether conclusions are 'correct'. Validity also "considers whether methods, approaches and techniques actually relate to what is being explored." However, as a qualitative work, this study does not seek 'correctness'. Rather, I am more interested in the authenticity of the process. O'Leary (2004) defines authenticity as "concerned with 'truth value' while recognising that multiple truths may exist." Truth to me is arbitrary, and depends on the views and experiences of the subjects under study. My main 
responsibility here was to try and capture their views as much as possible. Therefore, I was more concerned with the deep structure of experiences of the subjects. The cultural underpinnings, which are the phenomenon of study, were recorded in a manner that is 'true' to the experiences of participants at SSE and also due to my deep understanding of the context and culture.

\subsubsection{Reliability Versus Dependability}

Cavana, Delahaye, and Sekaran (2001, pp. 210-212) explained what reliability in quantitative research is about. They view reliability as "the extent to which the measure is without bias (error free) and hence offers consistent measurement across time and across the various items in the instrument." Bloor and Wood (2006) simply define reliability as "the extent to which research produces the same results when replicated". Again, as a qualitative study, this research is not concerned with reliability, for the tools used are qualitative. Rather, my concern was about the dependability of methods employed. In order to ensure dependability the methods employed were systematic as explained earlier in this chapter in my description of procedures at the data gathering stage. I recorded the methods and procedures as accurately as possible to ensure the dependability of this study.

\subsubsection{Generalisability Versus Transferability}

Cavana, Delahaye, and Sekaran (2001, p. 457) define generalisability as "the applicability of research findings in one to others." Generalisability is concerned about sampling strategies that are adequate and broad enough to represent the population. As a qualitative work, this research does not concern itself with generalisability, rather the transferability of its findings.

O'Leary (2006, p. 147) defines transferability as highlighting that "lessons learned are likely to be applicable in alternative settings or across populations." In my analysis chapter there was detailed discussion of the culture particularly to SSE but also generally. This was due to the influence of national culture and the environment in which SSE operates. This influence is a general influence, therefore the findings of my research are issues coloured with the effects and influences of this national culture 
and hence they may be transferable to other organisations operating in Solomon Islands.

\subsection{Summary}

In this chapter the research methodologies which were used in this work were outlined. I started by stating my assumptions in conducting this research. Then a rationale for the methodologies chosen, a discussion of ethnography and case study as research strategies were also provided. A description of the methods used, namely semi-structured interviews, documents analyses, observations and the use of focus groups was also given. In conducting the research my assumptions in relation to the nature of the study, my role as the researcher and the methodology were stated. I went on to discuss ethnography and case study as research strategies; then the methods of data collection and analysis were described. Explanations were given on what document analysis, semi-structured interview, observation and focus groups were and why these tools were chosen instead of other methodological tools. Finally, this chapter ended with an explanation of ethical issues.

In the next chapter, the background of the case organisation is provided. It was in this case organisation that the methodologies explained in this chapter were used. 


\title{
CHAPTER FIVE \\ BACKGROUND OF SOCIAL SECURITIES ENTERPRISES
}

\author{
"It must now be seriously considered that many Solomon Island workers are becoming urban wage- \\ earners and to return home empty handed after working fifteen or twenty years in their lives is a \\ saddening thought" \\ Anthony Saru
$27^{\text {th }}$ November 1970
}

\subsection{Introduction}

In the last chapter, I explained the methodology of this research and the methods employed to collect the data for this study. Following-on from the research methodology, this chapter is a short synopsis of Solomon Securities Enterprises (pseudonym), the case studied. This chapter covers the background of Solomon Securities Enterprises' (SSE) establishment, the organisation structure, and initial interaction with staff and finally it ends with the reasons why an understanding of knowledge management and culture is important for SSE. An understanding of SSE's background is necessary as it sets the context under which the analyses were made. An understanding of the background knowledge serves the reader to better understanding respondents' views and so this chapter is a prelude to the Analysis and Discussion Chapter.

\subsection{Background Of Solomon Securities Enterprises}

The Solomon Securities Enterprises is a social security organisation set up through an Act of Parliament. Its primary objective is to provide old-age, invalidity and survivors' benefits. SSE has played this role, slowly in the first few years, and then steadily increasing as more and more Solomon Islanders join the organization and members meet the contingency criteria for which they were covered. 
SSE plays a unique dual role in Solomon Islands economy. First, it provides social security protection for its members and their dependents. Secondly, SSE also plays an important role as utiliser of long-term savings for re-channeling of funds into public and private sectors for long-term investments. This was well documented in their $10^{\text {th }}$ Anniversary Report. Since its inception in 1976, SSE has become one of the biggest financial institutions in the country. In a country with a small economic base, this secondary role often almost eclipses its social security function.

The first ten years was a period of consolidation of funds. In the second ten years, SSE was optimistic to create dynamism and progress, and from 1988 onwards SSE introduced various short-term benefit schemes to its members. These included pledge facilities for loans with financial institutions, and furniture, rural housing and urban housing loan schemes. This was made possible through an amendment of the Act. These schemes proved very popular with SSE's members. However, many of the borrowers had problems servicing their loans, and compounded with civil unrest from 1998 to 2003, it exacerbated the loan arrears and so the schemes had to be closed.

The civil tensions of late made news around the world and the country was branded a failed state (Suter, 2003). This affected the operations of SSE in a major way since most of SSE's bigger investments are located in and around Honiara, the centre of the ethnic unrest. This difficult environment was expressed by SSE in their 2004 Annual Report (p.13) as follows:

The financial period ending June 2004 has been very challenging for the Fund's investment portfolios principally due to the recent social unrest. As a result, the investment environment lacked conduciveness, strategic businesses either closed or reduced operations and most economic fundamental pillars were destroyed.

In line with the reduction of business and service requirements, one-third of the workforce was retrenched in September 2003, as per Administration Manager's files. This exercise was difficult for both management and staff, who over the years had built cordial working relationships and friendships. Nevertheless, tough decisions had to be made in tough times. 
The export economy was in a free fall (Moore, 2007, p. 141) and services were at a stand-still. With the intervention of the Regional Assistance Mission to Solomon Islands (Moore, 2007) in July 2003, there was a gradual normalisation of law and order and stabilisation of public finance and business confidence was slowly restored (Moore, 2007).

During Solomon Islands' darkest period of economic gloom, SSE's role in providing some economic cushion to the nation cannot be overstated. Despite the difficulties, SSE continued to pursue one of its primary objectives which is highlighted in their 2004 annual report as "the development of Solomon Islands through prudent investment and sound management" (2004). For example, funds outlaid in 2004 for investment purposes looked something like this:

\section{Table 3: Investment Portfolio}

\begin{tabular}{|l|l|l|l|}
\hline Total Bonds & $\begin{array}{l}\text { Mortgage Loans } \\
\text { and Borrowers }\end{array}$ & $\begin{array}{l}\text { Equity } \\
\text { Investment }\end{array}$ & $\begin{array}{l}\text { Commercial } \\
\text { Properties }\end{array}$ \\
\hline$\$ 94,271,053$ & $\$ 100,017,665$ & $\$ 64,865,662$ & $\$ 50,600,000$ \\
\hline
\end{tabular}

Data from SSE 2004 Annual Report

Of course much has changed during the last four years. However, for small island states, these sums are huge contributions, and one that the government and all Solomon Islanders would appreciate, especially when the whole government recurrent budget for 2006 fiscal year was just $\$ 738$ million Solomon dollars (Lilo, 2007, p. 21).

This continual emphasis on national development also surfaced in one of the responses of a junior member of staff. When asked what was the second most important knowledge, his response was:

\footnotetext{
"The second most important... is contribution to the country as a whole... such as our tax to the government...to help build the country... like infrastructures and other things the government wants to improve in the country."
}

The response seemed out of line with the question. However, this response is still very important, as it illustrates the thoughts of the respondent. Although the respondent 
specifically mentioned the payment of tax, all of SSE's revenues are tax exempt. In reality tax is such a small portion of outflows of funds. By comparison, SSE outlays far more funds for investment and other government developmental projects.

But this is an example of how Solomon Islanders speak. It is not uncommon for people to provide answers different from what is being asked. They instead speak in parables, riddles and metaphors. A step by step progression of thought is not how they think. They instead see outcomes. To the respondent quoted above, the result of his work, though small, is a big step in the process of national development. In this case, to the officer, development stands as a pillar of nation building. Its importance is prominent in the mind of the officer, since his role is as the person tasked with the responsibility of raising the cheques that go out as investments.

During the period immediately after the conflicts, SSE had serious cash flow problems due to much of its funds being tied up in long term investments and physical assets. Though not on time, it did continue to provide services and payments to its members until the law and order situation was restored and confidence was regained in the business environment.

In order to carry out these important roles, SSE had to be structured in such a manner to effectively discharge these important functions.

\subsection{The Organisation Structure}

The structure has changed over the years to adapt to the changes in the external business environment. However, the general structure remains unchanged. The current Corporate Structure can be summarised in the following diagram: 
Figure 5: Corporate Structure

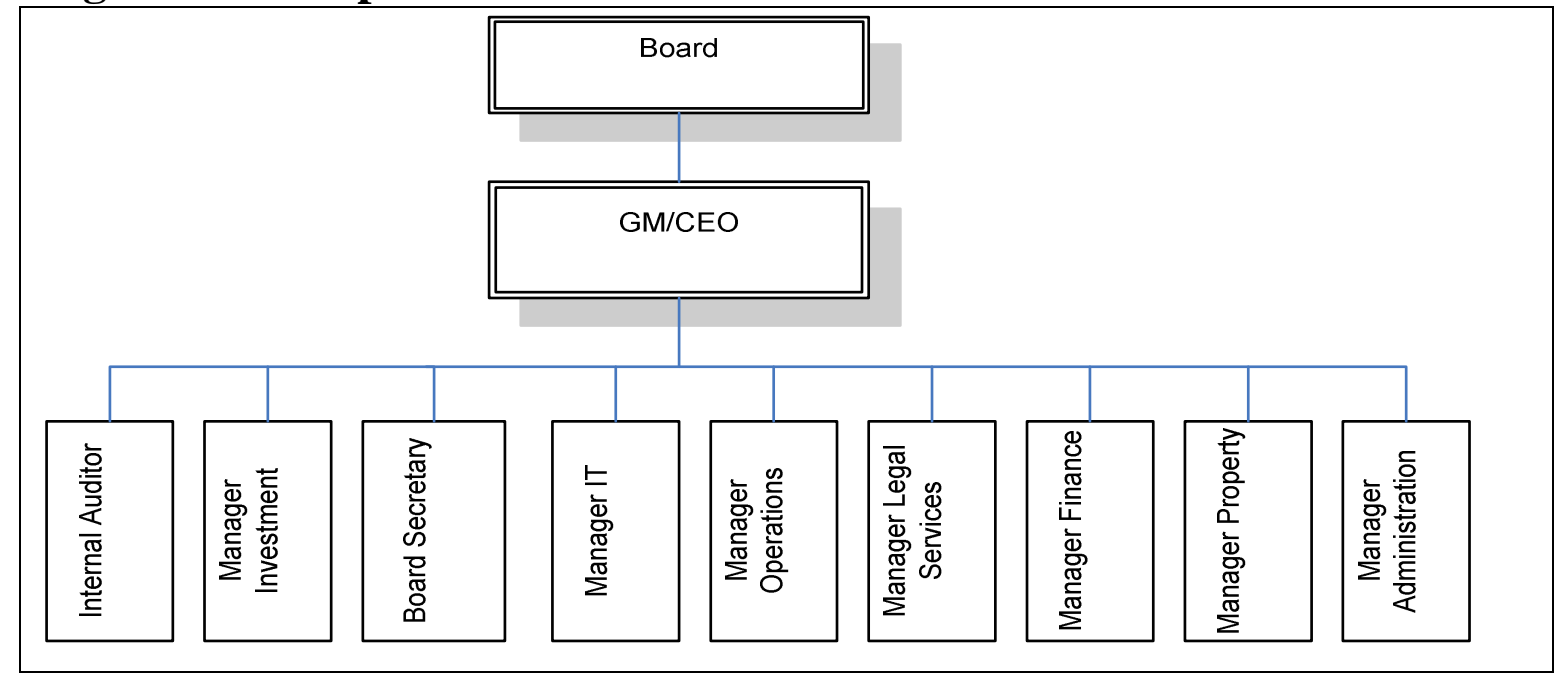

Adopted from SSE 2006 Annual Report

Eight Board members govern SSE's operations by virtue of powers vested upon them in the Act to both hire and fire a General Manager, Secretary and other agents, powers to inspect employers' records and invest funds received from members and other investment transactions. Board members are often successful business people in their own rights or bureaucrats who represent the Crown, employers, employees and some are appointed through ministerial discretion. The actual day-to-day administration and management of SSE lies with the CEO supported by nine managers and ninety-two staff operating out of the headquarters in Honiara and two branch offices in Malaita and Western Provinces.

The main departments that are responsible for the major functions of SSE are Operations, Investment, Property, and Finance. Administration and IT departments play a supporting role. However, they are major departments as their functions are performed by similar numbers of personnel to the other major departments and they influence all staff at work and even after hours. The other departments, that is, Internal Audit, Board Secretary and Legal Services also play supportive roles but are classified as Units rather than departments since they are manned by one or two personnel only.

As much as possible, SSE tries to provide Equal Employment Opportunity (EEO) to all Solomon Islanders. However there are specific retirement ages set in SSE's 
policies. Staff Policies and Procedures Manual (SPPM), Part 1, Section 31.1 states '50 years' as the normal retirement age and section 31.2 of the same document states '40 years' as the early retirement age. Although some might interpret these clauses as discriminating against older people, SSE here is trying to be consistent with their Act which also recognises these retirement ages. From my experience in SSE, they try as much as possible to maintain gender balance and ethnic and religious representation in the work place.

\subsection{Initial Meeting With Staff}

Through e-mail communication the Manager-Administration (MA) was made my point of contact with the organisation. Walking into his office on the $14^{\text {th }}$ of December 2007, I was greeted by my old colleague with open arms. The initial meeting was to address logistical issues. I was assigned to work from the training room and was given a lockable three-drawer cabinet to store documents.

In the initial meeting I went through my research purpose, explained the methodology and research paradigm. The MA expressed his support and eagerness to be part of the research project. In our discussions, I asked how staff would respond to my research. Would they be open and frank with me in their discussions and interviews or would they treat me as a former manager and so, an agent of management who was conducting research to 'spy' on them and report back to management? In his view, the MA felt that staff would be comfortable with me as a former employee and would not see me as an agent for management, since I no longer had any connections with the organisation.

During my discussion with the MA, the Manager-Finance (MF) walked in to greet and welcome me into the organisation, being a former working colleague and a good friend. The MF who is an accountant by profession holds a positivist world view. He used terms such as 'objective' to express his expectations of my research approach. It was a discussion where the MF explained what he knew to be research and what he believed I was doing. 
That afternoon the CEO summoned the MA and myself up to his office on the $4^{\text {th }}$ floor of the building. In the meeting I explained the purpose and my expectations from the organisation. It was also a time for me to express VUW's and my concern for the protection of the identity of participating staff. The CEO was very supportive and expressed his and the Board's happiness for me to conduct research. He expressed his expectation for the research to be conducted with confidentiality and he also expected staff to fully participate and express their true opinion. He clarified that he would welcome staff pointing out his weaknesses and saw those as opportunities for managers and indeed the organisation to tap into its potential to strengthen weak areas.

The CEO recognises the fact that KM is a new and emerging field. From the discussion, it was evident that since I last communicated with him, he had been busy reading about the subject. He acknowledged the importance of tapping into tacit knowledge that is held by staff to realise competitive advantage. From this first discussion it was clear that the CEO held high expectations and looked forward to reading the findings of the research and what measures could be taken to improve the organisation.

Many more of these initial meetings with other managers and staff followed. There were questions raised and in some instances I was wary not to disclose too much of my plan lest my data collection compromised. Needless to say, data collection went smoothly.

\subsection{The Importance of Knowledge Management and Culture to Social Securities Enterprises}

Organisational knowledge is the very thing that give life and meaning to any organisation. The unique combination of all the knowledge in existence in that organisation makes it what we perceive it to be. This is no different for SSE, and its management is vitally important for the firm to exist and function properly whether or not staff are consciously aware of it. Secondly, knowledge management does not exist in a vacuum. It is always set in context. How SSE's knowledge is being managed is 
determined by the culture in existence in the organisation. The culture determines the importance attributed to what knowledge and how that knowledge is treated. In identifying the 'organisational culture' we can then identify the “...problems for which to provide solutions..." (Riad, 2005, p. 1549). In exploring the culture in SSE would we observe whether or not it encourages knowledge creation and sharing and how well SSE adapts to the constantly changing environment. Lack of flexibility would create stagnation and the eventual 'death' of SSE's creativity, continuous improvement and competitiveness.

\subsection{Summary}

As a statutory body, the Solomon Securities Enterprises is a well-established social security organisation. The government has not needed to contribute to its operations, except as an employer. Over 10 years SSE consolidated funds from which it could open up various benefit schemes to its members.

The importance of SSE to the economy as a whole cannot be overstated. SSE plays a unique dual role in Solomon Islands' economy. In the country's darkest hours, SSE stood as a beacon. Not only was it contributing to the micro-economy but also to the national economy. First, it provides social security protection for its members and their dependents. The redistribution of money through members' withdrawal of contributions has assisted many families that otherwise could have suffered untold hardships. Secondly, SSE also played an important role as a utiliser of long-term savings for re-channelling of funds into public and private sectors for long-term investments. This has worked as a stabiliser to the national economy during the country's conflict period.

Despite the awesome responsibilities of the staff, they were very receptive and willing to participate in this research. The next chapter contains an analysis of the data collected from SSE and discussions of those analyses. 


\title{
CHAPTER SIX
}

ANALYSIS AND DISCUSSION

\begin{abstract}
I know that I have lived because I have felt, and, feeling giving me the knowledge of my existence, I know likewise that I shall exist no more when I shall have ceased to feel.
\end{abstract}

\section{Giacomo Casanova}

\subsection{Introduction}

The last chapter gave a background to Social Securities Enterprises (pseudonym), the case studied. This chapter will now focus on the analysis of data collected from SSE. This chapter also includes discussions of the findings of this research. Because of the ethnographic tradition that is being employed in this work, it was possible to conduct the interviews in pijin. If some of the quotes sound like improper English, it is because I have often tried to keep the original pijin structure in the translations. My discussions will shed light on the quotes and their English meanings, where necessary.

In this analysis, the data will be discussed under four major themes. The first major theme is how culture influences peoples' views on what is important knowledge. The second major theme is culture's influence on the importance of individual and organisational knowledge. Thirdly, this chapter outlines how culture sets up the context for social interaction, and finally a discussion of culture's effects on knowledge creation. Each major theme will consider emergent sub-themes as expressed by three functional sub-cultures. These are clerical staff, supervisory staff and management staff.

\subsection{Culture's Influence On What Constitutes Important Knowledge}

According to De Long and Fahey (2000, p. 116), “cultures and particularly subcultures heavily influence what is perceived as useful, important, or valid knowledge in an organisation." In my findings within SSE, sub-cultures have definitely 
influenced the way officers view important knowledge. Staff, whether clerical, supervisory or management saw knowledge related to their own work as the most important. In other words, the proximity of the knowledge to an individual determines the level of value imputed to that knowledge. For example, a male supervisor who works in the Finance department said:

\footnotetext{
"In my view, knowledge about computing, accounting are very important even management. How we manage our accounts etc."
}

Although computing and management are stated as also very important, they are only important as supplementary functions of accounting. The Computer department keeps all electronic copies of accounts and management is seen as important in relation to management of accounts. This officer valued his performance as an important contribution to SSE's operations.

Notable was the view of cross-functional or hierarchical sub-cultures. In the rest of this section (from 6.2.1 to 6.2.5), I will focus on the views of cross-functional subcultures; they are clerical staff, supervisors and managers. In SSE the most important knowledge are social security, strategic planning skills, financial management, administration and investment knowledge.

\subsubsection{Social Security}

According to the International Social Security Association (ISSA) website ${ }^{21}$, "social security is everybody's business and is concerned with the protection of health, the family, old age and employment." These are recognised as basic human needs. In providing cover for these contingencies the social security world hopes to contribute to greater social justice, and hence lasting peace. As a provident fund scheme, SSE is an affiliate member of ISSA, and strives to provide contingency covers specified in its Act.

In the view of the vast majority of staff, the executive office aside, the Operations Department is the most important department. Operations is the function of SSE that is responsible for the registration and storage of members' records. This department also processes members' withdrawal applications and ensures compliance of the Act.

\footnotetext{
${ }^{21} \mathrm{http} / / / \mathrm{www} . i s s a . i n t / \mathrm{engl} / \mathrm{homef.htm}$
} 
This department's purpose is to provide those social security services required by SSE's members.

When junior staff were interviewed in this research, they saw social security knowledge as most important. As one clerical officer commented:

"... I think knowledge about the members is the most important...so that we serve members' interests because we are owned by the members... so their interest is most important and we should cater for that."

This view held by junior staff has been influenced mainly by three factors. First, as front line officers, their level of interaction with the public and indeed members was higher than any other class of workers in SSE. Supervisors and Managers are 'hidden away' in their rooms, and so junior staff are the first line of contact with the outside world.

Concomitantly to the first reason, members' importance continues to be hammered home, enforced by supervisors and management who demand respect of members from their staff. For example, in the Operations department, counter staff are required to be available and not to leave their work stations unless they can find a stand-in officer. As supervisors and managers are seen as powerful individuals, it was in the best interest of staff to comply with their bosses' demands.

Thirdly, new recruits who enter the workforce are inducted through the legislative and administrative structures of the SSE. Often this ends with highlighting the importance of the members to the new-comers. It is therefore ingrained in the minds of staff that whatever can be done to assist members in both the long and the short terms is paramount in the role of SSE and its staff. In the early years of SSE, this was the main thrust of staff education, and Management were in the fore-front of leading this programming technique.

Then, in 1988, short term benefit schemes began to be introduced for members. Coinciding with this, regular in-house training was run by external consultants in the art of telephone techniques, quality customer service and strategic planning. Often, 
SSE would benevolently spend money on stationery and nibbles during the training sessions, practices that were new to SSE. This was aimed at providing quality service to SSE's members. From the research, it was evident that staff who had been with SSE during the 1980s tended to value social security more than those who were relatively new.

Similar views about social security being important knowledge were also held by senior managers, which was unexpected to some degree. Managers saw job skills that translate to service to members, and mission and vision statements of SSE, to be the most important knowledge. Two reasons were given for their position.

Firstly, these managers were mostly staff from rank and file who went through those early years of training and who eventually made their way up the hierarchy. Their views had been shaped by their long experience due to training and other social factors within the organisation. Coupled with the first reason and by virtue of their new role as leaders, managers place great importance on members.

Unlike the managers and clerical staff, supervisors think that all departments of SSE are inter-related and are equally important. This view therefore also places great importance on social security services. This will be discussed further in this chapter.

Clerical staff from various departments or in other words, the clerical and management sub-cultures recognised the importance of social security knowledge. It can therefore be concluded that recognising social security knowledge has become an organisational culture in SSE. Members are important stakeholders of SSE. It is crossfunctionally and hierarchically recognised as important knowledge.

\subsubsection{Strategic Planning Skills}

Besides recognising the importance of social security knowledge, particularly managers also regard vision and mission statements to be important knowledge that they must possess and put into action. This theme seems to emerge in the conversation with non-management staff as well, but mostly it is with managers that this view is expressed more often. In SSE, all managers contribute to the corporate 
strategy by planning for their respective departments. It is a common responsibility of management staff to participate and demonstrate this skill. Hence, it has become an important skill in managers' perception.

\subsubsection{Inter-Relational Functions Or Holistic Views?}

In contrast to managers' and clerical officers' views are those of the senior staff or supervisory/middle management staff. Normal expectations would be for the supervisors or middle managers to have common views with either the junior staff or senior managers, being in the middle. However, amongst senior staff, the view was that all functions in SSE were inter-related with none more important than the others.

This finding is consistent with literature recognising culture as being developed through association or through social interaction (Gegeo \& Watson-Gegeo, 2001, p. 60). The reality is that these supervisors spend time with both clerical staff and managers. They are the link between these two groups which are from the opposite poles of the organisation's structure. Being in the middle, they were in a better position to view the organisation as a single entity. Managers are expected to have a bird's eye-view of the organisation and so they often fail to see detail. On the other side of the scale, shop floor workers are so distant from the managers, and preoccupied with their daily work, that they do not see the 'big-picture', strategic view that managers see.

\subsubsection{Financial Management}

It was noticeable that supervisors saw financial management as the most important knowledge. This view initially looked surprising, since not all of these supervisors work in the finance department. However, this also reflected the middle managers' special role in the organisation. Being the assistants to senior managers, these middle managers are the technical staff of SSE. And so besides linking managers to staff, their daily involvement would be on technical aspects such as financial, administrative, operational and data analysis and evaluation. Most of the individuals who held this view were officers with financial backgrounds or who were working in 
the finance and accounts departments. This skewed their view of financial management being important knowledge.

These supervisory officers were mostly those who were recruited as diploma holders or who showed academic capability and were sent on training to obtain their diplomas and so got their promotion. Training clearly is a major source of shaping the views of individuals. For example, when asked where the source of his view that financial management was most important knowledge, one supervisor responded: "from my training". Due to the level of their awareness, middle managers or supervisors are much more conscious of SSE's second role as a financial institution than clerical staff. Often, this class of staff pride themselves as the educated elite since most, if not all, of them are individuals with a college diploma. Education as a power tool will be further discussed in this chapter.

\subsubsection{Administration And Investment: The Second Most Important Knowledge}

In the above discussion, I presented the views of all the cross-functional sub-cultures on what is the most important knowledge in SSE. I then asked the interviewees what the second most important knowledge was. All categories of officers rated the Investment (over 33\%) and Administration (over 33\%) functions as equal second most important functions. As a female officer stated for Investment:

\footnotetext{
'I think because SSE's main objective is to invest member's funds in order to make good returns for their money, how we use the money wisely so that members can enjoy good returns for their money is most important.

Because if we do not look after the members' funds wisely, then we are not achieving SSE's objectives and which is to benefit the members."
}

Firstly, investment, as this officer clearly states, is one of SSE's main objectives. Although it was not the purpose for which SSE was created, by its nature, SSE has become an important financial player in the economy. More of this was discussed in chapter five. Secondly, the investment of funds is a means to providing better social security to SSE's members. Social security, as an important knowledge was discussed in some length earlier in this chapter. 
On the other hand, there were several reasons given for recognising the importance of Administration knowledge. A middle management staff member expressed this view:

"Because for all the work of the company, Admin comes first... to look after all the conditions and so on, for all the staff. They make sure all the staff are happy."

Firstly, Administration looks after staff welfare and that staff must be motivated in order to carry out their duties effectively. This is again social security reasoning, but one involving the welfare of SSE's workforce.

Secondly, the staff thinks Administration is important because they ensure staff work within prescribed procedures. The assistant manager quoted above said that Administration "...look after all the conditions and so on, for all the staff..." This reasoning recognises the power held at the Administration department. As per the Staff Policies and Procedures Manual (SPPM), all recruitment is carried out by this department and the Board also exercises its power to fire through the channel of this department.

Finally, Administration is important because they are responsible for the administration of SSE's resources. "All the conditions" stated above and "... they make sure all the staff are happy" include the responsibilities of the department to facilitate the conditions set for staff in the staff policies document. In particular female staff seem to notice the powers of this department to expend resources more than their male counter-parts. While other departments also make important decisions, the physical manifestation of the Administration department to expend resources and touch the lives of staff on a daily basis is felt more by female staff. As Eichinger and Lombardo's (2004) work showed, "women... are more participative and attuned to others" and their surroundings. Men, on the other hand, seem to show less emotion and focus more on problem-solving skills and business acumen.

\subsubsection{Summary}

From the research it was clear that each person tended to highlight their own department as containing the most important knowledge in the organisation. This was consistent with literature (De Long \& Fahey, 2000) that sub-cultures "heavily influence what is perceived as useful, important, or valid knowledge". But across 
functions, it was also evident from this research that hierarchical sub-cultures do affect the way their members view what constitutes important knowledge. While clerical and senior management staff viewed knowledge about members as top priority, supervisory staff, who act as the gel that holds the various levels together, viewed the organisation holistically.

It can be concluded from this analysis that SSE has managed to create a shared understanding of what is important knowledge. The vast majority of staff recognise the importance of social security knowledge which stems from value given to their members. Secondly, the role of SSE as a financial institution is also given prominence. Investment knowledge was not only found to be important per se, but it directly related to the improvement of members' services.

It was also clear that women had a greater appreciation of the Administration department as it affected their welfare and the welfare of their families. Male staff in general did not respond or showed little emotion to the Administration function.

\subsection{Levels Of Knowledge: Individual And Organisational}

According to Delong and Fahey (2000, p. 118), culture “...embodies all the unspoken norms, or rules, about how knowledge is to be distributed among the organisation and the individuals in it." When culture was used as the lens to see how knowledge is distributed within SSE, three themes seemed to emerge. These are: who controls what knowledge and where it is located. In sections 6.3.1, 6.3.2 and 6.3.4, I present what structured, individual and social knowledge respectively, are. Since structured knowledge is not recognised as a form of knowledge in SSE, the section dealing with this subject will be brief. In the discussion of these levels of knowledge, who controls what knowledge, and where they are held, will become apparent. 


\subsubsection{Structured Knowledge}

Structured or organisational knowledge is knowledge embedded in the organisation's systems, processes, tools, and routines (De Long \& Fahey, 2000). Based on my experience with SSE, there are examples of structured knowledge everywhere in the organisation. All documents, policies, procedures, computer hardware and software, manual records, members' registration data, employers' records, accounts and financial records, housing loans and staff records belong to the Board.

However, when staff consider organisational knowledge, they think it is that which is contained in departments and at board level. For instance, in arguing the case of a need for knowledge sharing by the board, a senior manager stated:

\footnotetext{
"All decisions made by the board or management must be communicated horizontally and vertically and should not be hidden. When we talk about accountability and transparency, which is now preached, it has to be accepted within the organisation."
}

All staff, from managers to the general staff see structured knowledge but it is not considered organisational. They perceived that organisational knowledge would make them more efficient and effective in discharging their duties.

Interestingly, out of all the respondents, only one, a manager, saw knowledge as artefacts. His view of knowledge was:

\footnotetext{
"Knowledge is something you gain, through reading, experience through interaction with people and that develop your knowledge."
}

In order to clarify this response, he was asked where he thought knowledge could be found in the organisation. His answer was:

"I see knowledge as a process... and procedures...some people write it up. It is the experience of some people... they put it into writing. If you work in a place you will also have the experience to write it down."

This manager is the only one who gave a response that recognised knowledge from a holistic viewpoint. First knowledge was "something you gain through reading". This recognises the tacit cognitive dimension of knowledge. Knowledge was first 
individual and embrained in the cognitive psyche. It was personal and difficult to express or share.

Secondly, knowledge is "experience through interaction with people". This part of his sentence recognises the social dimension of knowledge. Knowledge here is generated through group interaction and is stored in the group situation and is only known to the group.

When asked to clarify where this knowledge can be located, the response was knowledge is "a process... and procedures...some people... put it into writing." The officer here recognises knowledge as structured and codified and contained in artefacts. Somehow, he is the only interviewee who saw knowledge in structured form.

However, in Solomon Islands' tradition, all knowledge is subjective and is socially constructed (Gegeo \& Watson-Gegeo, 2001). Since much of the traditional knowledge sharing in Solomon Islands is done without the use of the written alphabet, people tend to equate knowledge to human and social knowledge but not codified knowledge. This has transferred to SSE's employees' understanding of what form knowledge takes as well. This was discussed in detail in chapter two.

\subsubsection{Individual Knowledge}

As was also discovered by Gegeo and Watson-Gegeo (2001), knowledge was first of all individual and secondly social. Knowledge has its source in individual humans, in tacit form. Through the act of socialising with other members of a group, it becomes social knowledge. In this and the next sections, I will present the research findings under Individual knowledge and Social knowledge themes.

Firstly, most staff recognise their unique abilities, skills and knowledge and are proud to talk about them. These skills, abilities and knowledge are varied and relate to either their training or years of experience. There are however, a few who try to be modest and say they have no special abilities since what they know is also equally known by others in the organisation. 
The few more modest individuals are mostly amongst senior staff and managers. As an ethnographer, I know modesty is an inherent part of Solomon Islands culture which people hold in high regard. Those who praise themselves openly are disapproved of and their assertive behaviour is often interpreted as boasting. Westerners often misinterpret Solomon Islanders' modesty for naivety or just being unappreciative of compliments.

When the question was posed whether staff believed in sharing information and knowledge, some said they were willing to do so. They thought that it was not really a question of willingness. Rather, it was that other people did not take the time to find out or ask questions. A supervisor stated:

\footnotetext{
"I don't even see people hiding information, it's people not seeking that's lacking, instead they just concentrate on their jobs, but not to go out and search those knowledge is happening here."
}

The culture here is one that states clearly the completion of work as priority. It is stated in the staff policies manual, job descriptions and verbally reinforced through daily supervision. At the end of each 12 month-period this is re-enforced through performance appraisal reports in which staff performances are evaluated against their job descriptions. Those who performed or exceeded expectations get a salary increase or a promotion while those who fall short are reprimanded, have salary increments withheld, or are disciplined in some other way.

Another reason given for people being unwilling to share their knowledge is the fear of vulnerability to disposal. A senior manager commented:

\footnotetext{
"In an organisation there are some knowledge that you feel like not sharing. To them it's ...they fear that they can be replaced any time."
}

De Long and Fahey (2000, p. 118) also found this to be true. The reward system does encourage staff to hoard knowledge. For example, at the end of each year, it is customary for SSE to host a party for all its staff, attended by the Board, Managers and all spouses. During last Christmas' function, there were awards of long service 
and some token sums of money for those who had served for more than 10 years and also awards to those who had completed their diplomas from the local college. There were also monetary gifts for 'the best staff' from each department.

These reward systems underpin the necessity for excellence and loyalty. Those who are educated were rewarded and those who are 'uneducated' had to sit and watch. A cleaner or handyman would never dream of getting a reward for academic excellence. Similarly, those who were loyal and served the board faithfully were also rewarded as were those who executed their work to the expectation of their superiors. All these high performers were rewarded in the presence of the board, management, all staff and family members. The rest were people who had not reached that milestone for long, loyal service, or were uneducated or performed less than those honoured that night. This creates shame and rivalry between staff. From experience, such a reward system creates competition and forces staff to be inclined to hoard knowledge so that they are seen as exceptional, and thus putting themselves in contention for reward and honour.

\subsubsection{Human Knowledge}

When participants were asked what they thought knowledge was, of the 18 participants interviewed, more than $94 \%$ (representing 17 participants) viewed knowledge as tacit, and only one gave knowledge an explicit taxonomy. Tacit knowledge exists in two forms, cognitive and technical skills. These are further discussed below in sections 6.3.2.1.1 and 6.3.2.1.2 respectively. Since in SSE education is seen as tacit cognitive knowledge instead of structured knowledge, I will present the views of staff about education in section 6.3.2.1.3 and how it is linked with tacit knowledge.

\subsection{Tacit Cognitive Dimension}

Taking a closer look at the views of the 17 officers, 14 participants view knowledge under the cognitive (Nonaka \& Konno, 1998, p. 42) classification. For example, a female clerical officer who recently graduated with a college diploma defined knowledge as: 
"It is something that I learn which I read about or I learn at school."

In Nonaka and Konno's (1998, p. 42) view, tacit knowledge is in two forms, cognitive and technical. To staff, knowledge was firstly understanding about something. In other words knowledge is cognitive knowing. It is sapient (De Long \& Fahey, 2000, p. 114), abstract knowledge about something and largely conceptual. For example, a male clerical officer who is an extrovert stated the following when asked for his thoughts of what knowledge was:

\footnotetext{
"When I hear the word knowledge, what comes to my brain is savé (understanding in pijin). Savé how to do things, how to do a particular thing or savé about knowledge or savé about how to do things or about information about some things or something like that. So when this word knowledge comes, I can't think of any other thing, but I can only think of know-how."
}

Even this officer reverted to stating knowledge about things as well. He does not only recognise knowledge 'how' but also knowledge 'about'. In his mind, there was no clear distinction between technical and cognitive knowledge.

\subsection{Tacit Technical Knowledge}

But tacit knowledge is also technical or 'know-how' to do something. The skills and abilities to do something are sentient (De Long \& Fahey, 2000 p.114), or in the feeling and are embedded in the body of an individual. This view of knowledge is understood by fewer staff of SSE. Hands-on experience or informal learning has been around in Solomon Islands for centuries and in fact it is the only way Solomon Islanders learned in pre-European times. With the advent of the western learning style, this once important knowledge creation approach has been pushed back to the periphery of scholarship. It is now regarded as non-academic and is hardly recognised as learning at all. The general view now held is that learning must come from an 'expert' who imparts his knowledge and wisdom in a classroom environment. However, Bruner (1996), asserts that people do not just "learn about”, they also "learn to be". This learning, does not just involve acquiring "knowledge about", but it involves knowing "how" to respond in a socially recognised way. Of the participants interviewed, 16\% recognised knowledge as 'know-how'. For example, a 
female staff member who had a certificate in administration made the following remarks:

"When I hear the word knowledge, I am thinking of education, knowledge about education. How well you are educated and how you understand about culture and the organisation in which you are employed."

The reason why cognitive knowing is emphasised more amongst staff in SSE than technical knowledge may lie in the above views expressed by the officer. Since education involves much cognitive learning and since it represents important cultural values, cognitive knowledge has gained status in the minds of Solomon Islanders over technical knowledge. The importance of education will be further discussed below.

\subsection{Education: The Key To A Good Life}

Education has become a very important instrumental neutral value. Sanga (2006), defines instrumental neutral values as the means to an end or the means by which to achieve a terminal value. In today's Solomon Islands culture, every parent aspires for their child to have a good education. A good education entails a university degree from the University of the South Pacific in Fiji, one of the universities in Papua New Guinea, or better still from New Zealand, Australia or from another western country. Due to limited space, the education system in the Solomon Islands is highly competitive. Even what were once vocational training schools were soon converted to the academic stream. In a lot of instances, parents send their children to live with relatives in the city to access better education opportunities.

In this research, most staff in SSE value being educated. They rate it as an important knowledge or at least an achievement worth pursuing. This is a reflection of the culture where education is thought of as the magical place where one steps out of ignorance into being an all knowledgeable individual.

Those who were interviewed thought that to be educated would give one the capacity to better understand the organisation and its operations and so translate to better performance and service to SSE's members. This view was held by the entire spectrum of the workforce. 
Training is something people are proud of in SSE. Talking to individuals, they would not actually say it in many words, but one can tell from their manner that they are 'educated'. This is even true amongst senior staff. For example, half of the senior staff think that all departments are equally important and are all inter-related. They indicated their views as being influenced by their formal training at college. The fact that they had been for further training was relevant. But to state the actual "where" they went for training was irrelevant. It went beyond answering a question to publishing information about oneself.

Education, especially academic training, is viewed as a means by which to achieve a greater value, which is, a better life. What is better life? In a previous unpublished paper by the author (2006, p. 9), there are two themes that emerged: harmonious living and economic opportunity.

First, a better life to Solomon Islanders is "harmonious living in which people are happy". This is vital contextually, to understand the value people hold in education. The Solomon Islands is a nation of villages and, nearly always, all who live in those communities are blood relatives. Anything less than harmonious living would destroy the fabric of Solomon Islands society.

Second, and related to the first reason, for Solomon Islanders better life means a land where all its children have the opportunity to improve their own social and economic wellbeing. It is where the people are empowered and can see eye-to-eye with other peoples as equals. Solomon Islanders still see themselves as lesser people even compared to their island neighbours. This is the result of many factors including colonisation, culture, media, politics, language and a whole lot of other factors. Since they are beyond the scope of this research, we will not go there.

Observations and documents show that better life is a core organisational value, not only for staff but for their members as well. For example, in their 2006 annual report, one of SSE's core values is stated as: "We will secure and fulfil growth of wealth and social security to members." I also observed the 'better life' mind-set in action when a 
person brought a few cell phones to be sold in the office. They went in a couple of days once the word spread. People did not really care whether they could afford to have one. That was never a question. Of late, there has been a band-wagon effect on people owning cell phones in Solomon Islands. Cell phones are perceived to be state of the art products over landlines, similar to other imported commodities such as people's preference for cars and not bicycles or motor cycles. This perception is suddenly inadvertently promoted by the presence of Regional Assistance Mission to Solomon Islands (RAMSI) personnel who all have one.

Despite the view of staff that education is a means to acquire personal human knowledge, to a greater degree, it is in the form of structured knowledge, and not human or social knowledge. Human knowledge is what an individual 'know' and 'know how' to do, while social knowledge is knowledge present amongst group members only (De Long \& Fahey, 2000). There is confusion over how education is viewed. The confusion lies in the use of the cognitive brain to absorb structured knowledge that is presented in the classroom setting.

\subsubsection{Confusion}

Knowledge management is a new discipline and so, as I had anticipated, in SSE knowledge management became part of the vocabulary only after my research at the institution. The concepts were all muddled even among managers. For example, in a focus group discussion on whether all knowledge should be made available to all staff, one manager made these conflicting statements:

\footnotetext{
"So at the moment, [...] is now working on the business process where each individual department has to formulate the written down knowledge, the processes, the procedures to go through the system so that it is exposed to new staff coming in."
}

Later, the same manager said:

\footnotetext{
"We are talking about knowledge management ... it's not a document or information you file away. That's not knowledge, it's a document. Knowledge is what you know up here [pointing to the head] that you want to share."
}

In the first instance, this manager clearly recognised knowledge to be in the form of “...written down knowledge, the processes, the procedures..." or in other words, structured knowledge contained in artefacts. Then in the second statement, he regards 
documents as not knowledge but 'information'. Knowledge to him is now cognitive.

This is a debate even in mainstream that scholars continue to grapple with.

There is also confusion whether knowledge is being shared at all. One manager thinks the Board is withholding important knowledge from staff. He said:

\footnotetext{
"No, chair, in my view I want to see knowledge shared vertically, horizontally without any boundary, because if we hide some decisions or policy issues, it will affect work. All decisions made by the board or management must be communicated horizontally and vertically and should not be hidden. When we talk about accountability and transparency, which is now preached, it has to be accepted within the organisation."
}

Another manager, a female, refuted this by commenting that this has already been the practice. She feels that the barrier to good information flow is with managers. She said:

“Isn't it what's happening now. The board resolves, pass on to management, management to staff. I think some managers hold back information from staff but the board expects that whatever they resolve must be conveyed downwards because it is the staff that are going to carry out those resolutions."

Instead, in her view, it is individual knowledge that is not being shared. People are reluctant to share their knowledge for various reasons including personal reasons and reasons of the systems' security.

\subsubsection{Social Knowledge And Important Social Groups}

In De Long and Fahey's (2000) framework, there are three classes of knowledge; Individual, Organisational and Social knowledge. I have discussed the first two above and in this section I will now focus on social knowledge and its importance in SSE. Social knowledge creates synergy and is largely tacit and is shared by group members only, and develops through working together. In the research, important social groupings were highlighted. They are the Board of Directors, the Executive Management and others associated with these important social groups. Other concepts such as big-manism, wantokism and power relations are also discussed in this section to discover why these social groups have become so important in SSE. 


\title{
6.3.4.1 The Board: The Most Important Social Group
}

From the interviews it was clear that the most important social group within SSE in the eyes of staff is the Board of Directors, although this social group was not even mentioned amongst the various departments and functions. I deliberately did not want to place the board into the organisational equation. However, this social group kept cropping up in the discussions. For example, a female manager when asked which function was most important, excluding the board, responded:

"Yes, the Board is something, but before this one, Board should be first, but otherwise this one should be important I think."

Similarly, a senior manager saw the board as the most important social group, worth mentioning and dissecting, although again they were not mentioned in the question. The senior manager made these remarks:

\begin{abstract}
"All decisions made by the board or management must be communicated horizontally and vertically and should not be hidden. When we talk about accountability and transparency, which is now preached, it has to be accepted within the organisation."
\end{abstract}

In the question, again, I did not specifically speak of the Board as a social group, but to staff and managers alike, the Board of Directors is the most important social group of all. In their mind, the former hold so much coveted knowledge that must be exposed, probed and dissected.

Secondly, Management, of which the CEO is the leader of the pack, is a very influential and powerful social group. The other social groups that exist in SSE are also very powerful and influential; however, they are not viewed with the same respect that is afforded to these two groups. For example, an inspectorate staff member commented thus when asked which the most important group was:

\footnotetext{
"The executive means the Board and GM. It is important because the Act is managed by the Minister and the Board, so any good planning or directions coming from the Executive certainly must provide a good output because they provide the controls; they have the power to control. It depends on how they direct the SSE."
} 
The importance placed on the Board is evidenced and reinforced by culture's treatment of the Board. First, the board room occupies the top floor of SSE Building. This location is one of the best in Honiara and from a bird's eye-view one overlooks the Honiara Port from east to west. During Board sessions no manager, let alone staff should enter the board room unless specifically summoned to do so. This gives the staff a sense of awe in the presence of the Board or its members and is unparalleled in the whole of SSE. All the other social groupings are treated with contempt in comparison to the treatment received by the Board.

This may also be fitting since many of the Board members are successful business people in their own rights or some senior bureaucrats who are used to respect being afforded them. Compounded by the fact that the Minister of Finance appoints these public figures, their importance in society is further enhanced.

Next, the SSE reinforces their prominence by paying them monthly Board allowances plus sitting allowances for all scheduled and special board meetings. When this level of benevolence is endowed to someone in a country where the majority of people earn less than US\$1 a day, their image is further established as truly important people.

The Board is vested with the power to make investment decisions. This is often in millions of dollars and what process they take in arriving at those important investment decisions are often above the heads of the ordinary staff. This also contributes to the important impression displayed by the Board.

However, the most important reason for the fear that staff have of the Board is because of the power entrusted them to hire and fire any member of staff, including the CEO as stipulated under the Act. The Board has exercised this power before when they terminated all staff for going on strike in 1993 and senior managers through the years for inconsistent performance. The Board has also approved a redundancy exercise in the past and unintentionally this became a deterrent for staff to raise dissenting views or express their opinions freely. 
Despite not including the Board in my questioning, it emerged from all staff that this is the most important social group in SSE. It was evident that the organisation's treatment of the Board has left the impression in the minds of staff that the Board is a most important social group and the knowledge they possess is very much coveted knowledge. The powers vested on the Board through the Act cements their position as the number one most important social group in SSE.

\subsubsection{Executive Office: The Most Important Function}

Second to the Board, the Executive Office is also most important. Of the 18 staff that participated in the research, 50\% rate the Executive function of SSE as the most important function while more than $22 \%$ think the Operation function is the most important one. For example, when asked why the Executive Office was the most important, a middle manager stated:

\footnotetext{
"Because it is the CEO and everyone must report to it. Executive is only one person? This idea, you know in every place of work, there must be a leader, somebody who is the head of a group and so on. So SSE as a family, this man is important, but before this man, because you did not put Board."
}

The leadership role of the CEO has influenced this officer to view the position as the most important function in SSE. Nevertheless, this officer recognised the overall importance of the Board, and although the question did not include the Board, it was mentioned as more important, and in effect making the Executive office second most important office in SSE. In Solomon Islands culture, similar to other Melanesian cultures, leaders are often referred to as "big-men”(Sahlins, 1963; Sand, 2002).

\subsubsection{Big-man Status}

This is part of a conversation I had with a female staff member when asked how comfortable she was in approaching the CEO:

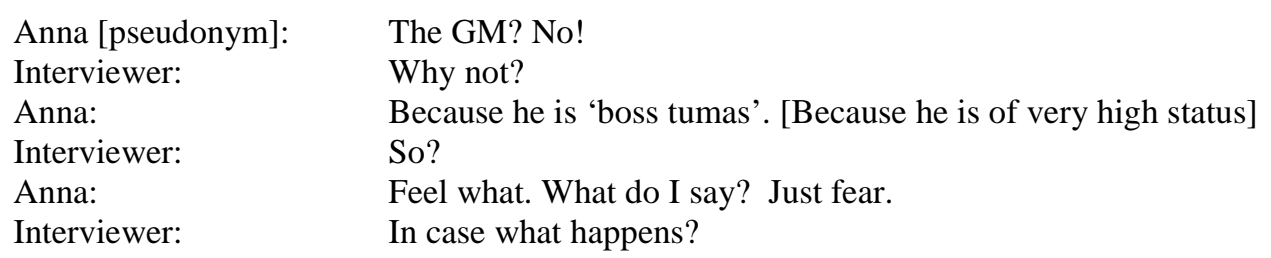


What this officer is trying to say is that the traditional culture and the organisational culture is not one that encourages staff to approach the CEO. The CEO is 'boss tumas'. He is a big-man (Godelier, 1982). Solomon Islanders don't just approach bigmen in their society. He is to be revered. Even male staff shared similar experiences. This male officer for example, when asked the same question has this to say:

"I feel comfortable to approach any manager, except for GM because I see him as little bit high or something like that... The way I look at it, I can joke with any other manager because I feel free to do so, but I do not interact or feel close to the GM."

These are the words of an officer who recently graduated with a college diploma.

Even with his qualification, the gap is not narrowed enough for him to be able to have an open dialogue with the CEO. This officer thinks that other departmental managers are more approachable but not the CEO. He is seen as 'a little bit high', meaning he is of a very high status. In order for two-way communication to take effect, the GM has to come down to the level at which point there is genuine mutual understanding of humour, resulting in the sharing of "jokes". Only at this point, can Solomon Islanders open their heart and true, honest dialogue take place.

Big-men must not assume that because they request it, staff will give their true opinion on organisational issues. In Solomon Islands culture there is such respect and fear of the leader that often subordinates will just repeat the popular view to be on the safe side. Superiors need to occasionally 'leave' their high status and come down to the level of clerical officers so as to build trust enough for officers to be frank with their opinions.

\subsubsection{Wantokism And Multiple Sub-Cultures}

It is not only females and males who are from other islands that have difficulty approaching the CEO. Even a male officer who is from the same region and speaks the same language [wantok] as the GM said it was easy to communicate with the GM only on informal matters: 


\begin{abstract}
"All of them [managers including the GM] are able to interact easily and freely with everyone... when it comes to informal interactions. I myself do not really engage in formal topics for discussions, unless we discuss formal issues in a formal setting... When formal things are discussed then we refer to the formal chain of command for these discussions. So when it is informal discussion, I do not really worry about the chain of command. But when we are in formal discussions, my mind tells me that I must refer to the chain of command."
\end{abstract}

SSE's formal culture could be gleaned from the whole discussion. However, there are subtle influences on the level of interaction between the CEO and staff who are considered to be his wantok. It was evident from the staff questioned above that whenever he felt 'exposed' as being close to the CEO, and he would resort to organisational rules and norms to defend himself from 'free access' to the CEO. Where there are multiple cultures, others would read this as wantokism or nepotism. Therefore, the 'chain of command' becomes his defence against criticism. For another example, another male staff member who also comes from the CEO's region and speaks the same language said this:

"People like managers and GM ...it is difficult to directly approach them. I think
there is a channel to follow....through my bosses."

Again, the training and cultural conditioning tell staff not to approach the CEO directly. This officer finds organisational protocols as the prohibition to approach the CEO. A senior manager who also comes from the same cultural background clearly was aware of this concern when he commented:

\footnotetext{
"With me... if I really want something to be done for my department, I should treat the GM as an advisor. So, anything that I want my department to achieve, I must see the GM. Not because we are from the same village. No! Because he's the boss and I've an obligation and duty to perform and some good advice will come from the GM."
}

Despite his statement to the contrary, the fact that this manager is from the same area as the CEO has much to do with how much freedom he feels in approaching the CEO. All other managers interviewed, both male and female found it difficult to approach the CEO.

While males who are from the same language group as the CEO may find it relatively easy to approach the latter, they still face the hurdle of organisational culture and expectations. While they may have broken down the traditional cultural barriers, the 
multiplicity of cultures and the organisational culture and sub-cultures may restrict them from expressing their opinions freely, lest they be criticised for wantokism.

SSE's workforce is made up of individuals from 8 of the 9 provinces. The smallest province no longer has representation here. When asked whether there was wantokism in SSE, staff denied it. However, people from the various language groups tend to stick together. This was clearly observed during SSE's Christmas function, where people from similar cultures tended to share tables.

Although it may not be obvious, wantokism is something staff are conscious about and try to avoid so as to be seen as politically correct. The statements uttered by those who are from the same cultural background as the CEO seemed to support the view that staff are consciously aware of the multiplicity of sub-cultures that do exist in SSE. As a result they avoid being seen as "too close" to the CEO. This can often lead to SSE not exploiting the opportunity for staff to interact with the CEO. This has also contributed to the loss of potential knowledge creation situations. Managers, who have power and influence, may have something to contribute to improving the situation.

\subsubsection{Power And Influence}

Of course, the CEO must be the most powerful individual in the entire SSE administration due to his position and the powers vested on him by virtue of the Act and him being the agent by whom the Board executes its functions. Interestingly, the board secretarial functions were rated as the least important in the whole of SSE. Of the 13 staff that attempted to make any ratings, eleven thought the board secretarial functions were the least important and one thought it was the second least important. This is a very high percentage (92\%) of staff who see comparatively little value in the board secretarial functions. The board secretarial functions are performed by the Board Secretary (BS). In the interview, it was revealed that along with the ManagerFinance, the BS is the most influential manager in SSE.

This issue was raised with a focus group comprising management staff. These managers interpreted staff's low rating of the board secretarial function as the result 
of two things. Firstly, the board secretarial function is non-operational. By this staff mean it is more a support service than a core function of SSE. Secondly staff think that the position is non-management. These caused the board secretarial function to be viewed as relatively unimportant.

One manager gave a third view: "I look from outside, viewing the operation, that's why I rate the BS low." Looking from outside, the board secretarial function is not a function of SSE that outsiders would normally notice. Unlike some of the main functions of SSE, the board secretarial function is totally concealed from the public gaze. However, these views do not explain why it is so influential.

When probed, several reasons were given for the influence the BS has among management staff. Firstly, a manager said: "I think it is just because she has been with the $[\ldots]$ for so long." This signifies that the incumbent has established herself as a 'big-man' of SSE. She has acquired much knowledge in SSE and she presents herself that way. Another manager saw her this way:

\footnotetext{
"The Board is so high up in the hierarchy; you have to be confident to speak to them without fear. Staff really don't understand,... and what the work load is."
}

She has to be a 'big-woman' to be communicating with the Board at that level. Her association with the Board gives the impression of her mirroring the Board. Therefore staff are obliged to afford the person honour.

Still another manager thinks it is due to the high level of interaction and communication she has with the CEO. She expressed this view this way:

“... she works closely with the GM. She has daily communication, anything not clear, the GM asks for her opinion."

There is some truth in this, since before the current CEO was recruited the BS was acting in the position for almost two years. It is therefore only logical that the new CEO consult the BS for clarification on matters of policy and governance. 
Finally, the rewarding of the incumbent of the board secretarial function reinforces its importance. A manager saw it this way:

\footnotetext{
"Why is it necessary for a separate post? With a very high package even more than managers...Before there was no BS why should they create one now with such high salary?"
}

From the above views it is clear that in the minds of staff there is no distinction between the position and the person. They are one and the same thing. A person sitting in a position of power automatically wields influence by virtue of the position. Through association with the most important social groups which are the Board and Executive, the BS also displays power through those associations. Unlike in traditional culture where a big-man eventually loses his importance due to his eventual inability to distribute wealth, in contemporary organisations the reenforcement of importance, which is salary, is difficult to alter as and when situations change, because of legal implications that may arise.

\subsubsection{Confidentiality Or Low Trust Culture}

Confidentiality is a major requirement in SSE. Section 4 of Part 1 of SPPM requires all staff to maintain confidentiality in respect to information which may be acquired during the course of their work. There is also confidentiality surrounding employees' personal information and any part of this information can only be divulged with the employee's consent or if approval is given by Administration Department or as required by law. Thirdly, confidentiality is required for all client information and can only be released on their approval or if required by law.

When staff are recruited, they have to sign a declaration form (Form 3) in which they agree to abide by certain rules. One of them is in clause 5 which says:

Maintain at all times the confidentiality of [...] and not to divulge any information which may appear to be confidential or of a nature which may adversely affect the [...].

The requirement to be confidential is contrasted with the need for transparency and flexibility. Transparency and good governance is a relatively new form of rhetoric which started to be preached mostly in relation to the government. Of late this has 
been preached within SSE as well and found a place in the mission statements in the 2005 and 2006 annual reports.

However, when one takes into consideration the rules regulating information and knowledge in SSE, the culture seems to suggest a low level of trust among departments and between management and staff. While there is a relatively free flow of information between management staff, less information gets trickled down to the shop floor or cross-functionally. For example, when management staff discussed freeing information to all, one junior manager had this to say:

\footnotetext{
"There should be some sort of internal control to control certain functions. For example, if Paul [pseudonym] has the knowledge in registration and changed members' age and there is no control, what's the use of knowing that? There should be internal control for particular knowledge."
}

All members and employers registration records are kept in a fire proof room and are accessible to authorised staff only who have the codes for the combination lock. This data is then computerised and electronic copies kept at the IT department and the data is accessible to a certain segment of staff of SSE. Again, the entrance to the IT department is only accessible to officers who have the codes for the combination lock. Similarly, Finance department has a combination lock, so does the Executive office which houses the CEO, Board Secretary and Board Room.

There are so many other rules such as staff being prohibited from driving company vehicles unless they are issued with a permit by the Administration department to do so, or that staff are not permitted to view management comments on their appraisals. All these restrictions highlight the culture of the staff not being trusted. It would be understandable if staff kept SSE information confidential from outsiders, but when there are so many rules restricting access of information from workers, it implies a lack of trust in staff. This low trust contributes to poor knowledge flow.

\subsubsection{Summary}

While the levels of knowledge are clear there is confusion over their taxonomy and where they are located. It was evident that staff of SSE recognise human and social knowledge but not structured knowledge, or at least it was not mentioned. This was 
rather surprising since all knowledge in Solomon Islands is underpinned in tradition, rules and culture. However, this confusion was explained in part by the fact that education, although structured knowledge, is regarded as cognitive knowledge and holds much hope for a better life. Along with individual knowledge, staff of SSE recognise social knowledge. The knowledge held by the Board and to some extent the Executive, which are considered the highest social groups, is much coveted. Again this has to do with the culture. In SSE there is so much respect afforded to these important social groups that it borders on submissiveness. These attitudes and treatment of knowledge inhibit healthy interaction and creation of knowledge.

\subsection{Context For Social Interaction}

According to Delong and Fahey (2000, p. 120), one of the ways cultures shape perceptions and behaviour is through establishing the organisational context for social interaction. In this section I will discuss the themes that emerged relating to the social context in SSE. These include sections 6.4.1 Face-to Face Interaction, 6.4.2 Vertical Interaction and 6.4.3 Horizontal Interaction. Other concepts such as Innovation, Dealing with Mistakes and Knowledge Acquisition are also discussed in relation to how the social culture impedes knowledge creation.

\subsubsection{Face-To-Face Interaction}

Face-to-face communication is still largely the preferred method of communication in SSE. Of the 10 clerical staff who were interviewed, $80 \%$ highlighted informal, face to face communication as a key medium for communication. The use of phone and intranet are becoming popular as well. However, face-to-face communication is still very popular as it is natural and therefore an effortless means of communication. Other forms of communication rely on other learned or external factors. For example, the use of intranet not only relies on the sender's keyboarding skills but also the actual writing abilities and the use of the technology. These skills are taken for granted in developed countries but in Solomon Islands they do pose a real communication problem. Similarly, phones may be available but face-to-face communication is more engaging and interesting, especially when the parties are acquaintances. So, staff 
generally use this form of communication style. One officer stated that she does this through betel nut ${ }^{22}$ breaks:

"Through sitting down and having coffee during tea break and during betel nut break."

These are actually coffee breaks provided for in the staff policies manual. But people who have coffee remain at their work stations or return as soon as they finish their coffee. However, it was observed that those who chew betel nut come in and sit around in the Staff Common Room and chew until around 8.30 when the official working hours should begin at 8 o'clock. At 10 am they would congregate again to chew. This ritual is also observed during lunch breaks, afternoon coffee breaks and after closing hours at $4.30 \mathrm{pm}$ and usually the chewing sessions last 15 to 30 minutes longer than they should. This has been made convenient by outsiders selling the mild narcotic substances right at the corner of the office building.

Most of the conversations during the chewing sessions were on unofficial conversation topics. There are two or three in the management team who from time to time join in and they would bring up some official subject matter and create more interesting discussions.

Another social group that meets frequently is known in the office as the "Garage Boys". This social group used to relax after hours in the office garage over a few beers since drinking is not permitted in any office property and stipulated in section 12 of Part 1 of the staff policy manual (SPPM). They have been given permission to move to another of SSE's properties that has better recreational facilities and is two minutes drive down the road. An interesting observation is that staff continue to chew betel nut in the office when the same section 12 of Part1 of SPPM also prohibits this practice.

\footnotetext{
${ }^{22}$ Fruit of the areca palm (Areca catechu), which is chewed together with lime and betel nut pepper as a stimulant.
} 
From observation, horizontal communication between staff at the lower level is frequent and free. Clerical staff utilise intra-net and the use of phones to some extent, but face-to-face communication is still the number one mode of interaction.

On the other hand, senior staff and managers use the intra-net a great deal. For example, with management staff all the important discussions are circulated to all members of the group by the $\mathrm{CEO}$ for their views and comments. Only matters that are scheduled for face-to-face discussion are included in the agenda for the monthly management meetings. A manager thus explained how their group communicates:

\footnotetext{
"Normally just verbal conversation... now after I returned I realise that most communication is through email... verbally through meetings and informally, after hours. Mostly, through email... between peers through email, also the staff use this as well."
}

The use of internet and intranet is becoming more popular amongst supervisors and management staff because of access. Many of the shop floor workers share computers and are given access to intranet but not the privilege of internet use. This limits their interaction options to mostly face-to-face communication.

\subsubsection{Vertical Interaction}

The vast majority of staff found it difficult to communicate with their managers, let alone the CEO. When asked how long ago they shared any sensitive issue with their managers, most said they had hardly ever. When asked why there is no vertical communication at this level, a female officer replied: "Because nothing like that happens."

Is it that there are hardly any sensitive issues arising in SSE or are people merely ignoring or closing their eyes to those sensitive issues? Or are they being impeded by other factors? One female staff commented when asked whether there was open interaction in her department:

"Not really.

I think the current one [manager], yes, I can comment on it but not the previous managers because they were all male..." 
This officer comes out with two reasons for not communicating freely with her previous managers. First, they were regarded as big-men and she "looked up to them". They were treated with respect even bordering on holiness. Big-men were not people who could be approached by any member of the society at will. This officer went on to say:

"No..., I did not find it hard. I just did not do it.

Because I look up to them, like they are big-men, and also because they are male, so I don't feel free to discuss with them. But I can speak up during a general meeting. When it comes to meeting them personally, I don't do it."

She also gave the gender barrier as another obstacle to free communication with her previous male managers. She reasoned that it was not only hard for her to approach them because they were male. She simply just does not do it! It is not expected of her to be seen speaking to any male for that matter, unless he was her husband or close family member. As an adult she could, but as a female she wouldn't. It is not culturally acceptable. Women who easily talk to other adult males are frowned upon and often this behaviour would be interpreted as licentious conduct.

Between senior staff and managers, sharing of sensitive issues is relatively easy. But when asked how comfortable they were to approach the CEO, even managers found it uncomfortable to do so. A long serving manager said this:

"As a matter of fact, not really. If we were to rate it from 1 to 10 it would be 4."

This seems a very low rating indeed for a manager of his CEO. This however, was not isolated to this manager alone. All the other senior managers interviewed, except one, found it difficult at times to approach the CEO. When asked why this is so, a manager responded:

"I don't know, may be because I am quite new on the position aaa...um may be ...I think it is because of the attitude; both the CEO and myself."

The manager explained that he was a junior officer for the major part of his working life with SSE and so he sees the CEO as "someone too high". The phrase 'too high' in pijin simply translates to 'very high' in English. Coupled with the fact that he is a shy type of person, he found it difficult to approach people considered to be of high calibre or big-men. 
Secondly, he views the CEO as someone who can be 'negative' in his responses. This behaviour has created a barrier between the CEO and his managers. The manager continued as follows:

\footnotetext{
"I also saw his reaction to some issues. I will not say aggressive but I am a person who will draw back from negativity. If he is negative in certain issues I will not seek assistance from such a person for fear that he might be negative to what I request. I am a person who fears uncertainty. And I always try to avoid... I cannot take a no... if they say no... it will be damaging... I might not react but internally, silently I will feel very demotivated... when you try to put a good idea and they tell you off bluntly ..."
}

Staff do not approach their superiors for fear of being scolded or belittled. Saving face is an important cultural obligation to the community at large. In the busyness of their executive responsibilities, managers often have little time for cultural sensitivity. In so-doing they often inadvertently distance themselves from their staff. The result is summarised below by this manager:

"No that is one thing I try to avoid... if I see it is sensitive and concerning him I try to avoid it."

True to Solomon Islands culture, this manager exemplifies the protocol for one to always avoid confrontation. This cultural tendency does not align well with cultures that encourage new knowledge creation. Similarly with the big-man culture there is so much respect given to senior people that distance is created and this has become a barrier for social interaction and so, knowledge creation.

\subsubsection{Horizontal Collaboration}

In their opinion little collaborative work goes on between staff. Generally, shop floor workers stick to their work schedules and aim at completing their given tasks. The little collaboration that is currently taking place is between certain staff from IT and Finance departments. These groups are working on a project to upgrade and improve accounting work through the use of technology. Other groups that should be working together are the inspectorate section of the Operations department with Finance people. However, accounts records are still very outdated and often cause work frustration for inspectors out in the field. This seeming lack of collaboration between staff is probably due to the organisational culture. 
Collaboration among managers is a constant process. All are well-educated officers who maintain professional relationships blended with pleasant Solomon Islands personalities. This makes collaboration relatively easy. One manager explained collaboration from his department's perspective:

\footnotetext{
"In our department we only collaborate when problems happen, when someone is sick or one goes on leave or if there is a need to clarify something in the staff manual."
}

Since people are often ill, and all members of staff theoretically go on leave once a year, collaboration in this department must be very high. However, this collaboration is only at a routine level. Deeper collaboration in which personnel from other departments are willing to sacrifice (De Long \& Fahey, 2000) their work for other colleagues is underdeveloped, probably reflecting limitations due to job descriptions and failure to establish collaboration to be an organisation-wide value.

\subsubsection{Innovation Versus Re-Cycling Knowledge}

Generally, clerical officers feel that they are required to be innovative instead of recycling old knowledge. All participants state in some form or other, that they are required to be innovative. A female staff member said this:

\footnotetext{
"In terms of those leading us or our supervisor, no such things happen. But with my manager, yes, we do discuss new ideas, new thoughts on how we can think of this new contribution system, on a daily basis, so yea, we can discuss."
}

At first glance, it seemed that staff had misunderstood the question. Knowledge acquired through education or some computer software fits into the category of recycled knowledge. When staff are introduced to existing structured knowledge, to them it becomes new. However, it is not created knowledge, rather, it is adopted knowledge. My observation confirmed that staff do spend most of their time reusing old knowledge. But, when one considers staff and their work in a holistic manner, reused knowledge to them is the constant base upon which they perform their jobs, and innovation is the aspiration they long to fulfil in order to meet some stated required performance ideals contained in their job descriptions. 
Therefore, staff feel they are required to come up with new ideas and not to recycle old knowledge. For example a newly recruited officer said:

\begin{abstract}
"I think they expect me to come up with new ideas. What I did in one year and three months is to use my own ideas on how to tackle the arrears and they have worked...For example, I have been able to change our approach, because when I first came and was given the papers to look at, I knew they would not work, so I have changed some of the approaches especially on negotiations and so on."
\end{abstract}

One who thinks that he is required to be both innovative but also to reuse old knowledge has this to say:

\begin{abstract}
"To be honest, I think SSE looks at both, where you bring in existing knowledge as well as develop some new thoughts in order to make something useful out of it...like for example in my role as the [...], SSE expects a lot from me, but I know I am doing less than ... expects out of me. I think there could be reasons why I am doing things less, and I also know that SSE is aware of this. I only hope that they address this quickly so that I can do better in my job and so that SSE is also happy with me."
\end{abstract}

This officer's main reason for underperforming was excused by his lacking the necessary technical skills. He sees training as the key to solving this inadequacy. But does he see anyone about it? Apart from the comments made in appraisal forms, and maybe expressing his disappointment to a few colleagues, he feels that the responsibility to identify his inadequacies falls on his supervisor or managers. The closest he attempted to formally express this view is in the annual performance appraisal which is hardly taken seriously or more correctly gets lost in bureaucratic red-tape. Only serious underperformances are taken up, but often as matters for discipline and not learning. This will be discussed further in the next section.

Managers also overwhelmingly think they should be creative, although they are aware that they do use existing ideas to a certain degree. A female manager has this to say:

\footnotetext{
"Currently we are using existing ones but we need to create new ideas. So that we move with current trends...for example inspectors... they should try out new ideas instead of sticking to old practices...since they are the ones to see employers they should think in or deal with accounts management and not inspectorate work only."
}

Since inception, SSE had always used a subjective performance appraisal system. This was amended in 2001 so that the current Appraisal Form now contains an 
outcome based section as well. On page 3 of the current Appraisal Form one would find 'Initiative and Innovation' as required subjective personal attributes. This is a carry-through from the old system of appraisal, where if one is innovative, it is assumed that he or she will perform at work.

Although in the staff appraisal there is the requirement to be innovative, it is given very little value. And there is no reason given for requiring one to be innovative or there is no organisational focus into outcomes to be achieved from innovativeness. Secondly supervisors and managers rarely take the time to set proper prescribed goals, job specifications, and personal specifications. Therefore all appraisal, in the end still remains subjective and there is little objectivity. On the other hand, staff get rewarded for performing their normal duties with perseverance and consistency. There seem to be mixed signals given here. Although staff would love to be innovative, there is no incentive to do so apart from their own self-perception and personal satisfaction.

It can be concluded that SSE culture is one where there is reuse of existing knowledge. This is shown by the fact that staff are eager to learn from each other and outsiders to acquire 'new' knowledge. Also as explained in chapter five, SSE is a statutory organisation and all employers are mandated to pay in workers' contributions into SSE on behalf of their employees. This law creates little incentive for the organisation to be innovative. There is no need to work hard and smartly in order to capture new markets or expand its market share. The law defines the market for it, and indeed the whole business context, including investment and revenue generation.

\subsubsection{Dealing With Mistakes}

Most of the responses highlight punishment as fair for those who err. Only one manager saw mistakes as opportunities to learn from and improve performance. The rest viewed punishment as the fair reward for mistakes. This response may be the result of my questioning technique but it also has to do with the current culture.

This culture, to some degree, has its sources set in the staff policies manual. Clauses 3 to 16 elaborately cover matters from staff conduct to termination procedures to 
appeal. From the policy document and also staff responses, different levels of punishment are dished out according to the seriousness of mistakes. These views are summed up by this manager:

\footnotetext{
"There should always be different categories if it is too serious, according to staff manual it must be a summary dismissal but if it is just a mistake or the stupidity of someone then give him a chance or warning."
}

Genuine mistakes could be forgiven and the officer concerned requested to explain him or herself and warned. Where damage to property is involved, staff are required to compensate for the damage. Staff may be reprimanded for minor misdemeanours, but serious mistakes involving the loss of money or wrongs with similar gravity may mean summary dismissal.

How can this culture evolve in a collective cultural context? Should not all mistakes be forgiven and forgotten in a collectivist society?

Firstly, in a collectivist culture, there is a fine balance between keeping the peace and meeting the full force of the people's wrath. This is done through confrontation avoidance. If someone over-steps the mark, who is not a person of status and power, another who has greater power will act as the jury, judge and executioner and come down on the one who erred like a ton of bricks. In conjunction with this, it must be remembered; staff fully understand their role as custodians of members' funds. It is imperative that they take good care of the funds to avoid loss through theft and through inflation. From this milieu, the policy was drafted by a lawyer manager. Given his legal background, everything is black and white and there are no shades of grey.

Mistakes then are viewed negatively and must be avoided at all costs. I think this view is taken because mistakes expose SSE's weaknesses. Because of the rules of accountability and responsibility, mistakes are seen as exposing management's weaknesses. Instead of using them as an opportunity to learn and improve systems, people are blamed and punishment dished out to pacify the unsettled corporate mind. 


\subsubsection{Rewarding Knowledge Acquisition}

Most clerical staff think that in SSE people are rewarded for performing their work. As long as staff do what they are supposed to do, they will get rewarded. Often, this means following the instructions of the superior. In order for this to happen, staff need to acquire knowledge and as much as possible hoard that knowledge to ensure competitiveness.

Managers also see that the reward system in SSE is for performance. Similar to the view expressed by general staff, they also want to see rewards for innovation.

A few however, also believe in knowledge sharing. As one female manager expressed, staff are rewarded:

\footnotetext{
"for performance and also to come up with new ideas and also extra skills that are out of....it's a good thing for us to adopt. If we keep our own knowledge it will be dark in the organisation so it's good to share our knowledge with other colleagues. It's not easy because each one is too bogged down with the task they are performing."
}

The importance of knowledge sharing is expressed, but it is not the practice. People are just too busy with their work. It is from this work that officers will get rewarded, hence knowledge sharing is seen as time wasting. This view is held even when managers think that it will impede the proper operation of SSE and it will create 'darkness' in the organisation.

The 'darkness' metaphor in the Gula' ala subculture on Malaita island in Solomon Islands is rorodo 'ala la, which means bad omen, bleak future, hardships, problems, danger or even death. It is therefore imperative that organisations avoid taking a path that would lead them to rorodo 'ala la or darkness.

The culture in SSE seems to encourage individual knowledge hoarding. Despite the fact that all staff and managers recognise the importance of knowledge sharing, it is not the practice. Staff are not rewarded for sharing their knowledge and SSE only rewards individuals for outstanding performance. These are clear messages for staff to 
show individual brilliance in order to be recognised and rewarded. Inadvertently, SSE has built a culture that inhibits the free sharing of knowledge.

\subsubsection{Summary}

From the above discussion, it can be said that SSE uses up-to-date communication technology but the facilities are extended to supervisors only and not the whole workforce. Therefore, avenues for interaction are limited. This policy is in part due to the respect afforded to big-men in SSE. This elaborate extension of respect has become a barrier to healthy social interaction vertically. It was also noted that while there was a free-flow of horizontal interaction a lot was at a superficial level and staff did not exploit every opportunity to interact at a deep sacrificial level.

It was also noted that while staff think that they are being innovative, in reality SSE culture is one where there is reuse of existing knowledge. Much has to do with the nature of the business and its protection by law and its status as a monopoly. Also due in part to its role as the members' saving scheme, mistakes are taken negatively so that they are not seen as opportunities to learn from and improve systems. This whole competitive culture also encourages staff to hoard knowledge despite the fact that everyone recognises the importance of healthy interaction and knowledge-sharing.

\subsection{Culture Shapes Creation And Adoption Of New Knowledge}

Knowledge becomes valuable when it affects decision-making and is translated into action (De Long \& Fahey, 2000). New knowledge is either adopted wholesale from external sources or is created internally by adapting external knowledge to the new context. It is therefore critical to create an effective knowledge-oriented culture. In the rest of this chapter, I will discuss how the culture in SSE shapes the view of external structured knowledge and expectations for participation. In the rest of this chapter as well, I will look at how the culture shapes the view of junior staff of their superiors. In so-doing, this discussion will shed light on the adoption strategy employed at SSE for the creation or non-creation of new knowledge. As a final overtone I discuss the need to show leadership in setting the strategy for knowledge creation and adoption in SSE. 


\subsubsection{External Structured Knowledge}

In SSE the majority of staff think they are not encouraged to seek out external knowledge and bring it into SSE and develop it further to create new knowledge. According to SSE's 2005 Annual Report (p.23), they spend a sizeable sum to train an average of 15 staff a year, whether the training is short term, long term, full time, part time, domestic or overseas. Few recognise educational training as external knowledge gathering, and staff often express interest to go for further educational training. This sending of people for training is an absorbing of external knowledge. Whether or not the training is transferred to work will never be known since there is no evaluation process in place.

The few that think they are encouraged to seek out external knowledge include those working with off-the-shelf accounting software. Again, this is an example of absorption of existing external structured knowledge.

SSE has been aggressive in its human resources training and development over the last decade. Much of this educational training can be categorised as external structured knowledge although the vast majority of staff do not recognise it to be so. Because of their blurred understanding, little is done by way of synthesizing the knowledge and improving on it so that it becomes appropriate and relevant to the organisational context. Instead, to a great extent, staff rely on management to be creative and set strategies. The followers will just do what they are told.

\subsubsection{CEO's Strategic Plan: A Gift From Heaven!}

A senior manager thinks that SSE is doing the right thing by encouraging managers to participate in strategy setting. However, he clarifies that they do not do any selfcritiquing and assessment. The CEO leads in strategic planning and his views are not supposed to be questioned. He summarised his views as follows:

"My view on this is, it is not. The avenue for that is not encouraged here. There is no debate to strategies to move organization forward. Sometimes we see the GM put 
something forward we say this is final. We say it is a gift from heaven! (laugh)... without further discussion. Although the GM may give us room for discussion, but there is not much discussion etc."

One wonders why whatever the GM says is like a gift from heaven, although he may encourage dissention and debate. Knowing the managers and the CEO, they are ordinary management staff with qualities expected from such high calibre individuals but nothing out of the ordinary. How then can senior managers so close to the GM not disclose their genuine thoughts to the CEO? It has to do with the national culture of respect that also permeates the workplace.

\subsubsection{Culture Of Respect Or Beaten Into Submission?}

Staff know their rightful place in relation to others. They are not supposed to question those in authority. They are people who deserve to be respected by virtue of their position. This culture has its roots in traditional culture. Even managers, those who are supposed to assist the CEO in matters relating to policy and the general overseeing of their respective departments, afford respect that a westerner would find unnecessary or undeserving. A manager expressed his views in the following way:

"I've been a junior officer for quite some time, for the rest or major part of my work life. Normally I see the CEO as someone too high."

The CEO is a big-man and someone to whom respect is due. This culture not only has its sources from traditional culture but also as stipulated in the Staff Policies and Procedures Manual (SPPM). In the SPPM, clause 9 of the introduction section states that:

Where authority has been delegated to an employee of a lower position... the decision or the performance of the senior responsible officer shall prevail over the decision or performance of the employee.

There is nothing wrong with this. It only safeguards power from being misused. But in Clause 3 of SPPM, under 'staff conduct', is a rule demanding the respect of those superior in position to oneself. It states:

All staff of the $[. .$. I are expected to apply themselves diligently to their respective duties. They must obey directions of their Senior Officers and behave with respect, courtesy and tact towards their Senior Officers in all dealings. 
These two rules whether explicitly or implicitly, together pronounce the powerlessness of junior officers to their superior who must respect the senior officers for the sole reason of their position and not their performance and quality of leadership. Often it works against creating trust and confidence in junior officers.

Therefore staff simply steer clear of any form of disagreement with the CEO or managers. Even when solicited, people have no guarantee that they will not be discriminated against for making dissenting comments. In a country where only $16 \%$ live in a cash economy (Harcombe, 1993), the safest way out is to avoid confrontation at all costs!

\subsubsection{High Expectations Or No Expectations?}

All managers and senior staff in the study think that expectations are high for them to participate in knowledge creation. They are truly expected to gather data, exercise judgment, to transform data into information and knowledge. However, some think that they haven't been given the resources to be able to meet those expectations. For example a senior staff said:

" [The expectations are] high but do not coincide with actions. For example I cannot work after hours as the doors are locked."

On the other hand, there was a mixed response from clerical staff. Most think that they are required just to perform their normal tasks. The few that think that expectations are high for them to participate in SSE's knowledge creation expressed the lack of space or context to do so. For example, this male clerk said:

\footnotetext{
"The expectations are high but it falls short by not providing room so that expectations can materialise."
}

A survey of job descriptions and other documents supports the view of those who stated that they are not expected to participate in knowledge creation, but rather to carry out their routine jobs. This might explain the fact that no avenue is created for this to take place among junior staff. 
It is clear from the discussion that in the minds of staff, expectation is high for them to participate in knowledge creation and therefore they question why their job descriptions do not reflect this. From observation and my experience, much of the expectation is verbally or otherwise communicated from managers and supervisors to their staff through their frequent interaction. Since it is not an organisational understanding, there is no initiative to provide space or context for knowledge creation to take place. The seeming lack of encouragement of staff to participate fully in creating knowledge may in part due to SSE's stable business environment. Since SSE has a monopoly of the social security business and is well protected by law, there is little incentive for entrepreneurship.

\subsubsection{Family Metaphor}

One of the management staff used the family analogy to compare it with SSE. This response was made in a focus group comprising management and senior staff. It was made when the question was raised if they thought regionalism was an issue in SSE. The female manager who had been in SSE's service for more than 27 years said:

\footnotetext{
"I am 27 years here and it's like a family organization. Some lower officers find it difficult to approach the GM because of their nature but if you look at social interactions, those that socialize with the GM also find it easy to approach him at work and those that do not also find it difficult to approach him. So they tend to go through their supervisor or manager. New people who are shy and those who are radical quickly adjust to SSE culture. If you come naughty you can very quickly go out the door."
}

The family metaphor is one used many times before by previous management when talking about SSE as an organisation and also in the global social security circles. In many ways the working environment is akin to a family setting and SSE takes care of many of the domestic responsibilities of staff by providing support, for example, furnished housing, transporting children to and from schools and much more. This goes beyond normal responsibilities in many other cultures, and other local institutions.

Added to this is the collectivist culture in Solomon Islands where there is always inclusiveness in speech. Interaction is an important concept and goes hand in hand 
with cultural practices. For example, a recent diploma graduate explains his understanding of knowledge in this manner:

“...when I hear the word knowledge its like, how we understand things, what do we understand about whatever or everything we interact with or with your knowledge, what you understand. That is what I understand when I hear the word knowledge. To me I think like, if it is your knowledge, what we understand about everything that you know about."

Notice that the speaker used the word 'we' four times in trying to explain his own personal understanding of knowledge. This is a typical example of the collective nature of Solomon Islands society. Collectivism provides the context for social interaction and communication. Through this, individuals are taught from an early age to view the world through their society's eyes.

\subsubsection{Maintaining The Status Quo}

Most staff and managers feel that they are not encouraged to challenge assumptions and beliefs which have shaped the organisation's earlier success. One junior officer blamed it on egos. Some managers do not want their successes to be questioned. They strive to have a good name for themselves. The officer said:

\footnotetext{
"Probably my answer is, there are bosses who just want to make a name for themselves. They do not care so much about those who actually do the work. At the end of the day, as far as [...] is concerned and from my experience, as long as their names are up, that's all they are concerned about. So they do not make room for that because they do not want people to challenge their success."
}

This was even noticed in a senior manager's response to what is important knowledge. This manager thinks knowledge relating to one's own work was most important. Then she gave a revealing reason:

"So that you can perform well or to the expectation of bosses or board."

Pleasing the 'boss' is always a reason to perform. When senior managers see this as a reason to perform, it means that they want to encourage junior staff to engage them in challenging those assumptions that have previously been perceived as successful, thereby restricting the opportunity to create new knowledge. 
Another interesting comment made by a female clerk after persistent questioning on whether staff should challenge managers' views was:

"No...because no one has said anything like that before."

Is it because no one has said anything like that before or is it something else? In reality, she is not expected to think that way. It is unimaginable to challenge successes, especially when they are approved by management. That is not how Solomon Islands women should think. It is not the kastom [culture in pijin]. It is going against the grain of social norms and cultural expectations. If one wants to be successful, one must work within the social norms. And the norms are: If it ain't broke, don't fix it! That is the culture in Solomon Islands and in SSE. We do not want to 'rock the boat', because it is disturbing the peace. It is also costly to constantly make changes.

\subsubsection{Summary}

Over the last decade, SSE has been aggressive in providing training for its staff. Although this is external structured knowledge, staff do not recognise it to be so. As a result, external knowledge is not synthesised for use internally. Instead, staff rely on management to constantly create knowledge and direct work. This has to do, in part, with the national culture of respect that permeates the workplace. Respect is always a necessary part of collective cultures. Collectivism provides the context for social interaction and communication and those in these cultures know their position and place in society, without being told. So, if members wants to be successful, they must tread within society's expectations and social norms.

\subsection{Leadership}

The leadership in SSE has a juggling act to perform. While management wishes to generate ideas from subordinates, they have the conflicting pressure of pleasing the Board. For example, a manager made the following remarks when asked how they find the work in their department: 


\begin{abstract}
"At the beginning of each financial year we should have our road-maps approved but during the year there are so many things not in the plan that comes on board. It makes officers concentrate on unfinished tasks doing this and that. In the end we don't complete the tasks and the plans that were set. Because of unrealistic targets, staff don't have time or are unmotivated by so many things and no longer have enthusiasm to share knowledge and ideas. If there is a plan there for...currently there is set in each department for those skilled to share their ideas in a set programme...this should be put into plan. If not there will be no time or motivation to do the exercise."
\end{abstract}

As illustrated by this example, there is also tension at the executive level. On the one hand the CEO may try to listen to his managers, while on the other hand there are competing demands from the Board. The stakeholder with the greatest bargaining power always wins at the end of the day. In accordance with Mitchell, Agle and Wood's (1997) definition, the Board being a definitive stakeholder would wield more power, legitimacy and urgency over subordinates, being discretionary stakeholders, who may have legitimacy but lack any urgency or power over the CEO. Eventually, when subordinates perceive this to be happening, they will block out their true preferences from their superiors. Often the subordinate gets what Timur Kuran (1995) refers to as 'reputation utility' from it. By voicing the majority or popular opinion, the subordinate enhances his or her own reputation, or at least is seen as not rocking the boat.

Another manager, a female officer thinks SSE has in mind to encourage rigorous debate and discussion of key strategic issues but simply does not find time to do so. She said:

\footnotetext{
"The SSE has view to... but maybe no opportunity to...maybe those responsible to search for those opportunities for staff to get involved may not search out for those opportunities."
}

This manager's view is that the Administration department should create the avenue for intense debate to take place. True, but the responsibility must first start with the leadership of the organisation. 


\subsection{Conclusion}

The analysis presented in this chapter is not an attempt to evaluate knowledge management practices in SSE. Instead, it is a record of a representative workforce's view and the researcher's interpretation of cultural effects as barriers to better knowledge management practices. Since the discipline is new, a fair number of the concepts seem confusing to the respondents and so in presenting the data I have referred to literature to guide me through the maze of confusing terminology. Much of the confusion lies in understanding the various classifications of knowledge- what they think knowledge actually is. Despite the confusion, staff of SSE seem to agree on what to them is important knowledge and they know their social context and the difficulties they face in interacting which are mostly vertical. This analysis also reveals the culture which inhibits staff from engaging in intellectual discussion. Finally, it has become apparent that leadership is crucial and must be shown, so that the whole organisation move away from an inhibiting culture to one which encourages real engagement from all, and where there is creation and adoption of new knowledge. 


\title{
CHAPTER SEVEN
}

\section{RESEARCH CONTRIBUTIONS AND IMPLICATIONS}

\author{
Between falsehood and useless truth there is little difference. \\ As gold which he cannot spend will make no man rich, \\ so knowledge which cannot apply will make no man wise.
}

\section{Samuel Johnson}

\subsection{Introduction}

Based on the data analyses and discussions in chapter six, this chapter will now outline the findings and their implication to SSE and the wider knowledge management community. According to De Long and Fahey (2000), culture embodies all the unspoken norms or rules about individual and organisational knowledge. It commands the rules that govern how knowledge should be distributed. It spells out what knowledge should be hoarded and by whom and where it should be located. The culture can encourage or discourage knowledge creation and adoption.

In this chapter, a summary of my research findings are presented, the general contribution of the work to the wider knowledge management community is also given. What the results imply to the case study is also outlined and the limitations of this work. Finally a view of what the possible future directions are for research is provided with a final comment from the researcher.

\subsection{Summary Of Findings}

The main research question in this study was to explore how Solomon Islands culture can be a barrier to knowledge management practices. This research has identified several aspects of the culture that has created obstacles for knowledge management practice in SSE. These findings are presented below under the four frameworks provided by De Long and Fahey (2000). 


\subsubsection{How Culture Shapes Assumptions About Which Knowledge Is Important}

First, staff of SSE understand knowledge to be tacit. Their understanding of knowledge is that it is mostly cognitive understanding and to a lesser degree technical knowledge. Although examples of codified or structured knowledge litter SSE, this study found that staff do not seem to recognise structured knowledge as knowledge at all. In relation to this, staff do not seem to recognise educational training as external structured knowledge. They instead see education as cognitive learning and aspire to the exposure and experience it gives. They perceived that by gaining educational experience they would increase their social and economic wellbeing.

Second, this research revealed sub-cultures as a big influence on people's understanding and perception of important knowledge. Mostly, important knowledge is knowledge related to the staff's own work and areas of responsibility. The importance or value attributed to particular knowledge is determined by one's proximity to that knowledge.

All staff also viewed knowledge kept in the Operations, Administration and Investment departments as very important. It was found that importance is assigned because of the impact of the departments on the staff's lives as in the case of Administration, or successful indoctrination by management in the cases of the Operations and Investment departments. This successful indoctrination could indeed be successful organisational learning of the core responsibilities of SSE.

Finally, the research showed that knowledge held by big-men is perceived as valuable knowledge. In the research it was revealed that cross-functionally, throughout the whole organisational hierarchy, knowledge held by the Board, Executive and officers at close proximity to these important offices, such as the Board Secretary, are recognised as valuable knowledge. 


\subsubsection{How Culture Mediates The Relationships Between Levels Of Knowledge}

Despite the general tendency that important knowledge is related to one's own work, all seemed to agree that the Board is the most important social group and knowledge held by this group is coveted by all. Besides the Board, staff saw the Executive Office as the most important function of the organisation. Similar to the Board, the CEO is rated as important due to its governance responsibilities and the powers vested on the position. The big-man status of these important offices is recognised and so all staff see them as locations where important social knowledge are being held.

Apart from coveting knowledge held by these high offices the research found that the culture in SSE seem to encourage competition and the hoarding of knowledge by the individual. Besides seeing education as a means to improve their status, it is also a means to avoid dispensability. This has much to do with the whole national culture or system which is designed to be competitive as a result of resource scarcity. This culture has been bought into and is in operation in SSE. The competitive culture does not encourage distribution and sharing of knowledge and ensuring that knowledge becomes organisational. This is reinforced by the reward system, which recognises individual brilliance and innovation. There is little recognition or time given for knowledge sharing, let alone reward given to those who show this behaviour. The rewarding of 'best' officers and individual performance is counterproductive to knowledge sharing and distribution. This is the practice and no one has stopped to think about it and suggest any changes to this practice.

\subsubsection{How Culture Creates A Context For Social Interaction}

The study found that there are several social groups in existence in SSE. Some are formal groupings and others informal. While formal groups use their social context to share knowledge, many of the informal groups meet only to socialise and share little knowledge relevant to SSE. The research found the culture to be very laid back. This attitude does not create a sense of urgency and responsibility to improve performance in SSE. Instead staff are content to do things as usual. 
The study also found the big-man culture to be playing an important role in shaping how staff behave toward their superiors. The study showed staff finding it difficult to approach senior managers, the CEO or the Board with sensitive issues or even to put forward their honest opinions on any matter, even when solicited by the superiors. This is true for both male and female staff. In particular, female staff found it more difficult to approach male superiors. Although many do interact with their male superiors, the level of interaction is not completely free and the vast majority still find it difficult to approach managers at all. They state kastom as the barrier and to some, even to comprehend facing the CEO was unimaginable. Some kastom reasoning are embedded in the spiritual dimension.

Next, the research found that the staff of SSE do not know how to engage in meaningful conversation when opportunities present themselves. Often their informal interactions with managers are limited to unofficial topics. The culture is one that does not encourage staff to question superiors or their directives and instructions. It instead promotes conflict avoidance and compliance to popular opinion.

Also related to the big-man culture, the research found that the culture in SSE is one that can be described as low trust and harsh. There are rules set up to guide the administration of SSE which inadvertently have resulted in the fashioning of staff to be submissive to authority. Furthermore, SSE is harsh in the way they deal with mistakes, and often the occasion is not seized as a learning opportunity. The research found this to work counterproductively to a culture of knowledge creation.

Finally, the research found that wantokism is constantly at the back of the minds of staff and managers. Where there is a multiplicity of cultures, managers have to be seen as fair and show impartiality in their decisions. Spending time whether in length or frequency with a wantok could be seen as nepotism. Constant pressure for political correctness can work against knowledge creation, adoption and sharing. 


\subsubsection{How Culture Shapes The Creation And Adoption Of New Knowledge}

Adoption of new knowledge is difficult when external structured knowledge is not recognised as knowledge at all. Whenever staff come into contact with this type of knowledge, it is mostly absorbed wholesale with little synthesizing being carried out.

Second, no real participation is expected from staff. While staff might hear it verbally expressed to them, no document, organisational statements or job descriptions outline the importance of active participation from staff. In fact to the contrary, staff are expected to perform within provided guidelines and not to assume power to create new knowledge. This is a culture which is wasteful of individuals' capabilities.

The study also revealed that opportunities for capturing new knowledge are not welldeveloped in SSE. Staff are not really encouraged to enter into intense debate on key strategic issues. Some clerical staff actually think that senior staff dislike being questioned as this undermines their seniority. This culture restricts SSE's flexibility to adapt to its environment.

\subsection{General Contribution Of The Study}

In this section, I will highlight the general implications and the significance of this study to knowledge managers in general and those interested in dealing with cultural issues in the workplace. Different cultures provide unique situations for knowledge managers. This study has shown that knowledge managers do not only wrestle with organisational culture. The national culture, which is a product of the blend of all the sub-cultures within the society, and the various factors that have influenced Solomon Islanders throughout its distant and recent histories, provide challenges for even the most enthusiastic knowledge manager.

Since there are multiple sub-cultures in place, an 'outsider' knowledge manager would generally be perceived as fair in his or her decision-making. His or her nonalliance with a particular national sub-culture would provide a non-threatening 
situation, therefore creating more trust in the outsider knowledge manager and decisions he or she may make would be more readily acceptable.

However, while this may be so, the study also showed that any manager that is perceived as a big-man and or is educated is a threat to the comfort of Solomon Islanders. Women in particular will distance themselves from their superiors, especially if they are of the opposite sex as a sign of respect and because it is the expected societal norm for chaste women.

Solomon Islanders fear being spoken to in case their 'foolishness' is exposed, since the big-man is also the knowledgeable one. They do not expect to be asked what their opinion is on any matter. Therefore, even when solicited, there would be great difficulty for managers to hear the genuine views of staff.

From this study, it can also be concluded that Solomon Islanders desire to gain knowledge through educational training. Staff regard educational training as cognitive learning but do not see it as structured knowledge. Educational training is seen as a major source of acquiring tacit cognitive knowledge which, with experience, can translate to technical knowledge (Nonaka \& Konno, 1998). Tacit individual knowledge is preferred over structured organisational knowledge. Since tacit knowledge is embedded in the individual, it shapes the values, norms, practices and perception of individuals. The competitive environment for individual knowledge makes people less willing to share their knowledge with others. Instead, they strive to build individual worth and indispensability.

This study is also revealing in that staff recognise tacit knowledge as important but structured knowledge as less important. Because of this, even when encouraged, staff will place little value on external knowledge gathering and analysis, and the opportunity to internalise knowledge from external sources is often missed. Similarly, they will overlook important internal structured knowledge and let slip the opportunity to study and learn from those artefacts. This limits the organisation's absorption capacity. 
As illustrated in this work, in poorer countries competition is tough for scarce resources. As this study has shown, this has disjointed the emphasis of important knowledge and its treatment. It will take time for the culture to shift in the way important knowledge is viewed. The length of time it will take is hard to predict, but the time taken for views to actually shift will correspond with the improvement of the socio-economic development of the people. Competition is not such a bad thing, if the knowledge manager knows how to use it to leverage organisational knowledge and competitiveness. The importance of harnessing knowledge and creating competition cannot be overstated. Failing to do this would see Solomon Islands businesses losing to the rest of the world.

There is no easy answer to solving this but staff must learn to ask questions of themselves and their managers. Questions must be asked both of the failures and of the assumptions that result in their success. On the other side of this same coin, the big-men of Solomon Islands organisations must take the first step down from their lofty positions and encourage vertical communication. On this note, flatter structures would better facilitate vertical interaction than steeper ones. Otherwise, no change will ever take place in the social interaction context.

Finally, at the organisational level, managers must take leadership and rise over petty organisational politics to overcome the low-trust culture and wantokism that will be ever-present. Wantokism can be very useful for rallying support. At other times it can lead to nepotism and corruption where leaders favour their own wantoks. But then again it can also be difficult for managers who try to be seen to be politically correct and so don't give responsibility to their own wantoks who may actually deserve it. With time and with fair consistent performance, staff will be able to develop trust in the big-man.

To the wider community of knowledge management practitioners, this research is important because it provides insights into Solomon Islands and the broad Melanesian cultures. This knowledge is vital for MNCs that wish to operate in this region of the world. Failing to recognise these multiplicities of cultures within countries could prove costly and frustrating. 
Finally this paper is significant as it vividly illustrated how Solomon Islands culture creates barriers to good knowledge management. This research highlighted the society's expected norms and standards of behaviour that work contrary to cultures that encourage knowledge creation and sharing. These cultural trends must be dealt with, which does not necessarily mean to do away with, before knowledge can become truly organisational and so provide that competitive edge.

\subsection{Practical Implications}

In this section of the chapter, I will now outline the practical implications of the study to SSE. The outline will be in terms of required managerial actions for certain findings of the four major categories of knowledge management, understanding and treatment.

1. Several actions are recommended to remedy the culture's effect on how people see important knowledge.

- Explore how the culture in SSE supports or undermines knowledge creation and sharing. For example, is performing one's prescribed job in the job description more important than teaching and sharing knowledge? What evidences of knowledge sharing might be institutionally required? How might performance of jobs be balanced with knowledge sharing?

- What would result if inspectors of the Operation Department held weekly meetings with the Finance Department on Forms 'A', 'B' and 'W' records and employers' information? Instead of viewing the sections as separate departments, could the tasks be recognised as the process flow of the same job? With improved regular communication, it is possible to achieve enhanced coherence through improved alignment and immediate rectification of issues. 
- The system of rewarding 'best' officers is a barrier to effective knowledge management. Could this practice be changed to reflect the desired norm of knowledge sharing? Could 'best officer' be defined as 'one who shares more'? One who mentors? One who teaches and coaches?

- $\quad$ Since all departments, sections and sub-cultures in SSE view important knowledge differently, could there be some discussion amongst the various groups to have a shared understanding of which knowledge is the most important for SSE? Why? And at what times? Might an organisational capacity be developed to assume responsibility for improving knowledge management and aligning these with changing organisational priorities and environments?

- Structured knowledge seems undesirable to staff of SSE. Can management initiate policy and an education process to do something about this view held by staff to change their perceptions? Could a balance be drawn between the investment in human knowledge and skills and structured knowledge?

2. The culture of SSE places higher importance on individual knowledge than organisational knowledge. This is mostly unintentional. Below are some recommendations for improvement of problematic areas within SSE that could also be applied in a general way to other organisations as suggested by De Long and Fahey (2000, p. 125) .

- How would you pro-actively change attitudes that encourage ownership of individual knowledge?

- How can managers increase their communication with staff and the distribution of important knowledge such as Board knowledge?

- Clearly communicate that knowledge hoarding is now no longer 
acceptable in SSE. Create avenues for knowledge sharing and those who do not share their knowledge will become obvious and dealt with in an appropriate manner.

3. Some characteristics of SSE's organisational culture that shaped the context for social interaction were identified with suggestions for improvement.

- Most importantly, it must be recognised that the culture in SSE creates barriers to discussing sensitive topics.

- The CEO and managers must evaluate the evidence where the staff perceive them as approachable. A careful eye must be kept on identifying elements of the culture that inhibit vertical interaction.

- Are there ways to change the norms and practices to encourage:

- A higher frequency of interaction?

- An expectation of collaborative problem solving?

- Seeking out existing expertise and knowledge instead of trying to "reinvent the wheel?"

- Teaching others?

- Identifying and learning from mistakes?

4. It is not easy to detach oneself and look objectively at ways to improve existing norms and practices that have become the acceptable way of doing things. Nevertheless, it is critical for knowledge creation, and management must lead the way in questioning existing norms, practices and assumptions that have previously resulted in creating success. Here are some questions they might like to ask:

- What norms and practices create barriers in looking for important new knowledge that has been ignored, discounted or undiscovered by SSE? 
Identify the norms and practices that inhibit adoption, creation and application of this new knowledge.

- Is it possible to strike a balance between the importance given to tacit knowledge and structured knowledge? Find opportunities to use eternal knowledge and create innovation in SSE.

- How can management encourage staff to seek out external knowledge and build on it within SSE?

- Since conflict is always a big taboo in Solomon Islands society, how can management use this to create constructive knowledge exploration rather than creating confrontation and antagonism?

- How can management remove the norms and practices that inhibit high levels of participation in both acquiring and challenging of critical knowledge to SSE?

- How can we keep in questioning our fundamental assumptions, beliefs, and the projections about the competitive environment, core technologies, and the culture itself?

\subsection{Limitations Of The Study}

Because this study is an exploratory work, it is in no way exhaustive and there are limitations to this research. For the purposes of this section, I will highlight the obvious limitations. They are found in four main areas: the researcher, access issues, the situation of the respondents and timing.

Firstly, this study was not meant to be a single intrinsic case study. If access had been easier, it would have been my ideal choice to conduct a multiple case study in order to facilitate clearer generalisations. This particular case was of no significance to the phenomenon studied. This is an instrumental case study as defined by Stake (2000). 
SSE's case is used to examine cultural barriers to knowledge management. SSE as an organisation is of secondary interest and serves only to play a supporting role.

Secondly, the topic of research is totally new to the staff of SSE. It may have helped to distribute the guide questions in advance so staff could think about and prepare their responses. I probably would have received fuller answers to the questions posed, instead of getting 'yes' and 'no' answers as in some of the cases. However, I was also aware that providing the questions in advance could stimulate discussion among the respondents and so there was the potential for people to repeat the thoughts of others and not their own.

The timing of the research also limited the pool of participants available to me. The ideal time to conduct the research for me would have been while all the staff were present, normally around mid-year. Two factors, both beyond my control, provided the parameters in which I had to collect the data. Firstly, mid-year is the end of SSE's financial year and is the busiest time for staff and so access would be difficult. If however I was given access in mid-year, it would be interfering with people when they are most busy and so participants would not corporate fully, hence the choice to conduct research at the end of the calendar year. This however, is when many of the staff were away on leave, and so the choices from which to pick participants in the study was limited. So the respondents may not have been the best ones to provide the required qualitative data. Secondly, since this work is a thesis, I had a time frame to work by and so the timing for me was inflexible.

Finally, as a first time researcher, I realised after drawing my conclusions that there may be better ways of conducting this research if I had the opportunity to do it all over again. For example, I would learn the subject well and use dialectical analysis to help me dig deeper in order to understand the underlying values that shape the views of respondents. The experience helped me to also realise that I need to be braver and explore outside the guide questions I had in hand.

Despite the weaknesses highlighted above, this study has raised important questions for further exploration. 


\subsection{Future Directions}

Knowledge management is a new field of study in Solomon Islands. This work has in some small way provided the foundation from which future research can be conducted.

For example, detailed study could be made to understand why tacit knowledge is recognised and desired over structured or codified knowledge. Or similarly, research could be made into organisational losses due to available structured knowledge being discounted and discarded. These would inform workers of the importance of structured knowledge and help management in the development of their change strategies.

Secondly, it would be interesting to study how and why Solomon Islanders falsify their true preferences in public (Kuran, 1987) or in the presence of big-men. Is it a need to be seen as complying with popular views, or is it due to the need to avoid certain social consequences, or is it the result of the reverse virtue of treachery or is it due to some deep spiritual belief? An understanding of this culture of silence could aid in creating a more inquisitive workforce and those willing to create, adopt and share their new knowledge with others.

As an offshoot of knowledge management, there is the need to create Learning Organisations (LO). It is becoming evident that it is not individual knowledge that creates competitiveness of organisations, rather, it is organisational knowledge (Senge, 2006). Organisational knowledge can only be achieved when the whole organisation learns together. Therefore it follows that Solomon Islands organisations must learn to learn together. It would be of particular interest to research the dynamics of LOs in Solomon Islands context, contrasting it with mainstream cultures or even conducting cross-cultural studies with other Pacific or Asian neighbours. 


\subsection{Final Word}

Knowledge in Solomon Islands is always a social construction and totally unlike the mainstream Anglo-European epistemology of positivism with focus on "objective knowing”. Knowledge cannot be separated from the knower, therefore, objectivism does not exist in traditional knowing. This was also discovered by Gegeo and WatsonGegeo (2001, p. 62).

Secondly, Knowledge in Solomon Islands tradition is not something to be shared openly, and with everyone. Important knowledge might mean the life or death of a community. Important knowledge always means knowledge important for the welfare and the wellbeing of the tribe or community. So, the knowledge giver is always dutybound to be selective in the appointment of his protégé. Knowledge is always shrouded in secrecy, as is the time for knowledge sharing: in pitch black night.

This is the canvas wherewith I used to sketch knowledge management practices of one organisation in Solomon Islands. Understanding these cultural undercurrents will be of great help to anyone who wishes to understand the culture, perspectives and choices that Solomon Islanders make in their recognition, creation, adoption and sharing or otherwise of knowledge. 


\section{REFERENCES}

Abdelkader, D., \& Noor, A.-N. (2006). The Role of Knowledge and Capability Evaluation in E-Business Strategy: An Integrative Approach and Case Illustration. S.A.M. Advanced Management Journal, 71(2), 11.

Alasia, S. (1989). Politics. In H. Laracy (Ed.), Ples Blong Iumi (pp. 164). Suva: Institute of Pacific Studies of the University of the South Pacific.

Alavi, M., \& Leidner, D. E. (2001). Review: Knowledge Management and Knowledge Management Systems: Conceptual Foundations and Research Issues. MIS Quarterly, 25(1), 107-136.

Alvesson, M., \& Kärreman, D. (2001). Odd couple: Making sense of the curious concept of knowledge management. The Journal of Management Studies, $38(7), 995$.

Amit, R., \& Schoemaker, P. J. (1993). Strategic assets and organisational rent. Strategic Management Journal (1986-1998), 14(1), 33.

Anthes, G. H. (1998). Learning how to share. Computerworld, 32(8), 75.

Barney, J. (1991). Firm Resources and Sustained Competitive Advantage. Journal of Management, 17(1), 99.

Bates, D. G., \& Plog, F. (1990). Cultural anthropology. New York: McGraw-Hill.

Becker, H., \& Geer, B. (1957). Participant observation and interviewing: a comparison. Human Organization, 16(3), 28-35.

Berkes, F., Colding, J., \& Folke, C. (2000). Rediscovery of traditional ecological knowledge as adaptive management. Ecological Applications, 10(5), 12511262 .

Bloor, M., \& Wood, F. (2006). Keywords in qualitative methods : a vocabulary of research concepts London: SAGE

Brown, J. S., \& Duguid, P. (2001). Knowledge and organization: A social-practice perspective. Organization Science, 12(2), 198.

Bruner, J. S. (1996). The culture of education. Cambridge, Mass. : Harvard University Press.

Burrell, G., \& Morgan, G. (1979). Sociological paradigms and organisational analysis : elements of the sociology of corporate life. London: Heinemann. 
Cavana, R. Y., Delahaye, B. L., \& Sekaran, U. (2001). Applied business research: qualitative and quantitative methods. Milton, Queensland: John Wiley \& Sons.

Clark, T. (1990). International Marketing and National Character: A Review and Proposal for an Integrative Theory. Journal of Marketing, 54(4), 66.

Conner, K. R. (1991). A Historical Comparison of Resource-Based Theory and Five Schools of Thought Within Industrial Organization Economics: Do We Have a New Theory of the Firm? Journal of Management, 17(1), 121.

Constas, M. A. (1992). Qualitative analysis as a public event: The documentation of category development procedures. American Educational Research Journal, 29(2), 253-266.

Cook, S., D. N., \& Brown, J. S. (1999). Bridging epistemologies: The generative dance between organizational knowledge and organizational knowing. Organization Science, 10(4), 381.

Cooper, C. L., Argyris, C., \& Starbuck., W. H. (Eds.). (2005). The Blackwell encyclopaedia of management (2 ed. Vol. 12). Malden, MA: Blackwell Publishing.

Davenport, T. H., De Long, D. W., \& Beers, M. C. (1998). Successful Knowledge Management Projects. Sloan Management Review, 39(2), 43.

Davies, M. B. (2007). Doing a successful research project : using qualitative or quantitative methods Basingstoke [England] Palgrave Macmillan.

De Long, D. W., \& Fahey, L. (2000). Diagnosing cultural barriers to knowledge management. The Academy of Management Executive, 14(4), 113.

Denscombe, M. (2007). The good research guide : for small-scale social research projects / Martyn Denscombe (3rd ed. ed.). Maidenhead, England Open University Press.

Donaldson, L. (2001). Reflections on knowledge and knowledge-intensive firms. Human Relations, 54(7), 955.

Drucker, P. F. (1993). Post-capitalist Society. Oxford Butterworth Heinemann.

Eichinger, R., W., \& Lombardo, M., M. . (2004). Gender, 360-Degree Assessment, and Performance. HR. Human Resource Planning, 27(2), 23.

Empson, L. (2001). Introduction: Knowledge management in professional service firms. Human Relations, 54(7), 811.

Fielding, N. (1996). Ethnography. In N. Gilbert (Ed.), Researching Social Life (pp. 154-171). London: Sage. 
Fink, G., \& Holden, N. (2007). Cultural Stretch: Knowledge Transfer and Disconcerting Resistance to Absorption and Application. In D. J. Pauleen (Ed.), Cross-cultural perspectives on Knowledge Management (pp. 66-80). Westport: Libraries Unlimited.

Fox, C. E. (1967). The Story of Solomon Islands. Sydney: Pacific Publications.

Frank, R. H. (1996). The political economy of preference falsification: Timur Kuran's Private Truths, Public Lies. Journal of Economic Literature, 34(1), 115.

Fugui, J. M. (2007). Culture of Solomon Islands: Advameg Inc.

Geertz, C. (1993). The interpretation of cultures : selected essays In (pp. 470 p. ). London Fontana.

Gegeo, D. W., \& Watson-Gegeo, K. A. (2001). "How we know"; Kwara'ae Rural Villagers Doing Indigenous Epistemology. The Contemporary Pacific, 13(1), $55-88$.

Gegeo, D. W., \& Watson-Gegeo, K. A. (2002). Whose Knowledge? Epistemological Collisions in Solomon Islands Community Development. The Contemporary Pacific, 14(2), 377-409.

Gerring, J. (2007). Case study research : principles and practices New York: Cambridge University press.

Godelier, M. (1982). The Making of Great Men (Vol. 56). Cambridge: Cambridge University Press.

Goffman, E. (1961). Asylums: Essays on the Social Situation of Mental Patients and Other Inmates. Hamondsworth, Middlesex: Penguin.

Gore, C., \& Gore, E. (1999). Knowledge management: The way forward. Total Quality Management, 10(4/5), S554.

Grant, R. M. (1996). Toward a knowledge-based theory of the firm. Strategic Management Journal, 17(Winter Special Issue), 109-122.

Grbich, C. (2007). Qualitative Data Analysis: an introduction. London: SAGE.

Grossman, M. (2007). The Emerging Academic Discipline of Knowledge Management. Journal of Information Systems Education, 18(1), 31.

Gu, Y. (2004). Global knowledge management research: A bibliometric analysis. Scientometrics, 61(2), 171-190.

Guba, E. G., \& Lincoln, Y. S. (2005). Pragmatic controversies, contradictions, and emerging confluences. In N. K. Denzin \& Y. S. Lincoln (Eds.), The Sage Handbook of Qualitative Research (3rd ed., pp. 191-215). Thousand Oaks: Sage Publication. 
Hall, E. T. (1976). Beyond culture (1st ed. ed.). Garden City, N.Y. : Anchor Press.

Hansen, M. T. (1999). The search-transfer problem: The role of weak ties in sharing knowledge across organization subunits. Administrative Science Quarterly, 44(1), 82 .

Hansen, M. T., Nohria, N., \& Tierney, T. (1999). What's your strategy for managing knowledge? Harvard Business Review, 77(2), 106-116.

Harcombe, D. (1993). Solomon Islands - a travel survival kit (2nd ed.). Hawthorne, Victoria: Lonely Planet.

Harris, L., \& Wasilewski, J. (2004). Indigenous Wisdom of the People Forum: strategies for expanding a web of transnational indigenous interactions. Systems Research and Behavioral Science, 21(5), 505.

Hassell, L. (2007). A continental philosophy perspective on knowledge management. Information Systems Journal, 17(2), 185-195.

Hedlund, G. (1994). A Model of Knowledge Management and the N-Form Corporation. Strategic Management Journal, 15, 73-90.

Hofstede, G. H. (1980). Culture's consequences : international differences in workrelated values Beverly Hills, Calif.: Sage Publications.

Holden, N. (2001). Knowledge management: raising the spectre of the cross-cultural dimension. Knowledge and Process Management, 8(3), 155.

Hull, R. (2000). Knowledge management and the conduct of expert labour. In C. e. a. Prichard (Ed.), Managing Knowledge. Basingstoke: Macillan.

Ibarra, H. (1999). Provisional selves: Experimenting with image and identity in professional adaptation. Administrative Science Quarterly, 44(4), 764.

Inkpen, A., \& Ramaswamy, K. (2007). End of the multinational: emerging markets redraw the picture. The Journal of Business Strategy, 28(5), 4.

Keesing, R. M. (1988). Melanesian Pidgin and the oceanic substrate Stanford, Calif. : Stanford University Press.

Kogut, B., \& Zander, U. (1996). What firms do? Coordination, identity, and learning. Organization Science, 7(5), 502.

Kogut, B., \& Zander, U. (2003). Knowledge of the firm and the evolutionary theory of the multinational corporation. Journal of International Business Studies, 34(6), 516.

Kozulin, A. (1998). Psychological tools : a sociocultural approach to education. Cambridge, Mass. : Harvard University Press. 
Kroeber, A. L., \& Kluckhohn, C. (1952). Culture; a critical review of concepts and definitions. Cambridge, Mass.: The Museum.

Kuhl, P. K. (2002). Born to learn: Language, reading, and the brain of the child. Paper presented at the Early learning summit for the Northwest Region, Boise, Idaho.

Kuran, T. (1987). Preference Falsification, Policy Continuity and Collective Conservatism. The Economic Journal, 97(387), 642-665.

Kuran, T. (1995). Private Truths, Public Lies: The Social Consequences of Preference Falsification. Cambridge, MA: Harvard University Press.

Lam, A. (2000). Tacit knowledge, organizational learning and societal institutions: An integrated framework. Organization Studies, 21(3), 487.

Lewis, R. D. (2000). When cultures collide : managing successfully across cultures. London Nicholas Brealey.

Lilo, G. D. (2007). Solomon Islands Government 2007 Budget Speech. Retrieved. from http://www.parliament.gov.sb/files/hansard/8th_session/3rd_meeting/speechM OF6february2007.htm.

Lincoln, Y. S. (2005). Institutional Review Boards and Methodlogical Conservatism: The challenges to and from Phenomenological Paradigms. In N. K. Denzin \& Y. S. Lincoln (Eds.), The Sage Handbook of Qualitative Research (3rd ed., pp. 165-190). Thousand Oaks: Sage.

Marshall, C., \& Rossman, G. B. (2006). Designing qualitative research (4th ed. ed.). Thousands Oaks, Calif. : Sage Publications

Maurial, M. (1999). Indigenous Knowledge and Schooling: A Continuum Between Conflict and Dialogue. In L. M. Semali \& J. L. Kincheloe (Eds.), What is Indigenous Knowledge? voice from the Academy (pp. 381). New York: Falmer Press.

Mitchell, R., K. , Agle, B., R. , \& Wood, D., J. . (1997). Toward a theory of stakeholder identification and salience: Defining the principle of who and what really counts. Academy of Management. The Academy of Management Review, 22(4), 853.

Mitroff, I. I., \& Mason, R. O. (1982). Business Policy and Metaphysics: Some Philosophical Considerations. Academy of Management. The Academy of Management Review, 7(3), 361.

Moore, C. (2007). Helpem Fren: The Solomon Islands, 2003-2007. The Journal of Pacific History, 42(2), 141. 
Mühlhäusler, P., \& Mühlhäusler, B. S. (2005). Simple English in the South Seas Evangelical Mission. Language Problems \& Language Planning, 29(1), 1-30.

Nahapiet, J., \& Ghoshal, S. (1998). Social capital, intellectual capital, and the organizational advantage. Academy of Management. The Academy of Management Review, 23(2), 242.

Nelson, R. R., \& Winter, S. G. (1982). An evolutionary theory of economic change Cambridge, Mass.: Belknap Press of Harvard University Press.

Nisbett, R. (2003). The geography of thought: How Asians and Westerners think differntly-and why. New York: Free Press.

Nonaka, I. (1994). A Dynamic Theory of Organizational Knowledge Creation. Organization Science, 5(1), 14-37.

Nonaka, I., \& Konno, N. (1998). The concept of "ba": Building a foundation for knowledge creation. California Management Review, 40(3), 40.

Nonaka, I., \& Peltokorpi, V. (2006). Objectivity and subjectivity in knowledge management: a review of 20 top articles. Knowledge and Process Management, 13(2), 73.

Nonaka, I., \& Takeuchi, H. (1995). The Knowledge-creating Company. New York Oxford University Press.

Nonaka, I., \& Toyama, R. (2003). The knowledge-creating theory revisited: knowledge creation as a synthesizing process. Knowledge Management Research \& Practice, 1(1), 2.

Nonaka, I., \& Toyama, R. (2005). The theory of the knowledge-creating firm: subjectivity, objectivity and synthesis. Industrial and Corporate Change, 14(3), 419.

Nonaka, I., Toyama, R., \& Konno, N. (2000). SECI, ba and leadership: A unified model of dynamic knowledge creation. Long Range Planning, 33(1), 5.

O'Leary, Z. (2004). The Essential Guide to doing Research. London: Sage Publication Ltd.

Parry, R. (2003). "Episteme and Techne". The Stanford Encyclopaedia of Philosophy (Summer 2003 Edition), from <http://plato.stanford.edu/archives/sum2003/entries/episteme-techne/>.

Pass, C., Lowes, B., \& Davies, L. (2005). Collins Dictionary of Economics ((4th Eds.). ed.). Glasgow.: HarperCollins Publishers.

Patton, M. (2002). Qualitative research and evaluation methods. London: Sage. 
Pauleen, D. J., Wu, L.-L., \& Dexter, S. (2007). Exploring the Relationship between National and Organisational Culture, and Knowledge Management. In D. J. Pauleen (Ed.), Cross-Cultural Perspectives on Knowledge Management (pp. 259). Westport: Libraries Unlimited.

Penrose, E. T. (1959). The theory of the growth of the firm Oxford B. Blackwell.

Polanyi, M. (1967). The tacit dimension. London: Routledge \& K. Paul.

Punch, K. F. (2005). Introduction to social research : quantitative and qualitative approaches (2nd ed.). London SAGE.

Report, (1986). 10 ${ }^{\text {th }}$ Anniversary Report 1976-1986. Honiara: Solomon Islands National Provident Fund.

Report, (2004). 2004 Annual Report. Honiara: Solomon Islands National Provident Fund.

Report, (2005). 2005 Annual Report. Honiara: Solomon Islands National Provident Fund.

Report, (2006). 2006 Annual Report. Honiara: Solomon Islands National Provident Fund.

Retna, K. S., \& Bryson, J. E. (2007). Asian Organisations Meet North American Theory: The Case of Singapore and Senge. In D. J. Pauleen (Ed.), Crosscultural Perspectives on Knowledge Management (pp. 259). Westport: Libraries Unlimited.

Riad, S. (2005). The Power of 'Organizational Culture' as a Discursive Formation in Merger Integration. Organization Studies, 26(10), 1529.

Sahlins, M. (1963). Poor man, rich man, big-man, chief: Political types in Melanesia and Polynesia. Comparative Studies of Society and History(5), 285-303.

Sand, C. (2002). Melanesian tribes vs. Polynesian chiefdoms: Recent archaeological assessment of a classic model of sociopolitical types in Oceania. Asian Perspectives, 41(2), 284.

Sanga, J. (1989). Remembering. In H. Laracy (Ed.), Ples Blong Iumi (pp. 176). Suva: Institute of Pacific Studies of the University of the South Pacific.

Sanga, J. B. (2006). To what extent can New Zealand help islands states with their development aspirations? A perspective from Solomon Islands. (pp. 32). Wellington: Victoria University of Wellington.

Sanga, J. W. (2001). An initial evaluation of the Solomon Islands regional development policy. Victoria University of Wellington, Wellington. 
Sanga, K. F. (1997). Post-secondary governance of international education. University of Saskatchewan, Sakatchewan.

Sanga, K. F. (2006). Overview on Leadership ethics. Paper presented at the NZAID Scholarship Students Workshop. Nov. 2006. Wellington.

Schein, E. H. (1985). Organizational culture and leadership (1st ed.). San Francisco Jossey-Bass Publishers.

Senge, P. M. (2006). The fifth discipline: the art \& practice of the Learning Organisation (2nd ed.). London: Random House.

Shaughnessy, J. J., Zechmeister, E. B., \& Zechmeister, J. (2000). Research Methods in Psychology. Boston: McGraw Hill.

Shiraev, E. B., \& Levy, D. A. (2004). Cross-Cultural psychology. Boston: Pearson.

Shotter, J. (1993). Conversational realities : constructing life through language London Sage Publications.

Silverman, D. (2005). Doing Qualitative Research (2nd ed.). London: SAGE.

Simon, H., A. . (1986). Rationality in Psychology and Economics. The Journal of Business (1986-1998), 59(4), IIS209.

Spender, J. C. (1989). Industry recipes : an enquiry into the nature and sources of managerial judgement Unpublished PhD, Blackwell, Oxford, UK.

Spender, J. C. (1996). Making knowledge the basis of a dynamic theory of the firm. Strategic Management Journal, 17, 45.

Spindler, G., \& Spindler, L. (1992). Cultural process and ethnography: an anthropological perspective. In M. D. LeCompte, W. L. Millroy \& J. Preissle (Eds.), The Handbook of Qualitative Research in Education. (pp. 53-92). San Diego:CA: Academic.

Stake, R. E. (2000). Qualitative Case Study. In N. K. Denzin \& Y. S. Lincoln (Eds.), Qualitative Research (3rd ed.). Thousand Oaks: SAGE.

Suddaby, R., \& Greenwood, R. (2001). Colonizing knowledge: Commodification as a dynamic of jurisdictional expansion in professional service firms. Human Relations, 54(7), 933.

Suter, K. (2003). Pacific Storms. The World Today, 59(11), 20.

Sveiby, K.-E., \& Simons, R. (2002). Collaborative climate and effectiveness of knowledge work - an empirical study. Journal of Knowledge Management, $6(5), 420$.

Tomasello, M. (2008). How Are Humans Unique? New York Times Magazine, 15. 
Tsoukas, H. (1996). The firm as a distributed knowledge system: A constructionist approach. Strategic Management Journal, 17, 11.

Vine, J. (2004). Knowledge Management Implementation in New Zealand Organisations: The Effect of Prior Experience with Quality Management. Victoria University of Wellington, Wellington.

Walsham, G. (2002). Cross-cultural software production and use: A structurational analysis. MIS Quarterly, 26(4), 359.

Wernerfelt, B. (1984). A Resource-Based View of the Firm. Strategic Management Journal, 5(2), 171.

Westrup, C., Jaghoub, S. A., Sayed, H. E., \& Liu, W. (2003). Taking Culture Seriously: ICTs Culture and Development In S. Krishna \& S. Madon (Eds.), The digital challenge : information technology in the development context (pp. 367 ). Aldershot, Hants, England Ashgate.

Wicks, A. C., \& Freeman, E. R. (1998). Organization studies and the new pragmatism: Positivism, anti-positivism, and the search for ethics. Organization Science, 9(2), 123.

Yin, R. K. (2003). Case study research : design and methods (3rd ed. Vol. 5). Thousand Oaks, Calif.: Sage Publications.

Zack, M., H. . (1999). Managing Codified Knowledge. Sloan Management Review, $40(4), 45$. 


\section{Websites}

Advameg inc: Culture of Solomon Islands.

http://www.everyculture.com/Sa-Th/Solomon-Islands.html

Infoplease: Solomon Islands

http://www.infoplease.com/ipa/A0107975.html sighted on 20th Aug 2007.

International Social Security Association

http://www.issa.int/engl/homef.htm sighted 26th May 2008.

Merriam-Webster Online Dictionary

http://www.merriam-webster.com/

National Parliament: Solomon Islands Government http://www.parliament.gov.sb/files/hansard/8th_session/3rd_meeting/speechM OF6february2007.htm

The Stanford Encyclopaedia of Philosophy (Summer 2003 Edition), from http://plato.stanford.edu/archives/sum2003/entries/episteme-techne/>. 


\section{APPENDIX A: INFORMATION HANDOUT TO MANAGEMENT OF SSE}

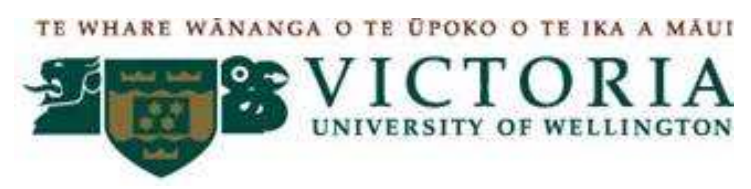

\section{Research on cultural effects on Knowledge Management in Solomon Islands' organisations}

\section{Overview}

My name is Joseph (Joe) Sanga and I am a Master of Management Student at Victoria University of Wellington, New Zealand. This project is a student research study which tries to understand how Solomon Islands culture affects knowledge management practices at the organisational level. Knowledge is becoming a critical organisational asset for some, in creating competitive advantage. For others it is a process that must be harnessed and carefully managed to create competition. Whichever way it is viewed, there seems to be universal agreement that knowledge is critical to give a firm the edge. Technology and patents could be copied but knowledge, especially tacit knowledge is hard to imitate.

The Management of knowledge is a common practice in large Solomon Islands organisations, although most do not recognise the practice as such. In order to gain understanding of how knowledge is created, shared, used and managed, it is important for the researcher to collect data in Solomon Islands as it would bring out the unique cultural underpinnings that help define Solomon Islands' cultural identity. This is most important in today's business geography where national physical barriers are slowly being removed and exposing Solomon Islands more and more to the outside world. Therefore, to do business successfully in the Solomons, one has to understand the way Solomon Islanders view and treat knowledge. It is an accepted proposition that people's worldviews are often shaped, among other things, by their environment.

This research is informed by the interpretive paradigm and so knowledge is taken to be the result of social construction. Having said that, I recognise the duality of knowledge as existing in both tacit and explicit form and so my study views knowledge holistically. I will therefore adopt methodological triangulation. All participating staff will be recruited on voluntary basis and will as much as possible be representative of all departments and gender. The Administration Manager may assist in identifying willing participants. Where other difficulties may be faced on the ground, I will resort to snowballing techniques in selecting participants. First, semistructured interviews will be conducted of four (4) management staff, six (6) supervisory officers and ten (10) clerical staff. These interviews will last between 4560 minutes and will be conducted in the training room of SSE. Concurrently with the period of interviews will be specific observations and observations in general. Furthermore, documents such as manuals, correspondences, instructions and rules and regulations will be analysed. After the analysis, the interviewees will be organised 
into four focus groups. The first group will be made up of all junior staff. The second group will be made up of senior managers and middle managers/supervisors. The final two groups will be made up of staff representing all levels, which is managers, supervisors and clerical staff. While one group will be made up of staffs that have members of informal groups in the office, the other will be made up of staff who do not socialise with each other much or at all. Each group should not take more than 1 hour of discussion. By bringing the interviewees together with people of like minds and levels, and others that seem not to have connections, underlying dynamics and issues raised in the interviews will be further explored and verified. Methodological triangulation is employed since no single method can adequately capture phenomena.

This research is done under the auspices of the Victoria University of Wellington, New Zealand and an ethical approval has been obtained from VUW to collect data. This is in recognition of meeting the required understanding of ethical issues that need to be properly addressed and carefully handled. Since this study is an academic paper, data gathered may be shared with my supervisor but at all times they will be kept locked and electronic copies wiped out as soon as I finish with my analysis. The final report will contain aggregate findings and individual persons and the organisation will not be identified. A copy of the thesis will be kept in Victoria University Library and other academic institutions such as the University of the South Pacific Centre in Honiara, Solomon Islands. Other ethical issues that relate to participants will be further explained below.

\section{How will your staff be affected?}

- With Management approval, this research will be conducted involving your staff.

- I am looking for a range of views - all kinds of different experiences and opinions from managers and general staff who agree to talk with me. I am keen to listen to people expressing their honest opinions regarding knowledge management policies and practices in the organisation.

- I will talk to people individually in confidence - their names will not be used and I will use pseudonyms in my thesis write-up where applicable. Everyone involved will sign an agreement where they can say just how they want information from them to be handled.

- What I'll be asking about is their view on knowledge management policies and practices - whether they agree or disagree with those policies and practices. How and why you hold the view you do.

- I will present some of my findings back to respondents/participants for their further comments.

- The participants will be recruited on voluntary basis.

\section{What do I want from the organisation as a whole?}

- Your organisation has been chosen as the single case for study. The co-operation of all management and staff will be appreciated.

- Since, this study will take the form of ethnography, there will be lengthy interviews and discussions held with managers and staff. Some office work may be minimally disrupted. Fortunately, interviewed total participants should not 
exceed 20 staff and as much as possible I hope to keep interviews outside the heavy traffic hours.

- Knowledge is present in two forms, tacit and explicit form. Explicit or codified knowledge is knowledge that is stored in artefacts such as rules, regulation, memos and other documents. To fully appreciate the underlying dynamics that materialize as knowledge, it would be appreciated if some documents are made available for analysis. This will be supplemented with further in-depth interviews.

- Total confidence in all data available to me is assured. Again, after analysis no copies of documents will be kept and electronic copies deleted.

The researcher: Joseph Sanga has a wide knowledge as a practitioner in administration and human resources fields in Solomon Islands and currently is a student of Victoria University of Wellington.

\section{CONTACT INFORMATION}

Dr. Kala S. Retna (Supervisor)

Lecturer

Victoria Management School

Victoria University of Wellington

Phone: 64-04-463 5066

Email: kala.retna@vuw.ac.nz

Address: Room 909, Rutherford House,

23 Lambton Quay,

Pipitea Campus,

Wellington, New Zealand
Joseph B. Sanga (Researcher)

Phone: 64-04-586 7076

Email: joe.sanga@gmail.com

Address: 21/41 Barber Grove

Moera, Lower Hutt 5010

Wellington, New Zealand 


\section{APPENDIX B: JOINT AGREEMENT BETWEEN SSE MANAGEMENT}

\section{AND JOSEPH SANGA}

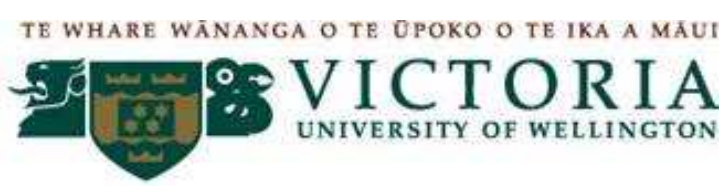

\section{Research on cultural effects on Knowledge Management in Solomon Islands' organisations}

I, Mr. John Mark, General Manager and CEO of the Solomon Securities Enterprises (Hassell) do make the following statements:

1. I have approved on behalf of the Board, for Joseph Sanga to conduct research in SSE from $3^{\text {rd }}$ December 2007 to $19^{\text {th }}$ January 2008;

2. That permission is given to Mr. Sanga to access all documents that are necessary for the successful conduct of research such as Board and Management minutes, Annual reports, Policy papers, manuals and personal documents such as letters, memos and other correspondences;

3. That staff identified in SSE and who willingly volunteer to participate in the study will fully co-operate with Mr. Sanga;

4. That having fully co-operated, I expect them to provide a wide ranging views and opinions, some of which might be dissenting. I further state that neither I nor any management staff will actively seek dissenting views in the study for the purpose of incriminating and punishing staff;

5. As an academic work, some of the data may be viewed by Mr. Sanga's supervisor.

I, Joseph Sanga, researcher and student of VUW make the following statements:

1. I agree to conduct research at SSE, Honiara, Solomon Islands;

2. That at all times, I will maintain a high standard of ethical behaviour during the course of my research;

3. That I will respect the integrity and privacy of all staff;

4. That the Manager Administration, Mr. Alfonse Akalo will be my first point of contact for logistics and to the wider organisation;

5. That all soft and hard copies of documents will be returned to SSE or electronically destroyed after the research;

6. That a bound copy of the thesis will be provided to SSE.

We hereby set our hands:

$$
\begin{aligned}
& \text { Mr. John Mark } \\
& \text { CEO, SSE }
\end{aligned}
$$

Date:
Mr. Joe Sanga

Researcher

Date: 
APPENDIX C: INFORMATION HANDOUT TO ALL INTERVIEW

PARTICIPANTS AND FOCUS GROUP MEMBERS

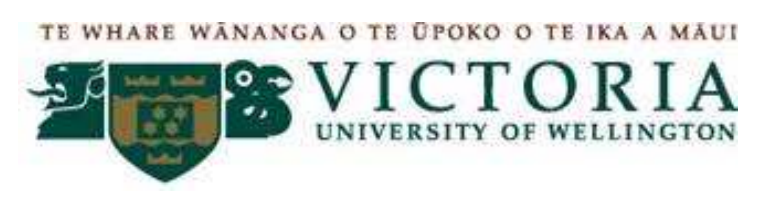

\section{Research on cultural effects on Knowledge Management in Solomon Islands' organisations}

\section{Overview}

My name is Joseph Sanga and I am a Master of Management Student at Victoria University of Wellington, New Zealand. This project is a student research study which tries to understand how Solomon Islands culture affects knowledge management practices at the organisational level. Knowledge is becoming a critical organisational asset for some, in creating competitive advantage. For others it is a process that must be harnessed and carefully managed to create competition. Whichever way it is viewed, there seems to be universal agreement that knowledge is critical to give a firm the edge. Technology and patents could be copied but knowledge, especially tacit knowledge is hard to imitate.

In order to gain understanding of how knowledge is created, shared, used and managed, it is important for the researcher to collect data in Solomon Islands as it would bring out the unique cultural underpinnings that help define Solomon Islands' cultural identity. This is most important in today's business geography where national physical barriers are slowly being removed and exposing Solomon Islands more and more to the outside world. Therefore, to do business successfully in the Solomons, one has to understand the way Solomon Islanders view and treat knowledge. It is an accepted proposition that people's worldviews are often shaped, among other things, by their environment.

This study has been approved by the Board and Management and will require the participation of staff in an interview and or in focus groups and so may be expected to be interviewed at length or more than once. A typical interview could last between 45-60 minutes. Similarly focus groups should not exceed 1 hour. Freedom will be given to participants to express their opinions with limited guide from the researcher. Some documentary analysis and observations will also be carried out. Willing participants may voluntarily submit their names to the Administration Manager or myself. Where other difficulties may be faced on the ground, I will resort to snowballing techniques in selecting participants.

This research is done under the auspices of the Victoria University of Wellington, New Zealand and an ethical approval has been obtained from VUW to collect data. This is in recognition for meeting the required understanding of ethical issues that need to be properly addressed and carefully handled. Since this study is an academic paper, data gathered may be shared with my supervisor but at all times they will be kept locked and electronic copies wiped out as soon as the researcher finishes with his analysis. The final report will contain aggregate findings and individual persons and the organisation will not be identified. A 
copy of the thesis will be kept in Victoria University Library and other academic institutions. Other ethical issues that relate to participants will be further

explained below.

\section{How will you be affected?}

- Permission was sought from Management and Board for this research to be conducted.

- The Manager Administration of SINPF may approach you to participate in this research. However, you have the final power to agree or otherwise to participate in this study. Your participation should absolutely be on voluntary basis.

- In terms of the research, we feel that you would contribute immensely to the study.

- I am looking for a range of views - all kinds of different experiences and opinions - from managers and general staff who agree to talk with me. I am keen to listen to people expressing their honest opinions regarding knowledge management practices in the organisation.

- I will talk to people individually in confidence - your name won't be used and I will use pseudonyms in my thesis write-up where applicable. Everyone involved will sign an agreement where they can say just how they want information from them to be handled.

- What I'll be asking about is your view on knowledge management policies and practices - whether you disagree with those policies and practices. How and why you hold the view you do.

- I will present some of my findings back to respondents/participants for your comments.

\section{What do I want from the organisation as a whole?}

- Your organisation has been chosen as the single case for study. The co-operation of management and staff will be appreciated.

- Since, this study will take the form of ethnography, there will be lengthy interviews (45 mins-1 1/2 hrs) and discussions held with managers and staff. Some office work may be minimally disrupted. Fortunately, interviewed participants should not exceed 20 staff and as much as possible I hope to keep interviews outside the heavy traffic hours.

- Knowledge is present in two forms, tacit and explicit form. Explicit or codified knowledge is knowledge that is stored in artefacts such as rules, regulation, memos and other documents. To fully appreciate the underlying dynamics that materialize as knowledge, it would be appreciated if some documents are made available for analysis. This will be supplemented with further in-depth interviews.

- Total confidence in all data available to me is assured. Again, after analysis no copies of documents will be kept and electronic copies deleted.

The researcher: Joseph Sanga has a wide knowledge as a practitioner in administration and human resources fields in Solomon Islands and currently is a student of Victoria University of Wellington. 


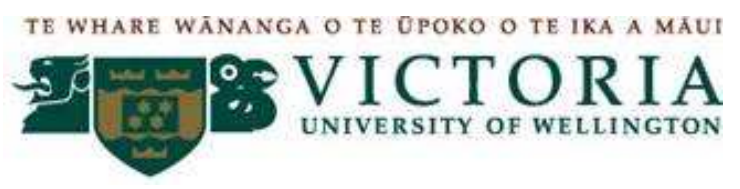

\section{Cultural Effects on Knowledge Management Policies and Practices in Solomon Islands}

\section{Consent to Participate in the Research}

I have been given adequate information and have understood the nature and objectives of this research project and have been given the opportunity to seek further clarifications and explanations.

$\square$ I understand that I may withdraw from all participation in this project and the data resulting from that participation before the 18 January 2008. I understand that I may do so without providing reasons, and that any data already collected will be destroyed by the researcher.

$\square$ I understand that any information or opinions I provide will be confidential. Only the researcher and the supervisor will have access to the information provided.

I give permission for the interview to be tape recorded.

I understand that the tape recording of interviews will be electronically wiped one year after the research project completion or be returned to me if required. All opinions and data obtained will be destroyed by the researcher.

I understand the published results will not be used in a way that identifies me personally or my business and no opinions will be attributed to me in any way that will identify me.

I agree to participate in this research project.

I would like to receive a copy of the findings.

\section{Participant:}

Name:

Signature:

Date: 


\section{APPENDIX E: INTERVIEW SCHEDULE}

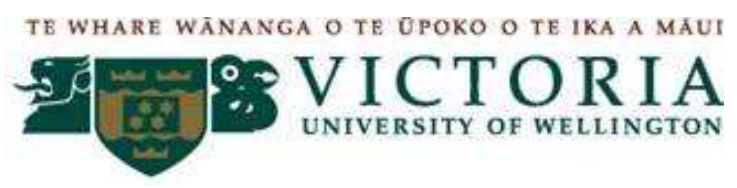

\section{Cultural Effects on Knowledge Management Policies and Practices in Solomon Islands}

Warm-up/ background: about 5-10 minutes

Ask about their career:

Prompts

- What is you current job?

- How long have you been in it?

- What is your highest education/ training level?

1. What is people's understanding of knowledge and knowledge management? (10-15min)

Prompts

- What is your understanding of the word knowledge?

- Where do you find knowledge in your organisation?

- What do you think knowledge management is about?

2. How does Culture shape assumptions about which knowledge is important?(10-15min) Prompts

- What is your department's most important function/role?

- Considering the organisation as a whole, which knowledge is most important? Why? Where do you get that idea from?

- Which is the second most important knowledge? Why?

3. How does Culture mediate the relationships between levels of knowledge?(10-15mins) Prompts

- List the departments in your organisation in order of importance. Why do you place them in that order?

- In which department do you work?

- How would you like to share your knowledge/records with other people/departments?

4. How does Culture create a context for social interaction? (10-15mins) Prompts

- Who do you find the most easiest to discuss official issues with in your department? ( More interaction bond)Why? 
- Who do you find most comfortable to discuss with in other departments? (Special behaviours that promote knowledge sharing) Why?

- Who do you find most comfortable to discuss with in other levels (vertical)? Lower? Higher? Why?

- Who do you find easiest to discuss with at you same level? (Horizontal) Why?

5. How does Culture shape creation and adoption of new knowledge? (1015mins.)

Prompts

- Do you have ideas that you want to share or be heard?

- Do you make any attempts to share them or be heard?

- Do other people listen to your ideas?

- Do you feel it is easy to make yourself heard in this organisation?

- Do you listen to other people's ideas? 


\section{APPENDIX F: FOCUS GROUP CONSENT FORM}

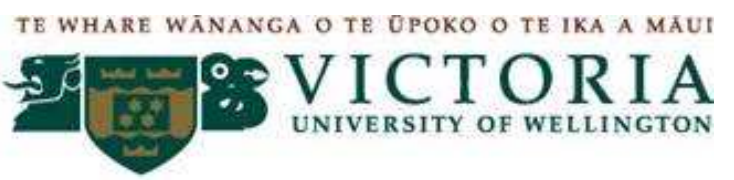

\section{Cultural Effects on Knowledge Management Polices and Practices in Solomon Islands}

We have been given adequate information and have understood the nature and objectives of this research project and have been given the opportunity to seek further clarifications and explanations.

We understand that we may choose not to participate as a group or individually from this project before the 18 January 2008 . We understand that we may do so without providing reasons, and that any data already collected will be destroyed by the researcher.

We understand that any information or opinions we provide will be confidential. Only the researcher and the supervisor will have access to the information provided.

We give permission for our discussions to be tape recorded.

We understand that the tape recording of discussions will be electronically wiped one year after the research project completion or be returned to us if required. All opinions and data obtained will be destroyed by the researcher.

We understand the published results will not be used in a way that identifies us personally or our business and no opinions will be attributed to us in any way that will identify us.

We agree to participate in this research project.

We agree and promise to keep the proceedings of the group discussion confidential.

We would like to receive a copy of the findings. 
In duly agreeing to the terms above, we individually herewith place our signatures.

\section{Focus Group Participants:}

Name:

Signature:

Date:

Name:

Signature:

Date:

Name:

Signature:

Date:
Name:

Signature:

Date:

Name:

Signature:

Date:

Name:

Signature:

Date:
Name:

Signature:

Date:

Name:

Signature:

Date: 


\section{APPENDIX G: DISCUSSION SCHEDULE: FOCUS GROUPS}

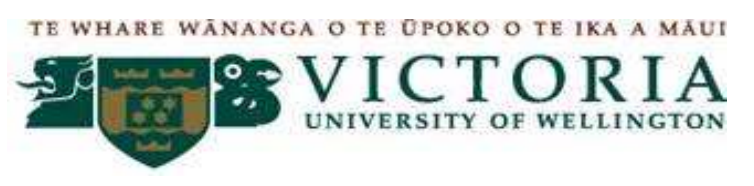

\section{Cultural Effects on Knowledge Management Policies and Practices in Solomon Islands}

\section{Focus Group 1: Management Staff}

1. During the interviews and rating of departments of SSE, the vast majority of interviewees rated the Board Secretary as very low that is 9. However in terms of influence in management, it is one of the most influential even among managers in meetings or decision-making. How is it possible and what's your view?

2. Another idea is related to information. They say that to create new knowledge, leverage that knowledge to create competitiveness of organisation has to do a lot with sharing and distribution of knowledge. If that is true, and all officers of fund have access to all information, horizontally and vertically without restriction, to create organisational knowledge as it is organisational knowledge that creates competitiveness and not individual knowledge. what is your view on that?

\section{Focus Group 2: Clerical Staff}

1. In the interviews, a lot of people express that some departments are more important than others. For example, some say that we do not really need sections such as PR and Operations front desk and instead we should concentrate on investment and ensuring high returns to members. What are your views on such ideas?

2. I just want to ask about time. From the interviews it seems that SSE is rewarding because staff have met expected targets, they get 1, 2 or 3 points. So Supervisors and senior staff feel that they would rather spend their time doing their work instead of teaching staff. Do you agree with their views?

\section{Focus Group 3: Related Cross-section}

1. May be one issue which people actually don't say but how they speak or their practices seem to highlight is wantok system or favouritism. People seem to congregate with others from their same region or cultures within Solomon Islands. What's your view on that? 
2. About $80 \%$ of staff think that the Executive office is the most important office in SSE. However, if you remove that office, SSE will still operate without the executive office. What's your view?

3. Innovation is the responsibility of the boss. They are paid for it. This is a view expressed in the interviews. What's your view?

\section{Focus Group 4: Unrelated Cross-section}

1. One idea that surfaced amongst staff is that it is the responsibility of the boss to be innovative because he is paid for it. What is your view?

2. Sometimes even when managers have good intentions and encourage staff to share their views, staff don't seem to respond or are silent. What's happening there?

3. Sometimes some supervisors, because of competition for their time want to see their tasks completed and they see that other tasks such as teaching their staff are not as important because they would be appraised on the list of duties in the Job Descriptions. What's your view? 


\section{APPENDIX H: GENERAL OBSERVATION INFORMATION SHEET}

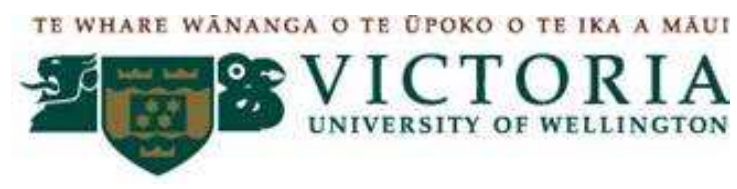

\section{Cultural Effects on Knowledge Management Practices in Solomon Islands}

My name is Joe Sanga, and I am carrying out a research project in partial fulfilment of the requirements of Masters in Management Studies programme. This process of data collection has been approved by the Victoria University Human Ethics Committee. The study will look at how Solomon Islands culture affects knowledge management practise at the organisational level. In order to do so I will use a variety of tools to collect data. These tools include interviews, the use of focus groups, document analysis and observations. Some individuals will be specifically observed in meetings and discussions and there will also be a general observation of the general staff. During a general observation, I will take notes on the activities of staff in and around the office environment. My role as the observer will be non participatory and anything I observe will clearly represent my understanding of the event.

\section{How will you be affected?}

- I will be present during formal meetings, and informal discussions. However I will be a non-participant observer, and will not be presenting any views or hindering any of the processes during the discussions.

- I will be looking for a range of views, experiences and opinions expressed during the interactions and how they represent the organisational culture from the viewpoints of those who are part of the groups.

- Your name will not be used in the write up, and confidentiality is assured.

- If anyone feels strongly that they do not want to be observed, they should come and see me so that they will not be included in my data collection pool.

- At any point of this data collection process if you disapprove of me being present at any particular meeting or discussion, whether it be formal or informal, I would not observe that meeting or group discussion.

- You may opt not to give consent to participating in the study up to $19^{\text {th }}$ January 2008.

The researcher: Joe Sanga, is a student of Victoria Management School, and is currently pursuing his Masters in Management Studies. 


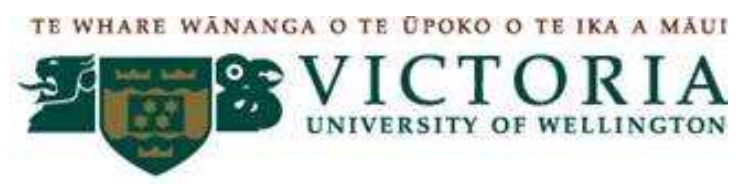

\section{Cultural Effects on Knowledge Management Policies and Practices in Solomon Islands}

I,$\ldots \ldots \ldots \ldots \ldots \ldots \ldots \ldots \ldots \ldots \ldots \ldots$, a transcriber for Joseph Sanga's MMS

Thesis, understand and agree to the following statements:

- Full, accurate, verbatim transcripts will be provided unless otherwise specified;

- Each transcript will clearly indicate the narrator, interviewer, and place and date of the interview;

- The transcribing process will include:

- Developing a draft transcript in pijin and translate to English

- Audit-editing the draft transcript

- Returning the draft for review

- Finalizing the draft, correcting any necessary changes

- Printing the final copy on paper

- Providing a copy on disc

- The final copy will be keyed to the recording and, if requested, will be indexed

- All work will be done in Microsoft Word unless otherwise specified;

- The interviewer will provide a list of proper and place names wherever possible to facilitate accurate transcribing;

- The interviewer will have 30 days to review draft transcripts and return them for corrections. After that time, they will be considered to stand as drafted;

- As transcriber, I understand the need for confidentiality of interview content and I promise not to divulge any information pertaining to this research to a third party, whomsoever he or she maybe. I further agree not exploit the narrator's story; and

- I will turn all materials, including copies of the interview recordings and discs containing the transcriptions over to the researcher immediately upon completing the transcribing work.

Signed

Date (Transcriber)

Signed

Date

(Researcher) 


\section{APPENDIX J: E-MAIL CONTACTS WITH CASE ORGANISATION \\ MANAGEMENT}

\section{Manager-Administration}

Alfons to me
$\begin{aligned} & \text { e } \\ & \quad \text { details }\end{aligned}$
$\quad$ 'Oh Apr 20
$\quad$ daing lea' Joe,

Greetings to you in the "land of the long white cloud". I regret very much the delay in replying your email, but I managed to get approval for your request. Approval was granted by GM just some minuites ago with the following conditions:

1. That the right for such a study report be granted by yourself to SSE;

2. That MA will assist you during interviews with SSE personnel ;

3. That hard and soft copies of the report belong to the SSE Board.

I look forward for your coming over for this research. I have no doubts that this research will be beneficial to the Fund; most especially the Admin Department.

Lea ma'ana.

Rete.

- Show quoted text -

\section{CEO' Note}

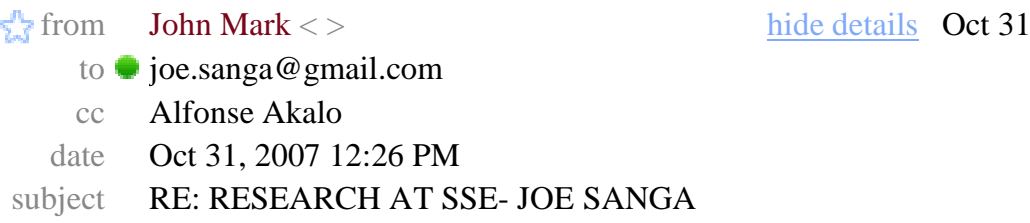

Ubongia, Joe.

Hope to see U then. I do understand that SSE will benefit from results of such research work. All the Best in your studies.

John M 